NBER WORKING PAPER SERIES

\title{
PARTY ON: THE LABOR MARKET RETURNS TO SOCIAL NETWORKS AND SOCIALIZING
}

\author{
Adriana Lleras-Muney \\ Matthew Miller \\ Shuyang Sheng \\ Veronica T. Sovero
}

Working Paper 27337

http://www.nber.org/papers/w27337

\author{
NATIONAL BUREAU OF ECONOMIC RESEARCH \\ 1050 Massachusetts Avenue \\ Cambridge, MA 02138 \\ June 2020
}

We are grateful to seminar participants at Northwestern University, SOCCAM, the all-California Labor Economics conference and Santa Barbara University. This project was supported by the California Center for Population Research at UCLA (CCPR), which receives core support (P2CHD041022) from the Eunice Kennedy Shriver National Institute of Child Health and Human Development (NICHD). Research done prior to joining Audible. Audible is a subsidiary of Amazon. All views contained in this research are the author's own and do not represent the views of Amazon or its affiliates. All errors are our own. The views expressed herein are those of the authors and do not necessarily reflect the views of the National Bureau of Economic Research.

NBER working papers are circulated for discussion and comment purposes. They have not been peer-reviewed or been subject to the review by the NBER Board of Directors that accompanies official NBER publications.

(C) 2020 by Adriana Lleras-Muney, Matthew Miller, Shuyang Sheng, and Veronica T. Sovero. All rights reserved. Short sections of text, not to exceed two paragraphs, may be quoted without explicit permission provided that full credit, including $\odot$ notice, is given to the source. 
Party On: The Labor Market Returns to Social Networks and Socializing

Adriana Lleras-Muney, Matthew Miller, Shuyang Sheng, and Veronica T. Sovero

NBER Working Paper No. 27337

June 2020

JEL No. I20,J31

\begin{abstract}
$\underline{\text { ABSTRACT }}$
A person's schooling years are a formative time for cognitive development, and also a period of intense social interaction and friendship formation. In this paper, we estimate the production of social capital during adolescence and its effect on wages. We develop a model where homophily and coordination play crucial roles in the decision to socialize and study, which in turn determine educational attainment, network formation, and labor market outcomes. We document that individuals make investments to accumulate friends and other forms of social capital. Sometimes these investments compete with schooling investments (particularly when they involve alcohol consumption), but not always. These social investments have payoffs in the labor market and cannot be thought of as pure leisure. We estimate that receiving five to six friend nominations in adolescence has an impact on wage earnings of approximately $10 \%$, comparable to a broad set of estimates of the return to an additional year of schooling. Therefore, policies that alter the schooling environment should be evaluated by their impacts on social capital as well as their impact on education.
\end{abstract}

Adriana Lleras-Muney

Department of Economics

9373 Bunche Hall

UCLA

Los Angeles, CA 90095

and NBER

allerasmuney@gmail.com

Matthew Miller

Audible

1 Washington St.

Newark, NJ 07102

mattmmiller@g.ucla.edu

\author{
Shuyang Sheng \\ Department of Economics \\ UCLA \\ 8283 Bunche Hall \\ Los Angeles, CA 90095 \\ ssheng@ucla.edu \\ Veronica T. Sovero \\ Lam Family College of Business \\ San Francisco State University \\ San Francisco, CA 94116 \\ vsovero@sfsu.edu
}

A data appendix is available at http://www.nber.org/data-appendix/w27337 


\section{Introduction}

The determinants of individuals' labor market success are of great interest to economists. Substantial progress has been made in the last 50 years in the study of the effects of education and ability on earnings. Consensus has emerged that today the returns to schooling are large, with estimates ranging from 2 to $15 \%$ (Card, 2001). Yet there remains substantial unexplained variation in wages. ${ }^{1}$ Existing work strongly suggests that non-cognitive "soft" traits (that are not typically measured by test scores or intelligence) play a crucial role in the labor market, despite the fact they may not affect education outcomes (Heckman, 2006; Heckman, Stixrud, and Urzua, 2006; Heckman, Pinto, and Savelyev, 2013). But what these skills are, how they are formed and why they matter is poorly understood.

This paper focuses on estimating the production of social capital during adolescence and its effect on education and wages. Adolescence is an intense period of socialization when individuals start to become independent and develop both social skills and many lifetime friendships (Heckman and Mosso, 2014a). Individual social capital can be thought of as having two key components: an individual's "sociability" or social skills, and an individual's connections. Glaeser, Laibson, and Sacerdote (2002) phrase it as a "person's social characteristics - including social skills, charisma, and the size of his Rolodex" (size of the network). Recent evidence suggests that social skills are important. They are associated with large and growing returns in the labor market (Deming, 2015; Weinberger, 2014). A person's network is presumably related but distinct from their social skills. The size and connectedness of an individual's social network can help immensely in finding a job, receiving promotions, bonuses, and preventing job loss (Calvo-Armengol and Jackson, 2004; Montgomery, 1991; Elliott, 2001; Granovetter, 1973; Granovetter, 1985; Corcoran, Datcher, and Duncan, 1980).

We estimate the formation of friendships (networks) during adolescence and the causal returns to having more friends on wages, holding initial sociability constant. Figure 1 provides preliminary evidence that the adolescent network size (the number of friends one has) is associated with large increases in wage earnings among adult men and women (Panel A). Wage earnings increase monotonically with the size of the network: moving from having no friends to having 20 friends increases log wages by $0.5 \log$ points. The increase in wage earnings associated with one more friend is about 2.5 percent. By comparison, one more year of education leads to about 10 percent higher earnings (Panel B). This does not imply necessarily that these estimates are causal. But we posit that individuals perceive these

\footnotetext{
${ }^{1}$ This puzzle in the literature summarized by Weiss (1995) who explains that years of schooling and work experience are highly correlated with labor market outcomes, but "estimates suggest that courses, test scores, and measurable learning in secondary school can explain ... less than one-quarter of the higher earnings of high school graduates ... what accounts for the other three quarters of earnings?"
} 
returns to socializing as causal and, thus, spend time and effort on social activities.

We develop a model of social investments and how they determine network size and where coordination and homophily play crucial roles. ${ }^{2}$ Students make studying and socializing decisions while facing a constraint on their time in a non-cooperative game. Both studying and socializing investment decisions, along with cognitive and social endowments, determine the level of education and the number of friends, both of which serve as forms of human capital that earn returns in the labor market. In making these decisions, individuals must take other individuals' actions into account because, by its very nature, it is not possible for individuals to socialize and form friendships without coordinating with others. Making friends requires interacting and spending time with other individuals, whereas studying does not. But interacting with others is not enough to make friends- links in the network (friendships) are only formed if a pair of individuals share (or not) certain characteristics with potential friends (homophily) (Jackson, 2005; Graham, 2015).

We exploit this model to estimate wage returns using Add Health data, a longitudinal study that tracks individuals from middle school into young adulthood. We use the determinants of friendships (homophily and cohort size) and other determinants of schooling as intruments for education and friendships to obtain unbiased estimates of their wage returns. Because the data contain information about individual-level relationships, as well as cohort and school-level information, we can estimate the formation of links as a function of homophily within a school cohort. Thus we identify the effects of friendships on wages by exploiting the difference (or distance) between an individual's characteristics and their peers within a school while holding the mean characteristics of their cohort constant. We assume that these distances affect wages through education and networks only, conditional on the school fixed effect and cohort mean characteristics.

We estimate that making five to six friends has an impact on wage earnings of approximately $10 \%$ compared with a broad set of estimates of the return to an additional year of schooling and not statistically significantly different from OLS estimates. Our findings are consistent other recent papers pointing out that excessive attention to traditional education measures like test scores might lower the long term outcomes of individuals and, thus, their well-being because they reduce investments in other important forms of human capital. ${ }^{3}$ They also suggest that education interventions that are becoming very common, such as remote learning, might deter from social capital formation and result in lost lifetime wages.

This paper makes several contributions. There is large literature on peer effects in edu-

\footnotetext{
${ }^{2}$ Our model is in the spirit of the econometric models on social interactions in endogenously formed networks (Goldsmith-Pinkham and Imbens, 2013; Johnsson and Moon, 2017; Hsieh and Lee, 2016; Auerbach, 2016;Qu and Lee, 2015a;Ridder and Sheng, 2018).

${ }^{3}$ In addition to the papers cited above, also see Xiang and Yeaple (2018).
} 
cation (e.g. Epple and Romano, 2011;Calvó-Armengol, Patacchini, and Zenou, 2009). There is also a smaller set of papers on skill formation has focused on the role of either time allocation (Caetano, Kinsler, and Teng, 2019) or peers (Agostinelli, 2018). Our setting considers the joint formation of both education and social skills that requires both peers and time. We highlight that investments in social skills and on networks differ from investments in other skills because they require coordination: one cannot party alone, but one can study alone. This also differs from other peer effects in the education literature, which typically posits that peers' characteristics matter for education only because they affect a student's outcomes directly (exogenous peer effects). We go further by suggesting that decisions to study (or to socialize) are jointly determined. Therefore, our model is one with endogenous social effects. ${ }^{4}$ We have some empirical evidence that supports the notion that coordination is important in this setting. Technically, our model provides a micro-foundation for strategic network formation models with individual fixed effects, as in Graham (2017), where the fixed effect corresponds to the individual's decision to socialize.

We provide the first estimates of the causal labor market returns to social capital that account for endogeneity in both education and friendships. The closest paper to ours is by Conti et al. (2013), who also attempt to estimate causal returns to friendships. Our paper differs in a few key ways. First, we take a model-based approach to derive instruments for estimating individual friendship links and predict network size, whereas they directly estimate the effects of network size. Second, our model implies that because both outcomes are endogenous and use some of the same inputs (time and peers), it will not be possible to obtain unbiased estimates of their returns without instrumenting for both, as we do. Nevertheless our estimates are, in fact, not too different from theirs although our point estimates are somewhat larger.

Last, we document that individuals make investments to accumulate friends and other forms of social capital, consistent with the large returns to individual social capital reported in the literature and with the predictions of the model. Because social investments have valuable returns in the labor market (and elsewhere), they compete with other human capital investments such as studying. Interestingly, we find that education and networks are positively correlated, suggesting that it is possible for individuals to increase both, though this depends on how one socializes. We also observe that high IQ individuals invest in their networks, not just their education, and that social individuals also study. Thus, we find there is never complete specialization based on initial endowments.

This paper is organized as follows. We first present our model (Section 2). Next, we

\footnotetext{
${ }^{4}$ This is consistent with evidence from Mehta, Stinebrickner, and Stinebrickner (2019) who document that study time by peers predicts individuals' education outcomes such as GPA.
} 
describe the data and document the basic patterns in the data (Section 3). In Section 4, we document investments in cognitive and social capital. In Section 5, we describe our empirical strategy for estimating the returns to education and network size on wages. Section 6 presents the results of the network formation and education formation model. The wage results are in Section 7. Section 8 discusses the results and investigates mechanisms. Section 9 concludes with a discussion of the policy implications of our results, a review of limitations of this study and directions for future research.

\section{Model}

In our model, each individual $i$ has to decide how to allocate their time (which we normalize to 1$)$ between hours of studying $\left(H_{i}\right)$, socializing $\left(S_{i}\right)$, and leisure $\left(L_{i}=1-H_{i}-S_{i}\right)$. Studying increases cognitive capital or education (denoted by $E_{i}$ ), whereas socializing improves social capital (number of friends, denoted by $D_{i}$ ). Both $E_{i}$ and $D_{i}$ raise wages. Any remaining time net of studying and socializing is devoted to pure leisure, which has no labor market returns. This represents time spent on solo activities such as watching television or sleeping.

Following Card (1999), we assume the individual's utility is determined by consumption and leisure (which is split into social and non-social leisure time), ${ }^{5}$ and can be written as

$$
\begin{aligned}
& U\left(E_{i}, D_{i}, H_{i}, S_{i}, X_{i}, \varepsilon_{i}, v_{i}, \eta_{i}\right) \\
= & \ln Y\left(E_{i}, D_{i}, X_{i}, \varepsilon_{i}\right)+V_{s}\left(S_{i}, X_{i}, v_{i}\right)+V_{l}\left(1-H_{i}-S_{i}, X_{i}, \eta_{i}\right)
\end{aligned}
$$

Labor market earnings $Y\left(E_{i}, D_{i}, X_{i}, \varepsilon_{i}\right)$ depend on cognitive capital $\left(E_{i}\right)$, social capital $\left(D_{i}\right)$, observed characteristics $\left(X_{i}\right)$, and unobserved characteristics of the individual that affect earnings $\left(\varepsilon_{i}\right) . X_{i}$ is a vector of observed characteristics of individual $i$, which includes individual-specific characteristics such as cognitive (IQ) and social endowments (sociability), as well as school-specific characteristics. The unobserved characteristics $\varepsilon_{i}$ can be any traits that are specific to the labor market, e.g., competence, motivation, etc. ${ }^{6}$

$V_{s}\left(S_{i}, X_{i}, v_{i}\right)$, the utility from socializing, depends on the time one spends socializing $\left(S_{i}\right)$, one's type of endowment $\left(X_{i}\right)$ and one's unobserved preference for socializing, denoted by $v_{i}{ }^{7} V_{l}\left(1-H_{i}-S_{i}, X_{i}, \eta_{i}\right)$ is the utility from other forms of leisure and depends on the

\footnotetext{
${ }^{5}$ We assume that all earnings are consumed. We abstract from saving and borrowing considerations in this paper because we only observe earnings in the data once.

${ }^{6}$ We exclude $S_{i}$ from $\ln Y_{i}$, which is a crucial exclusion restriction for our IVs to be valid. More explicitly, we are assuming that socializing increases one's utility (it is leisure) but it does not directly affect earnings, except through its effect on one's network and education. This will turn out to be a crucial assumption later on for our IVs to be valid.

${ }^{7}$ We do not explicitly include $E_{i}$ and $D_{i}$ in the utility from socializing, but this is equivalent to defining $V_{s}$ as $V_{s}\left(S_{i}, E_{i}, D_{i}, X_{i}, v_{i}\right)$ and replacing $E_{i}$ and $D_{i}$ with their reduced forms.
} 
amount of leisure $\left(1-H_{i}-S_{i}\right)$, one's type or endowment $\left(X_{i}\right)$ and the unobserved preference for leisure $\left(\eta_{i}\right){ }^{8}$ Both $v_{i}$ and $\eta_{i}$ are assumed to be privately observed by $i$.

We consider a static model, but the primitive variables in our model are realized with a certain timing. At the beginning of the schooling period, each student $i$ observes the public characteristic profile $X=\left(X_{1}, \ldots, X_{n}\right)$ and her private preferences $v_{i}$ and $\eta_{i}$, and then decides how much time to spend on studying $H_{i}$ and socializing $S_{i}$. Her $E_{i}$ and $D_{i}$ are realized at the end of the schooling period. After the schooling period, student $i$ enters the labor market, $\varepsilon_{i}$ is realized, and she receives earnings $Y\left(E_{i}, D_{i}, X_{i}, \varepsilon_{i}\right)$.

Following standard practice in the literature, we assume the log of earnings depends on education, networks and other traits and takes the form

$$
\ln Y\left(E_{i}, D_{i}, X_{i}, \varepsilon_{i}\right)=r_{e} E_{i}+r_{s} D_{i}+\beta^{\prime} X_{i}+\varepsilon_{i}
$$

where $r_{e}$ represents the returns to cognitive capital and $r_{s}$ represents the returns to social capital. $\beta^{\prime} X_{i}$ captures the effect of the observed characteristics of $i$. We assume that $X_{i}$ is independent of $\varepsilon_{i}, v_{i}$, and $\eta_{i}$ for all $i$. However, $\varepsilon_{i}$ can be correlated with $v_{i}$ and $\eta_{i}$. Given $X, v_{i}, \eta_{i}$, and the choices for $H_{i}$ and $S_{i}$, an individual's expected utility is given by

$$
\begin{aligned}
& \mathbb{E}\left[U\left(E_{i}, D_{i}, H_{i}, S_{i}, X_{i}, \varepsilon_{i}, v_{i}, \eta_{i}\right) \mid H_{i}, S_{i}, X, v_{i}, \eta_{i}\right] \\
= & \mathbb{E}\left[\ln Y\left(E_{i}, D_{i}, X_{i}, \varepsilon_{i}\right) \mid H_{i}, S_{i}, X, v_{i}, \eta_{i}\right]+V_{s}\left(S_{i}, X_{i}, v_{i}\right)+V_{l}\left(1-H_{i}-S_{i}, X_{i}, \eta_{i}\right)
\end{aligned}
$$

where

$$
\begin{aligned}
& \mathbb{E}\left[\ln Y\left(E_{i}, D_{i}, X_{i}, \varepsilon_{i}\right) \mid H_{i}, S_{i}, X, v_{i}, \eta_{i}\right] \\
= & r_{e} \mathbb{E}\left[E_{i} \mid H_{i}, S_{i}, X, v_{i}, \eta_{i}\right]+r_{s} \mathbb{E}\left[D_{i} \mid H_{i}, S_{i}, X, v_{i}, \eta_{i}\right]+\beta^{\prime} X_{i}+\mathbb{E}\left[\varepsilon_{i} \mid H_{i}, S_{i}, X, v_{i}, \eta_{i}\right]
\end{aligned}
$$

\section{Production of education and social capital.}

$E_{i}$ and $D_{i}$ depend on initial endowments and on the time individuals allocate to each activity. If individual $i$ spends $H_{i}$ studying, then the expected education given $H_{i}, S_{i}, X, v_{i}$ and $\eta_{i}$ is

$$
\mathbb{E}\left[E_{i} \mid H_{i}, S_{i}, X, v_{i}, \eta_{i}\right]=a\left(X_{i}, X_{-i}\right) H_{i},
$$

where $a\left(X_{i}, X_{-i}\right)$ (henceforth, $\left.a_{i}(X)\right)$ is productivity per unit time with respect to educational output. Productivity depends on $X_{i}$, the observed characteristics of $i$, which include

\footnotetext{
${ }^{8}$ The cost of studying is netted from $V_{s}\left(S_{i}, X_{i}, v_{i}\right)+V_{l}\left(1-H_{i}-S_{i}, X_{i}, \eta_{i}\right)$, so this summed utility can be positive or negative.
} 
their IQ (cognitive skills) and extroversion (sociability skills) ${ }^{9}$ and other characteristics, such as the school they attend. For instance, individuals with higher IQ may be more productive at studying and learn the same material faster than those with lower IQ. It also depends on $X_{-i}=\left(X_{j}, j \neq i\right)$, the observed characteristics of others $-i$, and it can be cohort-specific. This allows for (exogenous) peer effects in education, namely, the possibility that individuals learn faster (or slower) depending on the characteristics of their classroom peers. ${ }^{10}$

The production of social capital is different from a standard production function because it requires coordination-you cannot "party alone." We assume $i$ becomes a friend of $j$ under two conditions: they spend time together (they socialize), and they decide to be friends because they like each other (they derive nonnegative utility from the friendship). If individuals $i$ and $j$ spend $S_{i}$ and $S_{j}$ amounts of time socializing, then the probability that $j$ nominates $i$ as a friend is given by

$$
\operatorname{Pr}\left(D_{j i}=1 \mid H_{j}, H_{i}, S_{j}, S_{i}, X, v_{i}, \eta_{i}\right)=p\left(X_{j}, X_{i}\right) S_{j} S_{i}
$$

where the likelihood that $i$ and $j$ meet depends on how much time they spend socializing $S_{j} S_{i}{ }^{11}$ Importantly, both $i$ and $j$ have to spend time socializing together $\left(S_{i}>0\right.$ and $\left.S_{j}>0\right)$ for them to have a non-zero probability of becoming friends. ${ }^{12} p\left(X_{j}, X_{i}\right)$ (hereafter, $\left.p_{j i}(X)\right)$ represents the likelihood that $i$ becomes a friend of $j$, conditional on their meeting. The likelihood of becoming friends depends on the individual and shared characteristics of $i$ and $j$. This feature captures the empirical finding that individuals tend to form friendships with other individuals with whom they share similar characteristics, often referred to as homophily (Jackson, 2008). Empirically, we measure homophily as the absolute distance in traits, which we refer to as "social distance."

Individual $i$ 's social capital is measured by the number of friends or connections she has. Specifically we will use her in-degree $D_{i}$, the number of individuals who nominate $i$ as a friend:

$$
D_{i}=\sum_{j \neq i} D_{j i}
$$

\footnotetext{
${ }^{9}$ In the model and later in the empirics, we focus attention on extraversion as the main social trait. We discuss this choice in more detail in the empirical section.

${ }^{10}$ The model does not assume endogenous peer effects in education because there is no coordination in the education production function.

${ }^{11}$ This model is similar in spirit to dyadic network formation models with fixed effects (Graham, 2017), where the time spent socializing $S_{i}$ and $S_{j}$ act as individual effects. Unlike Graham who considers additive individual effects, we consider interactive individual effects $S_{i} S_{j}$ to account for the coordination in socializing.

${ }^{12}$ While individuals may engage in shared activities (such as studying) with others, we assume that there is no socializing (friendship formation) occurring. Put differently, studying with others is an outcome of prior socialization (friends study together).
} 
where $D_{j i}$ is an indicator for whether $j$ nominates $i$ as a friend.

\section{How do individuals decide how much to study and socialize? Best response functions and equilibrium.}

Given her information $X$ and $\varepsilon_{i}$, individual $i$ chooses $H_{i}$ and $S_{i}$ in order to maximize her expected utility. Expected labor market earnings are a function of $i$ 's expected education, expected in-degree, observable characteristics, and expected labor market shocks. For individual $i$, the expected in-degree depends on the time she spends socializing and the expected amount of time others spend socializing. ${ }^{13}$ We make the assumption that conditional on $X$, $v_{i}$ and $\eta_{i}, H_{i}$ and $S_{i}$ are uncorrelated with $\varepsilon_{i}$, i.e., $\mathbb{E}\left[\varepsilon_{i} \mid H_{i}, S_{i}, X, v_{i}, \eta_{i}\right]=\mathbb{E}\left[\varepsilon_{i} \mid X, v_{i}, \eta_{i}\right]$. In other words, studying and socializing have no direct effect on earnings: they affect the earnings only through their effects on education and in-degree. ${ }^{14}$

Given the beliefs $\mathbb{E}\left[S_{j} \mid X\right]$ for $j \neq i$, the optimal amounts of studying $H_{i}^{*}$ and socializing $S_{i}^{*}$ satisfy the following first-order conditions

$$
\begin{aligned}
r_{e} a_{i}(X) & =\frac{\partial V_{l}}{\partial L_{i}}\left(1-H_{i}^{*}-S_{i}^{*}, X_{i}, \eta_{i}\right) \\
\frac{\partial V_{s}}{\partial S_{i}}\left(S_{i}^{*}, X_{i}, v_{i}\right)+r_{s} \sum_{j \neq i} p_{j i}(X) \mathbb{E}\left[S_{j} \mid X\right] & =\frac{\partial V_{l}}{\partial L_{i}}\left(1-H_{i}^{*}-S_{i}^{*}, X_{i}, \eta_{i}\right)
\end{aligned}
$$

where $\frac{\partial V_{l}}{\partial L_{i}}\left(L_{i}, X_{i}, \eta_{i}\right)$ denotes the derivative of $V_{l}\left(L_{i}, X_{i}, \eta_{i}\right)$ with respect to $L_{i}=1-H_{i}-$ $S_{i}$. The optimal amounts of studying and socializing balance the marginal utility with the marginal cost of studying and socializing, respectively. The marginal benefit from studying (the left-hand side of (6)) is the additional earnings from studying one more unit of time. The marginal benefit of socializing (the left-hand side of $(7)$ ) has two terms. The first term is the direct utility individuals derive from socializing one more unit of time. The second term comes from the additional earnings individuals get when they socialize and accumulate additional social capital. The marginal cost of studying and socializing is the utility loss due to one less unit of leisure, respectively.

\footnotetext{
${ }^{13}$ Individual $i$ needs to form an expectation about how much time others will spend socializing because $S_{j}, j \neq i$, depends on $j$ 's preference for socializing $v_{j}$, which is not observed by $i$.

${ }^{14}$ This is a crucial exclusion restriction for us to get valid instruments. See Section 5 for more details.
} 
Then, under standard assumptions, ${ }^{15}$ we can derive the optimal $H_{i}^{*}, S_{i}^{*}$ and $L_{i}^{*}$

$$
\begin{aligned}
H_{i}^{*} & =1-S_{i}^{*}-L_{i}^{*} \\
S_{i}^{*} & =g_{s}\left(r_{e} a_{i}(X)-r_{s} \sum_{j \neq i} p_{j i}(X) \mathbb{E}\left[S_{j} \mid X\right], X_{i}, v_{i}\right) \\
L_{i}^{*} & =g_{l}\left(r_{e} a_{i}(X), X_{i}, \eta_{i}\right)
\end{aligned}
$$

where $g_{s}$ and $g_{l}$ denote the inverse of the marginal utility functions from socializing and from leisure respectively.

The optimal amount of socializing depends on the decisions of others to socialize; thus, Equation (8) corresponds to the "best response function" of a given individual, who takes others' actions as given. In a Bayesian Nash equilibrium, $S_{i}^{*}$ satisfies the equilibrium condition

$$
\mathbb{E}\left[S_{i}^{*} \mid X\right]=\mathbb{E}\left[g_{s}\left(r_{e} a_{i}(X)-r_{s} \sum_{j \neq i} p_{j i}(X) \mathbb{E}\left[S_{j}^{*} \mid X\right], X_{i}, v_{i}\right) \mid X\right], \text { for all } i .
$$

Let $\mathbb{E}\left[S^{*} \mid X\right]=\left(\mathbb{E}\left[S_{1}^{*} \mid X\right], \ldots, \mathbb{E}\left[S_{n}^{*} \mid X\right]\right)^{\prime}$ be a belief profile. Because $\mathbb{E}\left[S^{*} \mid X\right] \in[0,1]^{n}$ and the right-hand side of (11) is a continuous function of the components in $\mathbb{E}\left[S^{*} \mid X\right]$, by Brower's fixed point theorem there exists at least one equilibrium $\mathbb{E}\left[S^{*} \mid X\right]$. Although there might be multiple equilibria, in Appendix 1 we show that under additional assumptions there exists a unique equilibrium in which the best response is given by

$$
S_{i}^{*}=g_{s}\left(r_{e} a_{i}(X)-r_{s} \sum_{j \neq i} p_{j i}(X) \mathbb{E}\left[S_{j}^{*} \mid X\right], X_{i}, v_{i}\right) .
$$

This equation states that the optimal level of social investment is a function of the returns to schooling, the returns to social capital, schooling inputs, homophily and initial endowments.

\subsection{Empirical implications.}

We now investigate a few properties of the model that can be examined empirically.

Proposition 1. If there are no labor market returns to social capital $\left(r_{s}=0\right)$, then in an OLS regression of log earnings on socializing, the coefficient on socializing will be negative (the coefficient on studying will be positive) when education and in-degree are not controlled

\footnotetext{
${ }^{15}$ We assume that $\frac{\partial V_{s}}{\partial S_{i}}\left(S_{i}, X_{i}, v_{i}\right)>0, \frac{\partial^{2}}{\partial S_{i}^{2}}\left(S_{i}, X_{i}, v_{i}\right)<0, \frac{\partial V_{l}}{\partial L_{i}}\left(L_{i}, X_{i}, \eta_{i}\right)>0$, and $\frac{\partial^{2} V_{l}}{\partial L_{i}^{2}}\left(L_{i}, X_{i}, \eta_{i}\right)<0$.
} 
for.

Proof. See Appendix 2. If there are no social returns $\left(r_{s}=0\right)$, then the optimal amount of socializing becomes

$$
S_{i}^{*}=g_{s}\left(r_{e} a_{i}(X), X_{i}, v_{i}\right)
$$

In this case, individuals still socialize $\left(S_{i}^{*}>0\right)$, but socializing would have negative returns in the labor market because it is pure leisure. In Section 7.1, we will show that socializing is in fact associated with higher wages, contrary to a model where socializing is simply utility-increasing.

Proposition 2. If coordination matters (friendship formation depends on i's socializing effort $S_{i}$ and the socializing effort of others $S_{-i}$ ), then the formation of friendship links will depend on both the sender's and receiver's homophily measures.

Proof. See Appendix 2. This proposition provides an empirical test for whether coordination plays a role in social capital formation. The network formation in (4) requires both students to coordinate on their socializing to form a friendship link. Coordination is not a key assumption to generate investments in social capital, but is a natural assumption given the nature of socializing. When coordination matters, the likelihood that $j$ nominates $i$ as a friend depends on the socializing decisions of both the sender $j$ and the receiver $i$, which are a function of their respective homophily measures. If coordination does not matter, then the likelihood of forming a friendship depends only on the receiver's socializing. Therefore, the homophily measures of the sender would no longer affect the formation of the friendship. We test this prediction when we estimate the formation of friendships. ${ }^{16}$

Proposition 3. If we estimate the earnings equation by $O L S$, then the estimated returns to education and in-degree will be biased. Without further assumptions, the directions of the biases in the OLS estimates of returns to education and in-degree are ambiguous.

Proof. See Appendix 2. In the model, both education and in-degree can be correlated with the error term because tastes for leisure and for socializing are unobserved. If we estimate the earnings equation by OLS, then the estimated returns to education and in-degree will be biased; however, this proposition states that ex-ante it is not possible to assign the direction of the bias. In Section 6, we use an instrumental variables approach to estimate the returns to in-degree that are based on our model. We also investigate explanations for the direction of the bias we observe in the results.

\footnotetext{
${ }^{16}$ This result relies on the assumption that the sender $j$ 's homophily measures with respect to other students do not affect her socializing productivity with $i$ in their friendship $\left(p_{j i}(X)\right)$.
} 
Proposition 4. Increasing an individual's homophily level has ambiguous predictions on socializing and on social capital.

Proof. See Appendix 2. While the model suggests that homophily plays a role in social capital formation, it cannot be used to extrapolate whether a student would accumulate more social capital in an environment where she is more similar to her peers. For instance, one might expect that $i$ 's socializing is increasing in her homophily or similarity to her classmates (decreasing in distance). But predictions are in fact ambiguous because of general equilibrium effects: when placing $i$ in a new group of students who are socially farther to her, it is unclear how much the other students will socialize in this new setting. Therefore, the effect of homophily on social outcomes is an empirical question.

Proposition 5. Without further assumptions, the effect of an individual characteristic $X_{i}$ on socializing $S_{i}^{*}$,and, thus, on social capital is theoretically ambiguous. The same is true for studying $H_{i}^{*}$ and education.

Proof. See Appendix 2. One might expect that individuals reinforce their initial endowments, but that is not necessarily the case. If we assume that extroversion does not affect studying productivity, then extroverts spend more time socializing and less time studying. Consequently, they accumulate more social capital and less education. Whether or not smart students socialize more depends on their socializing and studying productivity. If the marginal productivity of socializing is increasing in intelligence and large enough to induce a reduction in studying time, then high-IQ students can accumulate more social capital. We investigate these questions empirically.

\section{Data}

\subsection{Add Health data}

Our main data is the restricted-use National Longitudinal Study of Adolescent to Adult Health (henceforth, "Add Health"), which contains detailed data on the friendship networks of individuals in middle school and high school (Harris et al., 2009). There are two main samples in the Add Health data: the in-school sample and the in-home sample. The in-school sample is a roster of all students in a given school during the 1994/1995 school year. The in-school questionnaire includes basic demographic data as well as friendship nominations. A random sample of the students interviewed in school was selected for in-home interviews in Wave 1 during the 1994/1995 school year (ages 12-18 years) and tracked over subsequent 
survey waves. In Wave 4, respondents were ages 24-32 years. For this sample, we observe measures of endowments, investments, and cognitive and social outcomes we now describe.

Summary statistics are presented in Table 1. Our estimation sample includes 9,738 individuals with complete data for our key measures. ${ }^{17}$ Our key outcome of interest is total earnings from wages or salary in the last year. This variable is asked of everyone. ${ }^{18}$ Individuals in our sample made roughly $\$ 38,000$ in the previous year.

Our primary measure of social capital is a person's in-degree. For a given student $i, i$ 's in-degree is the number of people who nominate $i$ as one of their friends in Wave 1 . Indegree has been widely used in the social network literature as an objective measure of an individual's social capital because it does not rely on self-reporting (Conti et al. (2013)). However, because individuals could list up to five nominations of each gender, this measure might underestimate a student's actual number of friends (some friends were not listed), or overestimate it (if individuals felt compelled to list five friends but had fewer). Another measure of social capital is network size, which represents the total number of individuals who either sent a nomination to student $i$ or received a nomination from student $i^{19}$ On average, in-degree is 4.5 , while network size is 7.1. Figure 2 presents histograms of in-degree and network size. As expected, network size is more comprehensive, with fewer individuals listing zero friends compared with in-degree. However, network size is likely to be measured with more error because it relies on self-reported friendships. We return to this issue later in the paper. ${ }^{20}$

We use self-reported extroversion as the main measure for the social tendencies (endowment) of individuals. About $65 \%$ of individuals report being extroverted. Extroversion and, conversely, introversion or shyness, is one of the "Big Five" psychological traits, and there is evidence this trait is both relatively stable over time (Cobb-Clark and Schurer, 2012) and associated with higher education and better labor market outcomes (Lenton, 2014;Widiger, 2017;John and Srivasta, 1999), consistent with columns 4 and $5 .^{21}$

Education-related output is measured by years of schooling and GPA. Both measures predict wages and could be used in our wage regressions. However, years of schooling is more commonly used in the literature and is available for many more survey participants, so

\footnotetext{
${ }^{17}$ We drop observations with missing cognitive test scores, gender, age, and whether the student is white.

${ }^{18}$ We drop 1-individuals (2\%) who did not know their wage earnings in the last year even if they provided a rough guess, and 2 -individuals who report 0 wage earnings $(\sim 6 \%)$ so they were unemployed the entire year.

${ }^{19}$ We also examine other measures of social capital in the empirical results.

${ }^{20}$ Total network size has an additional disadvantage for our purposes: there are many individuals that are named as friends who are not interviewed by Add Health and whose characteristics we cannot observe. This makes the estimation of network formation more difficult.

${ }^{21}$ Due to the survey design this measure is missing for $25 \%$ of individuals in the data: shyness was measured in Wave 2, which was a follow-up survey conducted one year after Wave 1. Students who were in grade 12 during Wave 1 were not surveyed during Wave 2.
} 
we will use this measure for most of our analysis. On average, individuals in our data obtain almost 15 years of schooling.

The Add Health Picture Vocabulary Test (AHPVT) score is our main measure for cognitive endowment or IQ. This test, administered in Wave 1, is an abbreviated version of the widely used Peabody Picture Vocabulary test and it measures verbal ability. While this test is not an overall measure of intellectual ability, it has a high correlation with other intelligence tests (Canivez, 1995; Hodapp and Gerken, 1999; Dunn and M.Dunn, 2007). Consistent with this, high-IQ individuals have more years of schooling, higher GPAs, and higher earnings (columns 2 and 3).

Our model separates time spent studying from socializing and other activities, but measures of time allocation are limited in Add Health. We observe reported study effort (no effort, some effort, very hard study effort), which captures whether individuals are really studying as opposed to listening to music or daydreaming while they "study". On average, $37 \%$ of individuals report studying very hard.

Reliable metrics for socializing prove the most elusive. We do not observe hours spent with others, or on social activities. However, we observe reported frequencies of time spent with friends and frequency of alcohol consumption. Respondents report time spent with friends as either never, sometimes, or frequently hanging out with friends, and $38 \%$ report frequently hanging out with friends (this fraction is larger among extroverts). We assume that the decision to consume alcohol during high school and college is primarily a decision to socialize (measures socializing effort). Alcohol consumption among adolescents appears to be largely motivated by its capacity to facilitate social interactions and boost the energy of social events (Feldman et al., 1999; Kuntsche et al., 2005). About $46 \%$ report drinking moderately or frequently and, consistent with its social role, extroverts report drinking more.

\section{Do people invest in social capital? Investments in cognitive and social capital}

We start by showing that education and social capital increase with socializing and studying investments. Figure 3 shows that studying effort is associated with greater years of schooling (panel a), albeit with a decreasing rate. Similarly, friendships increase time spent with friends or with drinking (panels $\mathrm{d}$ and f). Surprisingly, time spent with friends is not associated with lower schooling outcomes (except for those that socialize a lot) and neither is drinking, except for those that a drink a lot (panels c and e); surprisingly, more studying is associated with more (not fewer) friends, except for those who study a lot (panel b). 
Table 2 reports the results from regressing outcomes on investments, school fixed effects, peer characteristics and other predetermined individual characteristics. We consider two social outcomes: in-degree and network size, and two education outcomes, years of schooling and GPA. As expected, study effort is strongly and positively correlated with education outcomes. Individuals who exert some (very hard) study effort have 0.5 (0.7) more years of schooling and have a GPA that is 0.13 (0.34) points higher than those who report not exerting any effort. Interestingly, the number of friendships is also increasing in modest study effort (one hour results in 0.3 more nominations or in 0.5 more individuals in the network), though studying very hard does not; also as expected, those who sometimes (frequently) spend time with friends have 0.8 (1.2) more friends. Spending time with friends, however, does not predict negative schooling outcomes-the coefficients are statistically insignificant. Together these results suggest that individuals who spend some time studying together can increase both their schooling and social outcomes. ${ }^{22}$

Those who drink (occasionally or frequently), however, do so to the benefit of their friendships and to the detriment of their schooling outcomes. For example, individuals who drink alcohol frequently (more than once a month) have 0.6 more friends but obtain 0.35 fewer years of schooling and their GPA is 0.21 points lower relative to those who drink less frequently. This suggests that individuals who drink frequently substitute away from studying instead of consuming less leisure.

These results suggest that social investments result in friendships, consistent with our model. But perhaps the causality runs the other way; i.e., those who have friends spend time with friends and drink with them. To investigate this issue, we make use of the fact that we have a measure of the number of friends in adulthood. Unfortunately, this measure is self reported and categorical. ${ }^{23}$ However, it can be used to assess if the timing of investments lines up with a causal interpretation. Table 3 shows that drinking and spending time with friends in Wave 3 (when individuals are in their early twenties) increases the number of adult friendships (column 1), even controlling for the number for friends in adolescence (column 2). Column 2 further shows that once education, friendships and social investments in adulthood are accounted for, social investments in adolescence do not matter much: in these regressions, drinking in adolescence lowers the number of adult friends and other socializing measures are insignificant, except for "frequently hanging out with friends" in W1 (though

\footnotetext{
${ }^{22}$ Interestingly, IQ positively predicts both cognitive and social capital, even conditional on investments. Extroversion predicts social outcomes, conditional on investments, but not cognitive ones. This suggests that either the investments are not fully accounted for or that these traits have independent benefits in the production of these forms of capital.

${ }^{23}$ This comes from the question "How many close friends do you have?" The possible answers are: zero, one to two, three to five, six to nine, and ten or more friends.
} 
this coefficient is smaller than the coefficient for "frequently hanging out with friends" in W3).

In sum, our results suggest that individuals spend time and effort in both schooling and socializing activities, and that these activities do in fact increase schooling outcomes and network size. Interestingly, we find that studying and socializing are not necessarily in conflict: moderate socializing increases education, and moderate studying increases one's friends. Indeed, there is a positive correlation (0.15) between education and network size that remains positive even after conditioning on covariates (Appendix Figure A.1). This suggests that the existing perception, documented by Bursztyn and Jensen (2015), that there is a trade-off between education and socializing, is not necessarily correct. But there does appear to be a trade-off between studying and some social activities like drinking. And there is also a trade-off for individuals doing very high levels of either activity.

\section{Estimating Returns to Social Capital}

We now turn our attention to estimating the labor market returns to social capital. We wish to estimate the following equation

$$
\ln Y_{i}=r_{e} E_{i}+r_{s} D_{i}+y\left(X_{i}\right)+\varepsilon_{i}
$$

where the outcome of interest is the log of earnings for a given individual $i$ and the objects of interest are the coefficients for education $E_{i}$ and in-degree $D_{i}$. Proposition 4 shows that OLS estimates of $r_{e}$ and $r_{s}$ will be biased because both education and friendships are jointly determined. So we require instruments for both education and in-degree to estimate the causal effect of social capital. The ideal instruments $Z_{i}$ satisfy three conditions: i) they predict $E_{i}$ and $D_{i}$; ii) they affect wages only through $E_{i}$ and $D_{i}$; and iii) they can separately identify $E$ and $D$.

Our model motivates our choice of instrumental variables. Recall that $p_{j i}$, the probability that $j$ nominates $i$ as a friend, depends on the likelihood they become friends upon meeting. We assume that $p_{j i}$ depends on the social distance between $j$ and $i$, defined as $\left|X_{i}-X_{j}\right|$. This social distance would be a valid instrument for the friendship because it affects the friendship formation. Thus homophily affects socializing and studying effort, and ultimately, education and number of friends, but it does not directly affect the earnings of $i$, conditional on the friendship and on the education level. Similarly, proper instruments for education affect the productivity in education production $a_{i}$ but not earnings, conditional on education. For example, peer characteristics and cohort-specific education supply side measures likely affect 
$a_{i}$, but are unlikely to directly affect earnings, except through their effect on education (and networks). For these instruments to be valid, we need to assume that the time spent studying $H_{i}$ and socializing $S_{i}$ does not have a direct effect on earnings; otherwise, $H_{i}$ and $S_{i}$ would be part of $\varepsilon_{i}$, and the IVs would not be excluded from the earnings equation. This is the key identifying assumption. ${ }^{24}$

How to construct individual-level instruments? We model pairwise interactions, whether $i$ is a friend of $j$ as a function of the distance between $i$ and $j$. But the wage equation is at the individual level; thus, a function of the total number of friends $i$ has ( $i$ 's in-degree). A simple solution is to directly instrument for in-degree by aggregating the homophily measures (summing over them). This approach that uses aggregated instruments could be inefficient: Newey and McFadden (1994) and Wooldridge (2010) show that under homoscedasticity (in the earnings equation), an efficient instrument for in-degree is given by $\mathbb{E}\left(D_{i} \mid Z_{i}\right)$, i.e., the projection of in-degree onto the pairwise homophily measures. ${ }^{25}$ Instead we proceed as follows. We start by estimating the likelihood $i$ and $j$ will be friends as a function of their homophily

$$
\mathbb{E}\left(D_{j i} \mid Z_{i}\right)=\beta_{1}^{\prime}\left|X_{i}-X_{j}\right|+\beta_{2}^{\prime} Z_{i}^{e}+\beta_{3}^{\prime} X_{i}+\beta_{4}^{\prime} \bar{X}_{c}+\alpha_{s}
$$

Because $i$ 's in-degree is the sum of $i$ 's friendship nominations from other students, our instrument for in-degree is the sum of the predicted nominations, $\mathbb{E}\left(D_{i} \mid Z_{i}\right)=\sum_{j \neq i} \mathbb{E}\left(D_{j i} \mid Z_{i}\right) .{ }^{26}$ We use distance in gender, race, age, and "the number of years a student has been at their school" as our main homophily measures. ${ }^{27}$ Except for years in school, the previous

\footnotetext{
${ }^{24}$ If $H_{i}$ and $S_{i}$ have a direct effect on earnings, then they would enter the earnings equation through $\varepsilon_{i}$. Because our IVs are variables that affect productivity in the education production $a_{i}$ and preference in the social capital production $p_{j i}$, they would be correlated with $\varepsilon_{i}$ through $H_{i}$ and $S_{i}$ and, thus, become invalid.

${ }^{25}$ Under heteroscedasticity, an efficient instrument for in-degree is given by $\mathbb{E}\left(\varepsilon_{i}^{2} \mid Z_{i}\right)^{-1} \mathbb{E}\left(D_{i} \mid Z_{i}\right)$, i.e., the projected in-degree divided by the projection of the squared error term in earnings onto the pairwise homophily measures. Because the error term in earnings $\varepsilon_{i}$ is at the individual level, while the pairwise homophily measures in $Z_{i}$ are at the pair level, it is not obvious how to estimate $\mathbb{E}\left(\varepsilon_{i}^{2} \mid Z_{i}\right)$. We try to approximate it by projecting the estimated $\varepsilon_{i}^{2}$ onto the aggregate homophily measures, but this seems to introduce too much noise. Therefore, we only use the unadjusted projected in-degree as the instrument.

${ }^{26}$ Using the predicted in-degree as an instrument instead of a regressor in the second stage is also in line with what Angrist and Pischke, 2009, Section 4.6 suggest to avoid a forbidden regression in the case of a nonlinear first stage. Our first stage is nonstandard in a different way: it is at the pair level. Using the predicted values as instruments and keeping the original moment condition with the observed endogenous variables would allow us to obtain consistent estimates.

${ }^{27}$ In principle we could also include distances in IQ, shyness and socio-economic status indicators but these have a lot of missing values due to the survey design. Students who were not included in the in-home surveys do not have information on IQ, whether they are extroverted, and SES covariates. We experimented with alternative approaches, namely limiting our estimation sample to individuals with non-missing covariates. We found evidence that this was not a randomly selected sample, which biased our estimated coefficients in this approach. It is important to note that we observe all nominations sent to $i$ regardless of whether they are in our main analytic sample (the in-home sample in Add Health).
} 
literature has already demonstrated these measures are excellent predictors of friendship formation (Jackson, 2008). As usual, we include the instruments for education $\left(Z_{i}^{e}\right)$ (more on this below) and $i^{\prime} s$ characteristics $X_{i}$ in this first stage. We also control for the mean characteristics in $i^{\prime} s$ cohort $\bar{X}_{c}$ and the school fixed effect $\alpha_{s}$ to account for sorting of individuals into schools, and for variation in the composition of students across cohorts within a school. We estimate a linear specification but we also estimate a probit specification as a robustness check.

The identification assumption is that the pairwise homophily measures $\left|X_{i}-X_{j}\right|$ are excluded from the earnings equation conditional on these controls. For example, we control for $i$ 's gender, the fraction of $i$ 's cohort that is female and a school fixed effect. Thus, the coefficient $\beta_{1}$ in the first stage is identified by comparing pairs of individuals that are in the same school, and are in a cohort with the same gender composition, but who are of the same or opposite gender. At the aggregate level this is akin to saying that the instrument for indegree is the interaction between $i$ 's gender and the gender composition of $i$ in their school, controlling for the mean gender in $i$ 's cohort. The interaction is the excluded instrument. In other words, we are comparing different cohorts within a school that have identical mean characteristics but different variances in these characteristics.

We also estimate a first stage for years of schooling using the following specification:

$$
\mathbb{E}\left[E_{i} \mid Z_{i}\right]=\beta_{1}^{\prime} Z_{i}^{e}+\beta_{2}^{\prime} \sum_{j \neq i}\left|X_{i}-X_{j}\right|+\beta_{3}^{\prime} X_{i}+\beta_{4}^{\prime} \bar{X}_{c}+\alpha_{s}
$$

where $Z_{i}^{e}$ are the instruments for education. Gender and race distances are highly predictive of individual schooling outcomes (Sacerdote, 2011) as is the distance with peers' ages, often referred to as "relative age" (Black, Devereux, and Salvanes, 2011). These are also instruments for friendships, after aggregation. Because we need additional excluded variables to separately identify the effect of education from that of in-degree, we also include five other instruments, which are inspired by recent work: 1-distance in maternal education; 2-distance in whether father lives in the household (which also proxies for SES); 3-distance in physical maturity; 4-racial distance with teachers; and 5-cohort size. ${ }^{28}$ As before we control for cohort

\footnotetext{
${ }^{28}$ Recent work suggests that measures of the dispersion in backgrounds (maternal education, father presence) within a cohort affect education (Bifulco, Fletcher, and Ross, 2011), as does distance in distance in physical maturity (Sabia and Rees, 2012). Recent work also suggests that students benefit from being of the same race as their teachers (Gershenson, Holt, and Papageorge, 2016; Egalite, Kisida, and Winters, 2015; Redding, 2019). We calculate the race composition of teachers at the school level and include the racial distance between a student and teachers. Finally we include cohort size. Larger cohorts are likely associated with having larger class sizes, which has been suggested to have adverse affects on academic achievement (Angrist and Lavy, 1999); however, Wo[ss]mann and West (2006) and Woessmann (2016) suggest this matters only when teachers are of low quality).
} 
mean characteristics, including the mean SES characteristics of peers and of their parents $\left(\bar{X}_{c}\right)$ and school fixed effects $\left(\alpha_{s}\right)$. Our identifying assumption is again that conditional on the school fixed effects and the mean peer characteristics, the instruments do not directly affect wages except through education and in-degree.

Estimation and inference. With the predicted in-degree and years of schooling as the instruments, we estimate the parameters in the earnings equation by GMM. ${ }^{29}$ To allow for heteroscedasticity in the earnings equation, we implement the estimation by two-step GMM provided in STATA, which uses the optimal weighting matrix that accommodates heteroskedasticity. Because we use the predicted values as the instruments instead of regressors, the default formula in two-step GMM gives us the correct standard errors. It is well-known that instruments for education could be weak. We therefore provide robust confidence intervals for the effects of education and in-degree that are immune to weak instruments and heteroskedasticity as proposed by Andrews (2018).

\section{The Formation of Social and Education Capital}

\subsection{What predicts network formation?}

We now estimate the network formation using data on bilateral pairs that can be constructed using Add Health as in Eq. (14). We concentrate on predicting nominations within the same grade, which account for $80 \%$ of all nominations. ${ }^{30}$

The results are presented in Table 4 (Appendix Tables A.1 and A.2 show the results for receiver controls and peer means). The first column shows the results for all pairs of students regardless of their gender. Consistent with the findings in the literature, homophily is an important predictor of friendship formation. The coefficients for white, female, age and years at school distances are negative and statistically significant, confirming that friendship nominations are more likely when the sender and receiver are similar in all of these dimensions. Because of missing data we are unable to study the effect of other homophily measures. ${ }^{31}$

Individual receiver characteristics also predict nominations. Tall and physically mature individuals, those with high IQs, extroverts, women, whites, and those who have been in school for more years receive more nominations-all these coefficients are statistically signifi-

\footnotetext{
${ }^{29}$ We use predicted education as an instrument for education.

${ }^{30}$ Estimation of all possible pairs is computationally burdensome. Our exploratory work suggested that estimating the entire possible network would take substantially more time but make little difference to the estimates.

${ }^{31}$ When measuring total distance, we need to correct for the fact that many pairwise distances are missing for these measures. Specifically, $\sum_{j \neq i}\left|X_{i}-X_{j}\right|$ will be biased downward if we exclude pairwise distances where $X_{j}$ is missing. Our approach is to impute missing data when $X_{j}$ is missing.
} 
cant. The fact that IQ predicts nominations can help explain the positive correlation between in-degree and educational attainment. Interestingly, individuals who come from high-SES households (measured by income, food stamp receipt, presence of parents) are more likely to receive a friendship nomination, providing some evidence that individuals are attracted to those who may provide valuable connections in the labor market. ${ }^{32}$

Some (but not all) education instruments matter for friendship formation: those in large cohorts are less likely to become friends and those with large racial distance with teachers make more friends. Importantly, three education instruments (distance in father presence, mother's education and physical maturity) are not statistically significant predictors of friendships. This suggests we might be able to separately identify the effects of education and in-degree in the second stage. However the F-statistics testing the joint significance of the excluded instruments are only barely above 10, suggesting the instruments might be weak. Nevertheless predicted nominations statistically significantly increase nominations: one more predicted nomination results in 0.27 actual nominations, conditional on other controls. ${ }^{33}$

Gender effects. Prior research has often restricted attention to same sex friendships, because mixed gender nominations can also represent romantic interests (e.g. Fletcher, Ross, and Zhang, 2013). Mixed-gender friendships might also form differently because these friendships are different in nature - indeed female and male networks exhibit different properties (Lindenlaub and Prummer, 2014). Columns 2-4 of Table 4 investigate this. Overall, there is great similarity across columns: female-female friendships (column 2), male-male friendships (column 3), and female-male friendships (column 4) are predicted, in general, by the same factors though there are some differences. Age, race, and years at school distance matters less across genders, but physical maturity matters more, consistent with the view that some opposite-gender nominations correspond to romantic relationships. ${ }^{34}$ In addition, the share of females in the cohort affects males and females differently (Appendix Table A.2). Women are less likely to become friends in school cohorts with more females, whereas males are more likely to become friends when the share of females is higher. In the next section we investigate whether the wage return to same-sex or opposite-sex relationships differs.

Coordination tests. By examining whether the likelihood of forming a link depends on the homophily measures of the sender, we can test whether there is coordination in network formation (see Section 2.1). We implement this test using both the overall in-school sample

\footnotetext{
${ }^{32}$ All coefficients for mean cohort characteristics, except for mean income, are both individually and jointly statistically insignificant, but it is difficult to separately identify the effects of the group means once individual and pair distances are controlled for.

${ }^{33}$ Results available upon request. We obtain this result by regressing nominations on predicted nominations and controls.

${ }^{34}$ There are other notable differences in the magnitude of the predictors of friendships by gender that are worthy of further investigation. A full exploration of these differences is beyond the scope of this paper.
} 
and the smaller in-home sample (used in our estimation). The results are in Appendix Table A.3. In both samples, the social distances of the sender to his/her peers measured by white, female, age, and years at school are all statistically significant, suggesting that coordination is crucial in the formation of social capital.

\subsection{The production of education}

The results for years of schooling are presented in Table 5. Recall that these regressions are estimated at the individual level rather than the pair level and include school fixed effects. ${ }^{35}$ Individual characteristics have the expected signs: IQ statistically significantly raises education, whereas extroversion does not. Mean peer and teacher characteristics also show previously observed patterns. Greater maternal education in one's cohort is associated with more years of schooling, whereas a greater share of peers receiving food stamps is associated with fewer years of schooling. If teachers differ from students in their race, then students have fewer years of schooling and lower GPAs. However, this effect is statistically insignificant in the years of schooling estimates. But not all peer characteristics matter. Cohort size, mean extroversion, and mean peer IQ are not statistically significant.

Homophily measures matter. Consistent with the literature on relative age, individuals in cohorts with greater age dispersion end up with lower education outcomes. Conditional on the mean maternal education of your peers, greater dispersion in maternal education also negatively predicts years of schooling and GPA. We find similar results for total distance in father's presence and physical maturity: conditional on the mean, dispersion in these outcomes lowers attainment. These results suggest that segregating students into groups that are homogeneous in terms of age, physical maturity, and SES improves schooling outcomes. There are some exceptions. Race diversity does not statistically predict education outcomes, and neither does diversity in years at school. Suprisingly, greater female distance increases education, suggesting same gender schools are detrimental for some children.

The fact that some of the instruments that predict networks are not significant predictors of education suggests that we will be able to separately identify the effects of education and networks in the wage equation. But the F-value on the excluded instruments is less than 10 for education and only slightly above 10 for networks despite the fact that many variables are statistically significant. This suggests that the excluded instruments are weak, a complication that we deal with in the estimation of the wage returns, which we turn to now.

\footnotetext{
${ }^{35}$ As a result some of the measures in the pair-wise regressions cannot be easily separately identified. For example at the pairwise level we compute female distance. At the aggregate level this measure becomes the total gender distance. This measure is now very similar to the fraction of females in the group and differs only in functional form.
} 


\section{The Returns to Social Networks}

\subsection{Preliminary evidence that social investments have returns in the labor market}

If socializing were pure leisure, then it would be expected to detract from labor market productivity (Proposition 5). However, we claim that individuals socialize in part because it increases their wages. Some preliminary evidence for this is presented in Table 7, which shows the results of a regression of (log) wages on individual endowments (IQ and extroversion), and individual and school characteristics (as in Table 2). In column 1, we do not control for education and network size, but we include social and educational investments. We find that study time and effort are statistically significant predictors of wages. More interestingly, moderate or large alcohol consumption in high school does not decrease wages: these coefficients are positive and statistically insignificant. Time spent with friends is positively and statistically significantly associated with higher wages. Column 2 repeats the estimation controlling for years of schooling. Now time and effort on studying are no longer significant predictors of wages (the coefficients are now much smaller and statistically insignificant), consistent with the idea that they only affect wages because of their effect on education. Coefficients on drinking become even smaller and remain statistically insignificant. Time spent with friends remains positive and a statistically significant predictor of wages. We can reject the hypothesis that drinking and socializing have negative effects on wages, suggesting these activities are not simply pure leisure but also serve as investments.

\subsection{IV estimates of the effects of education and networks on wages}

We now present our estimates of the causal effects of education and network, which are obtained after instrumenting both measures. These regressions control for endowments (IQ and extroversion), pre-determined characteristics (age, years at school, SES, white, gender), peer characteristics and school fixed effects as in previous tables. The identifying assumption is that, conditional on the controls, the homophily and schooling instruments affect wages only through their effect on education and (grade) in-degree.

Table 8 shows the results. Column 1 reproduces the OLS from the previous table to make the comparison between IV and OLS easier. Column 2 shows the IV results. The coefficient on years of schooling is now $13 \%$, consistent with previous IV estimates of the causal return to school which also find similar point estimates, and similar increases (30\%) in the coefficient of education compared with OLS (Card, 2001). The IV estimate of the return to friendships is about $9 \%$ and statistically significant. It is about four times larger 
than the OLS estimates, though the standard errors are large.

\subsection{Why is the IV estimate larger than OLS?}

There are two possible reasons: measurement error and omitted variable bias.

Measurement error. Table 6 investigates the sensitivity of OLS estimates to our choice of network measure. Column 1 shows that one more person in one's network increases wages by 1 percent. Column 2 investigates whether being nominated (in-degree) or nominating someone (out-degree) has the same effect on wages. ${ }^{36}$ The results show that in-degree matters but out-degree does not. In column 3, we use in-degree in one's cohort: for computational reasons, this is the measure we predicted in the previous section. ${ }^{37}$ We find that more nominations in one's grade is associated with a 2.2 percent increase in wages, very similar to the coefficient for in-degree. In column 4, we investigate whether same-gender and opposite-gender friends are associated with the same returns in the labor market. Samegender friendships in adolescence appear much more useful later on: one more friend of one's gender raises wages by 3.3 percent, whereas a friend of the opposite sex only increases wages by 1 percent, perhaps because they do not correspond to friendships; however, both are statistically significant predictors of wages. Finally, in column 5, we compare friends with high and low engagement. Friends are classified as high-engagement if individuals report doing many activities with the nominated person such as going out, talking on the phone, visiting their home etc. ${ }^{38}$ One more close friend is associated with 3.3 percent higher wages, whereas a low-engagement friend is only associated with 1.1 percent higher wages. Both, however, are statistically significant predictors of wages.

These results suggest in-degree is a good measure but also suggest there might be important measurement error. Measurement error on network size can generate attenuation bias and result in large IV estimates. The extent of attenuation depends on the signal-to-noise ratio in in-degree. To assess this, we estimate plausible values of the signal-to-noise ratio. Appendix Table A.5 shows the variance-covariance measures for various measures of in-degree (after they have been regressed on all other covariates). We use this table to compute the

\footnotetext{
${ }^{36}$ Note that network size $=$ in-degree + out-degree - reciprocal degree.

${ }^{37}$ The number of possible pairs grows very large. However, the benefit of using this large data is limited because although the number of possible friends increases three-fold, the number of actual friends only raises by 1 (see summary statistics in Table 1). This is because as the results in previous section shows individuals like to make friends with people of the same age, with the exception of cross-gender relationships.

${ }^{38} \mathrm{We}$ use a measure of tie strength inspired by Gee, Jones, and Burke (2017). For each nomination in the survey, the sender (nominator) states if they do five activities together (going to the friend's house, meeting during the week, meeting over the weekend, talking on the phone, and talking about a problem). A nomination is coded as high-intensity if the person listed three or more of these interactions.
} 
possible extent of the bias, and conclude the bias is potentially large. ${ }^{39}$ For example, suppose that high-activity nominations are the "true" network measure, and that grade in-degree is the poor measure. Also suppose that the measurement error is not classical. The covariance between (residualized) grade in-degree and (residualized) high-engagement degree is 2.3 , and the (residualized) variance of grade in-degree is 8.3 . Their ratio is about $1 / 4$, suggesting than IV coefficients could be four times larger than OLS, consistent with our findings.

Omitted variable bias. Omitted variable biases in our model are in general ambiguous (Proposition 3). The bias is given by the correlation between education or in-degree and the error term in earnings, multiplied by the inverse of the matrix $X^{\prime} X$, where $X$ consists of the two columns of residualized education and residualized in-degree. In our sample, the inverse matrix $\left(X^{\prime} X\right)^{-1}$ has positive diagonal elements and negative off-diagonal elements, and the latter are relatively small. Thus the signs of the OLS biases in the returns are mostly determined by the correlations that education and in-degree have with the error term. Our results suggest that the correlation between in-degree and $\varepsilon_{i}$ is negative, yielding a downward bias in the social returns (depending on $X^{\prime} X$ ). For example this would be the case if individuals who have a strong taste for socializing also have a strong taste for leisure.

\subsection{Robustness checks.}

Columns 3-10 of Table 8 conduct a series of robustness checks.

Comparison with previous estimates. Column 3 shows the results if we instrument for in-degree but not for education, as in Conti et al. (2013). These estimates are substantially lower than our IV estimates for education, and higher for in-degree. This is consistent with the predictions of our model: because these are jointly determined, estimates that instrument only for one will be biased. However, the standard errors in all the IV estimations are large.

Aggregate 2SLS. Rather than estimating individual friendship links, we can follow the standard approach in the literature and directly regress student $i$ 's in-degree on the aggregate instruments to estimate $D_{i}$ (Section 5). ${ }^{40}$ Columns 4 and 5 present estimates that use the aggregate first stage for in-degree and instrument for education (column 4) or not (column 5). The point estimates for in-degree (0.42 and 0.6) are still higher than OLS, though smaller than with the pair-wise approach. The coefficient of education is much more sensitive to these alternative specifications, possibly because our instruments for education are weaker.

First stage non-linear model. In columns 6 and 7, we estimate the first stage using

\footnotetext{
${ }^{39}$ For classical measurement error, the ratio is given by the variance of the true measure divided by the variance of in-degree (Wooldridge (2010)). For non-classical measurement error, the ratio is given by the covariance between in-degree and the true measure, divided by the variance of in-degree.

${ }^{40}$ First stage estimates for in-degree at the aggregate level are presented in Appendix Table A.4.
} 
a probit model instead of a linear probability model. The point estimates for in-degree are again higher than OLS. Again, the coefficient on education also changes substantially depending on whether we instrument for it or not.

Weak instruments. These results, combined with the low F-statistics on the first stage for education and in-degree suggest that our instruments are weak. We follow the approach proposed by Andrews (2018) and compute confidence sets that are robust to weak IV and heteroscedasticity. The confidence set of in-degree ranges from 0.019 to 0.196 . These bounds are wide but they do not include $0 .{ }^{41}$

We conclude that the preponderance of the evidence supports the assertion that there are positive causal returns to social networks in the labor market. However, the exact magnitude of the return is difficult to ascertain and includes OLS estimates.

\section{Interpretation and Limitations}

\subsection{Interpretation}

Why are friendships in adolescence related to adult wages and how do we interpret our findings? Our findings do not imply that adolescent friends by themselves affect wages. We estimate a "reduced form" coefficient of the effect of friends in adolescence, which includes the direct effect of adolescent friends as well as many indirect effects. Appendix Table A.6 shows adolescent friendships are associated with a host of other intermediate outcomes in adulthood. Individuals with more connections in adolescence are more socially connected in adulthood: they have a higher score on the Extraversion Personality Scale (column 1), and they report having more friends (column 2). Social skills and social networks in adulthood are both associated with improved labor market outcomes (Deming, 2015; Schmutte, 2015). ${ }^{42}$

What do these results imply about the importance of social and cognitive skills observed early in life? Table 8 shows the results from regressing wages on these endowments, without controlling for years of schooling or in-degree. The results show that both IQ and extroversion in Wave 1 have large and statistically significant associations with wages. The returns to extroversion are large: being an extrovert increases wages by roughly the same amount as one standard deviation in IQ. Interestingly, neither IQ nor extroversion measured during adolescence garner greater wages once we control and instrument for years of schooling and in-degree. To a first approximation then, schooling and in-degree capture the two most

\footnotetext{
${ }^{41}$ The confidence set for education is [-0.012;0.227]. It is wide likely in part because our instruments for education are weak.

${ }^{42}$ We investigated other mechanisms. We found decreases in the likelihood of being depression (column 4) but no impact on marital outcomes (column 3), or the likelihood individuals are working (column 5).
} 
important dimensions through which these endowments affect wages.

We empirically investigate how these early skills affect investments (Table 9), and the returns to these investments (Table 10). Extroverts spend more time socializing compared with shy individuals: they drink more and are more likely to frequently hang out with friends. They are less likely to report studying very hard relative to shy individuals. However, extroverts have greater returns to studying and socializing: both activities increase education and networks. Extroverts also appear to suffer somewhat lower education losses from drinking and spending time with friends. On net extroversion increases network size but does not affect education. IQ is different. High-IQ individuals do not necessarily invest more in schooling or friends but have larger returns to education and social investments. In the case of drinking however, they have larger costs as well compared to low-IQ individuals. On net higher IQ leads to greater networks and schooling.

Summary. Overall we find that individuals invest to reinforce initial endowments, spending relatively more time in the activity they have greater returns on. However, there is no full specialization - individuals with a high endowment in one dimension still invest in the alternative skill. This occurs because IQ and extroversion affect the rate of return to socializing and to studying. On net, the wage returns to extroversion mostly operate through the effect of extroversion on networks, while leaving schooling outcomes unchanged. On the other hand the returns to IQ operate through both greater schooling and greater network size. A rough computation suggests that about $10 \%$ of the returns to IQ operate through greater networks. Finally, the results suggest individuals study together and that this benefits both friendship formation and schooling outcomes, particularly for extroverts and for high IQ individuals. But drinking presents a large trade-off.

\subsection{Limitations}

This paper has some limitations related to measurement. It is for data quality reasons that we abstain from estimating a full structural model. If we did, then we could conduct counterfactual analysis to investigate for example how earnings distributions would change if schools provided more support for students to socialize, banned alcohol, or sorted individuals differently into groups. The challenge in estimating the utility function and production functions is that important model components are poorly observed. ${ }^{43}$ The time spent socializing is

\footnotetext{
${ }^{43}$ Our measures of individual sociability and social behaviors are limited. We worked with a self-reported indicator of extroversion, which is considered one of the five important personality traits. However spoken skills, non-verbal language, and other forms of emotional intelligence are likely to contribute to a person's social skills. Relatedly, data on schooling and socializing investments are vague, self-reported, and categorical-ideally, we would have access to data on time spent studying or socializing.
} 
poorly measured and so are social skills. ${ }^{44}$ We do not observe some well-known determinants of education outcomes. ${ }^{45}$ The measurement of IQ and education-related outcomes (GPA, test scores) has received substantial attention in the social sciences. However, the measurement of other important individual traits, such as social skills, is in its infancy (Deming, 2015). Another difficulty we encounter is that missing data on individual characteristics makes it very difficult to estimate network formation models. Missing data on a single node prevents estimation of the formation of any links to that node.

\section{Conclusions}

This paper has shown that individuals with more adolescent friendships make more money as adults and that as a result, individuals invest time and resources in the development of their network. Although socializing activities can detract from educational activities, particularly if they are associated with alcohol consumption, individuals still socialize, optimally so, partly because of the high return that a large network commands. Our estimates suggest that having a large network of friends appears to increase one's wage. The magnitude of this effect is not trivial, though our estimates are not precisely estimated. Our estimates suggest that five friends in adolescence increases wages as much as one year of school or more.

Our results suggest that social skills, in particular extroversion, have large returns in the labor market. We do not find that schooling and socializing are necessarily substitutes, though they can be as when socializing occurs under the influence of alcohol. Interestingly social skills are known to be modifiable throughout childhood and into adolescence, whereas other cognitive skills are less so (Heckman and Mosso, 2014b). Our research suggests that greater attention needs to be paid to the development of these social skills as they might provide avenues for improving the lifetime outcomes of individuals who received low cognitive investments early in childhood. Our results also confirm recent findings emphasizing the importance of adolescence as a formative period for socio-emotional outcomes (Jackson et al., 2020) and particularly for friendships (Denworth, 2020).

The importance of socialization during schooling years has further implications for higher education policy. Many colleges and universities face criticism for investing in infrastructure for non-academic, recreational facilities that are believed to contribute to increasing tuition

\footnotetext{
${ }^{44}$ Without knowing $S_{i}$, we will have to replace $S_{i}$ by the model-predicted optimal socializing $S_{i}^{*}\left(X, v_{i}\right)$ and estimate a reduced-form version of the production functions, hoping that we are able to uniquely determine the structural parameters from the reduced-form estimates. To make sure that this procedure can yield consistent estimates, we have to at least correctly specify (1) the utility function and production functions, and (2) the equilibrium selection mechanism, when there are multiple equilibria.

${ }^{45}$ For example, we do not observe classroom size (only cohort size) or teacher quality, both of which which determine education and wages (Chetty, Friedman, and Rockoff, 2014; Krueger, 1999).
} 
levels (Jacob, McCall, and Stange, 2013). These investments are more reasonable in the presence of high returns to socialization. Our results help rationalize why, for instance, Greek fraternities and sororities persist, despite the fact that they can detract from strictly academic endeavors. While partying decreases education, it does not necessarily decrease wages.

Therefore education interventions and other policies that affect school environments should be evaluated by their impacts on non-education measures as well as their impact on education. Education interventions that raise schooling outcomes but depress social ones might not ultimately benefit individuals. For example, the recent proliferation of massively open online courses (MOOCs) might negatively affect social life, despite their potential academic benefits. The rise of online schooling could have long lasting negative effects on wages. On the other hand, policies that promote joint studying might have very large returns in both academic and social spheres.

\section{References}

Agostinelli, Francesco. 2018. "Investing in childrenâs skills: An equilibrium analysis of social interactions and parental investments." Working Papers 2018, Arizona State University. URL https://economics.yale.edu/sites/default/files/agostinelli ${ }_{j} m p . p d f$.

Alan, Sule, Teodora Boneva, and Seda Ertac. 2019. "Ever Failed, Try Again, Succeed Better: Results From a Randomized Educational Intervention On Grit*." URL https://doi.org/10.1093/qje/qjz006.

Andrews, Isaiah. 2018. "Valid Two-Step Identification-Robust Confidence Sets for GMM." The Review of Economics and Statistics 100 (2):337-348. URL https://doi.org/10.1162/REST ${ }_{a 0} 0682$.

Andrews, Isaiah, James H. Stock, and Liyang Sun. Forthcoming. "Weak Instruments in IV Regression: Theory and Practice." Annual Review of Economics .

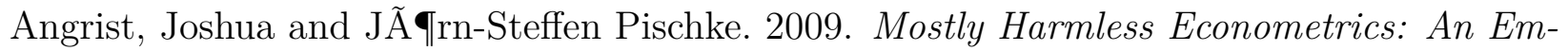
piricist's Companion.

Angrist, Joshua D and Victor Lavy. 1999. "Using Maimonides' rule to estimate the effect of class size on scholastic achievement." The Quarterly Journal of Economics 114 (2):533-575.

Auerbach, Eric G. 2016. "Identification and Estimation of Models with Endogenous Network Formation." 
Bandiera, Oriana, Iwan Barankay, and Imran Rasul. 2010. "Social incentives in the workplace." The Review of Economic Studies 77 (2):417-458.

Bifulco, Robert, Jason M. Fletcher, and Stephen L. Ross. 2011. "The Effect of Classmate Characteristics on Post-secondary Outcomes: Evidence from the Add Health." American Economic Journal: Economic Policy 3 (1):25-53. URL http: //www . aeaweb. org/articles?id=10.1257/pol.3.1.25.

Black, Sandra E, Paul J Devereux, and Kjell G Salvanes. 2011. "Too young to leave the nest? The effects of school starting age." The Review of Economics and Statistics 93 (2):455-467.

Blume, Lawrence E, William A Brock, Steven N Durlauf, and Yannis M Ioannides. 2010. "Identification of social interactions." .

Bramoullé, Yann, Habiba Djebbari, and Bernard Fortin. 2009. "Identification of peer effects through social networks." Journal of Econometrics 150 (1):41 - 55. URL http://www.sciencedirect.com/science/article/pii/S0304407609000335.

Bramoullé, Yann, Rachel Kranton, and Martin D'amours. 2014. "Strategic interaction and networks." The American Economic Review 104 (3):898-930.

Bursztyn, Leonardo and Robert Jensen. 2015. "How Does Peer Pressure Affect Educational Investments?" The quarterly journal of economics :qjv021.

Caetano, Gregorio, Josh Kinsler, and Hao Teng. 2019. “Towards causal estimates of children's time allocation on skill development." Journal of Applied Econometrics 34 (4):588-605. URL https://onlinelibrary.wiley.com/doi/abs/10.1002/jae.2700.

Cai, Hongbin, Hanming Fang, and Lixin Colin Xu. 2011. "Eat, drink, firms, government: An investigation of corruption from the entertainment and travel costs of Chinese firms." The Journal of Law and Economics 54 (1):55-78.

Calvo-Armengol, Antoni and Matthew O Jackson. 2004. "The effects of social networks on employment and inequality." The American Economic Review 94 (3):426-454.

Calvó-Armengol, Antoni, Eleonora Patacchini, and Yves Zenou. 2009. "Peer effects and social networks in education." The Review of Economic Studies 76 (4):1239-1267.

Canivez, Gary L. 1995. "Validity of the Kaufman Brief Intelligence Test: Comparisons With the Wechsler Intelligence Scale for Children Third Edition." Assessment 2 (2):101-111. URL https://doi.org/10.1177/107319119500200201. 
Card, David. 1999. "The causal effect of education on earnings." Handbook of labor economics 3:1801-1863.

2001. "Estimating the return to schooling: Progress on some persistent econometric problems." Econometrica 69 (5):1127-1160.

Chetty, Raj, John N. Friedman, and Jonah E. Rockoff. 2014. "Measuring the Impacts of Teachers I: Evaluating Bias in Teacher ValueAdded Estimates." American Economic Review 104 (9):2593-2632. URL http://www . aeaweb.org/articles?id=10.1257/aer.104.9.2593.

Cobb-Clark, Deborah A and Stefanie Schurer. 2012. "The stability of big-five personality traits." Economics Letters 115 (1):11-15.

Conley, Timothy, Nirav Mehta, Ralph Stinebrickner, and Todd Stinebrickner. 2015. "Social Interactions, Mechanisms, and Equilibrium: Evidence from a Model of Study Time and Academic Achievement." Tech. rep., National Bureau of Economic Research.

Conley, Timothy G and Christopher R Udry. 2010. "Learning about a new technology: Pineapple in Ghana." The American Economic Review 100 (1):35-69.

Conti, Gabriella, Andrea Galeotti, Gerrit Mueller, and Stephen Pudney. 2013. "Popularity." Journal of Human Resources 48 (4):1072-1094.

Corcoran, Mary, Linda Datcher, and Greg Duncan. 1980. "Information and influence networks in labor markets." Five thousand American families: Patterns of economic progress 8 (S 1):37.

Cunha, Flavio, James Heckman, and Lance Lochner. 2006. "Interpreting the Evidence on Life Cycle Skill Formation." chap. 12. Elsevier, 1 ed., 697-812. URL https://EconPapers . repec .org/RePEc : eee : educhp: 1-12.

Deming, David J. 2015. "The growing importance of social skills in the labor market." Tech. rep., National Bureau of Economic Research.

Denworth, Lydia. 2020. Friendship: The Evolution, Biology, and Extraordinary Power of Life's Fundamental Bond. W. W. Norton Company, 1 ed.

Dunn, Lloyd and Douglas M. M.Dunn. 2007. Peabody Picture Vocabulary Test. Minneapolis, MN: Pearson. 
E. Carrell, Scott, Mark Hoekstra, and Elira Kuka. 2018. "The Long-Run Effects of Disruptive Peers." American Economic Review 108:3377-3415.

Egalite, Anna J., Brian Kisida, and Marcus A. Winters. 2015. "Representation in the classroom: The effect of own-race teachers on student achievement." Economics of Education Review 45 (C):44-52. URL https://ideas.repec.org/a/eee/ecoedu/v45y2015icp44-52.html.

Elliott, James R. 2001. "Referral hiring and ethnically homogeneous jobs: How prevalent is the connection and for whom?" Social Science Research 30 (3):401-425.

Epple, Dennis and Richard E. Romano. 2011. "Chapter 20 - Peer Effects in Education: A Survey of the Theory and Evidence." North-Holland, 1053 - 1163. URL http://www.sciencedirect.com/science/article/pii/B9780444537072000037.

Feldman, Linda, Bart Harvey, Philippa Holowaty, and Linda Shortt. 1999. "Alcohol use beliefs and behaviors among high school students." Journal of Adolescent Health 24 (1):4858.

Fiorini, Mario and Michael P Keane. 2014. "How the allocation of children's time affects cognitive and noncognitive development." Journal of Labor Economics 32 (4):787-836.

Fletcher, Jason, Stephen Ross, and Yuxiu Zhang. 2014. "The Determinants and Consequences of Friendship Composition." Working Papers 2014016, Human Capital and Economic Opportunity Working Group. URL https://ideas.repec.org/p/hka/wpaper/2014-016.html.

G Victora, Cesar, Rajiv Bahl, Aluisio J D Barros, Giovanny V A França, Susan Horton, Julia Krasevec, Simon Murch, Jeeva Sankar, Neff Walker, Nigel C Rollins, Katrina Allen, Shyamali Dharmage, Caroline Lodge, Karen Peres, Nita Bhandari, Ranadip Chowdhury, Bireshwar Sinha, Sunita Taneja, Elsa Giugliani, and Linda Richter. 2016. "Breastfeeding in the 21st century: Epidemiology, mechanisms, and lifelong effect." The Lancet 387:475490.

Gee, Laura K., Jason Jones, and Moira Burke. 2017. "Social Networks and Labor Markets: How Strong Ties Relate to Job Finding on Facebook's Social Network." Journal of Labor Economics 35 (2):485-518. URL https://doi.org/10.1086/686225.

Gershenson, Seth, Cassandra M. D. Hart, Joshua Hyman, Constance Lindsay, and Nicholas W. Papageorge. 2018. "The Long-Run Impacts of Same-Race Teachers." 
NBER Working Papers 25254, National Bureau of Economic Research, Inc. URL https://ideas.repec.org/p/nbr/nberwo/25254.html.

Gershenson, Seth, Stephen B Holt, and Nicholas W Papageorge. 2016. "Who believes in me? The effect of student-teacher demographic match on teacher expectations." Economics of Education Review 52:209-224.

Glaeser, Edward L., David Laibson, and Bruce Sacerdote. 2002. "An Economic Approach to Social Capital*." The Economic Journal 112 (483):F437-F458. URL https://onlinelibrary.wiley.com/doi/abs/10.1111/1468-0297.00078.

Goldsmith-Pinkham, Paul and Guido W. Imbens. 2013. "Social Networks and the Identification of Peer Effects." Journal of Business \& Economic Statistics 31 (3):253-264. URL https://doi.org/10.1080/07350015.2013.801251.

Graham, Bryan S. 2015. "Methods of identification in social networks." Annu. Rev. Econ. $7(1): 465-485$.

Graham, Bryan S. 2017. "An Econometric Model of Network Formation With Degree Heterogeneity." Econometrica 85 (4):1033-1063. URL https://onlinelibrary.wiley.com/doi/abs/10.3982/ECTA12679.

Granovetter, Mark. 1985. "Economic action and social structure: The problem of embeddedness." American journal of sociology 91 (3):481-510.

Granovetter, Mark S. 1973. "The strength of weak ties." American journal of sociology 78 (6):1360-1380.

Harris, K.M., C.T. Halpern, E. Whitsel, J. Hussey, J. Tabor, P. Entzel, and J.R. Udry. 2009. "The National Longitudinal Study of Adolescent to Adult Health: Research Design." http://www. cpc. unc .edu/projects/addhealth/design.

Heckman, James, Rodrigo Pinto, and Peter Savelyev. 2013. "Understanding the mechanisms through which an influential early childhood program boosted adult outcomes." The American economic review 103 (6):2052-2086.

Heckman, James J. 2006. "Skill formation and the economics of investing in disadvantaged children." Science 312 (5782):1900-1902.

Heckman, James J. and Stefano Mosso. 2014a. "The Economics of Human Development and Social Mobility." Annual Review of Economics 6 (1):689-733. URL https://doi .org/10.1146/annurev-economics-080213-040753. 


2014b. "The Economics of Human Development and $\begin{gathered}\text { So- } \\ \text { cial Mobility." Annual Review of Economics } 6 \text { (1):689-733. }\end{gathered}$ URL
https://doi.org/10.1146/annurev-economics-080213-040753.

Heckman, James J, Jora Stixrud, and Sergio Urzua. 2006. "The effects of cognitive and noncognitive abilities on labor market outcomes and social behavior." Journal of Labor economics 24 (3):411-482.

Hodapp, Albert F. and Kathryn C. Gerken. 1999. "Correlations between Scores for Peabody Picture Vocabulary Test III and the Wechsler Intelligence Scale for Children III." Psychological Reports 84 (3_suppl):1139-1142. URL https://doi.org/10.2466/pr0.1999.84.3c.1139.

Hsieh, Chih-Sheng and Lung Fei Lee. 2016. "A Social Interactions Model with Endogenous Friendship Formation and Selectivity." Journal of Applied Econometrics 31 (2):301-319. URL https://onlinelibrary.wiley.com/doi/abs/10.1002/jae.2426.

Jackson, Matthew O. 2005. "The economics of social networks." .

Jackson, Matthew O. 2008. Social and Economic Networks. Princeton, NJ, USA: Princeton University Press.

Jackson, Matthew O, Brian W Rogers, and Yves Zenou. 2016. "The economic consequences of social network structure." .

Jacob, Brian, Brian McCall, and Kevin M Stange. 2013. "College as Country Club: Do Colleges Cater to Students' Preferences for Consumption?" Tech. rep., National Bureau of Economic Research.

John, O.P. and S. Srivasta. 1999. The Big Five trait taxonomy: History, measurement, and theoretical perspectives. New York, NY, USA: Guilford Press.

Johnson, William R. 2017. "Parties or Problem Sets: Review Article on How College Works and Paying for the Party." Journal of Economic Literature.

Johnsson, Ida and Hyungsik Roger Moon. 2017. "Estimation of Peer Effects in Endogenous Social Networks: Control Function Approach." SSRN Electronic Journal .

Kerr, Norbert L and R Scott Tindale. 2004. "Group performance and decision making." Annu. Rev. Psychol. 55:623-655. 
Krueger, Alan B. 1999. "Experimental Estimates of Education Production Functions." The Quarterly Journal of Economics 114 (2):497-532. URL http://www . jstor.org/stable/2587015.

Kuntsche, Emmanuel, Ronald Knibbe, Gerhard Gmel, and Rutger Engels. 2005. "Why do young people drink? A review of drinking motives." Clinical psychology review 25 (7):841861.

Lenton, Pamela. 2014. "Personality characteristics, educational attainment and wages: an economic analysis using the British cohort study." The Sheffield Economic Research Paper Series 201401.

Lindenlaub, Ilse and Anja Prummer. 2014. "Gender, Social Networks And Performance." .

Mas, Alexandre and Enrico Moretti. 2009. "Peers at work." The American Economic Review 99 (1):112-145.

Mehta, Nirav, Ralph Stinebrickner, and Todd Stinebrickner. 2019. "TIME-USE AND ACADEMIC PEER EFFECTS IN COLLEGE." Economic Inquiry 57 (1):162-171. URL https://onlinelibrary.wiley.com/doi/abs/10.1111/ecin.12730.

Montgomery, James D. 1991. Social networks and persistent inequality in the labor market. Center for Urban Affairs and Policy Research.

Muralidharan, Karthik and Ketki Sheth. 2016. "Bridging Education Gender Gaps in Developing Countries: The Role of Female Teachers." Journal of Human Resources 51 (2):269297. URL https://ideas.repec.org/a/uwp/jhriss/v51y2016i2p269-297.html.

Newey, Whitney K. and Daniel McFadden. 1994. "Chapter 36 Large sample estimation and hypothesis testing." Elsevier, 2111 - 2245. URL http://www.sciencedirect.com/science/article/pii/S1573441205800054.

$\mathrm{Qu}, \mathrm{Xi}$ and Lung-fei Lee. 2015a. "Estimating a spatial autoregressive model with an endogenous spatial weight matrix." Journal of Econometrics 184 (2):209-232. URL https://ideas.repec.org/a/eee/econom/v184y2015i2p209-232.html.

- 2015b. "Estimating a spatial autoregressive model with an endogenous spatial weight matrix." Journal of Econometrics 184 (2):209-232. URL https://ideas.repec.org/a/eee/econom/v184y2015i2p209-232.html. 
Redding, Christopher. 2019. "A Teacher Like Me: A Review of the Effect of StudentâTeacher Racial/Ethnic Matching on Teacher Perceptions of Students and Student Academic and Behavioral Outcomes." Review of Educational Research 89 (4):499-535. URL https://doi.org/10.3102/0034654319853545.

Rees, Daniel I. and Joseph J. Sabia. 2011. "The Effect of Migraine Headache on Educational Attainment." Journal of Human Resources 46 (2):317-332. URL http://jhr. uwpress.org/content/46/2/317. abstract.

Ridder, Gert and Shuyang Sheng. 2018. "Estimation of Social Interactions in Endogenous and Strategically Formed Networks." Working Papers 2018, UCLA.

Sabia, Joseph and Daniel Rees. 2012. "Does the number of sex partners affect educational attainment? Evidence from female respondents to the Add Health." Journal of Population Economics 25 (1):89-118. URL https://ideas.repec.org/a/spr/jopoec/v25y2012i1p89-118.html.

Sacerdote, Bruce. 2011. "Chapter 4 - Peer Effects in Education: How Might They Work, How Big Are They and How Much Do We Know Thus Far?" Elsevier, 249 - 277. URL http://www.sciencedirect.com/science/article/pii/B9780444534293000041.

Schmutte, Ian M. 2015. "Job Referral Networks and the Determination of Earnings in Local Labor Markets." Journal of Labor Economics 33 (1):1-32. URL https://doi.org/10.1086/677389.

Stevens, Stephan, Alexander L Gerlach, and Fred Rist. 2008. "Effects of alcohol on ratings of emotional facial expressions in social phobics." Journal of anxiety disorders 22 (6):940-948.

Stock, James H and Motohiro Yogo. 2002. "Testing for weak instruments in linear IV regression."

Weinberger, Catherine J. 2014. "The increasing complementarity between cognitive and social skills." Review of Economics and Statistics 96 (4):849-861.

Weiss, Andrew. 1995. "Human capital vs. signalling explanations of wages." The Journal of Economic Perspectives 9 (4):133-154.

Widiger, T.A. 2017. The Oxford Handbook of the Five Factor Model. Oxford library of psychology. Oxford University Press. URL https://books .google. com/books?id=1V6UjwEACAAJ. 
Woessmann, Ludger. 2016. "The Importance of School Systems: Evidence from International Differences in Student Achievement." Journal of Economic Perspectives 30 (3):3-32. URL https://ideas.repec.org/a/aea/jecper/v30y2016i3p3-32.html.

Wooldridge, Jeffrey M. 2010. Econometric Analysis of Cross Section and Panel Data, MIT Press Books, vol. 1. The MIT Press. URL https://ideas.repec.org/b/mtp/titles/0262232588.html.

Woolley, Anita Williams, Christopher F Chabris, Alex Pentland, Nada Hashmi, and Thomas W Malone. 2010. "Evidence for a collective intelligence factor in the performance of human groups." science 330 (6004):686-688.

Wo[ss]mann, Ludger and Martin West. 2006. "Class-size effects in school systems around the world: Evidence from between-grade variation in TIMSS." European Economic Review 50 (3):695-736. URL https://ideas.repec.org/a/eee/eecrev/v50y2006i3p695-736.html.

Xiang, Chong and Stephen Yeaple. 2018. "The Production of Cognitive and Non-cognitive Human Capital in the Global Economy." Working Paper 24524, National Bureau of Economic Research. URL http://www.nber.org/papers/w24524. 


\section{Tables and Figures}


Figure 1: Log Earnings on Education and Social Outcomes
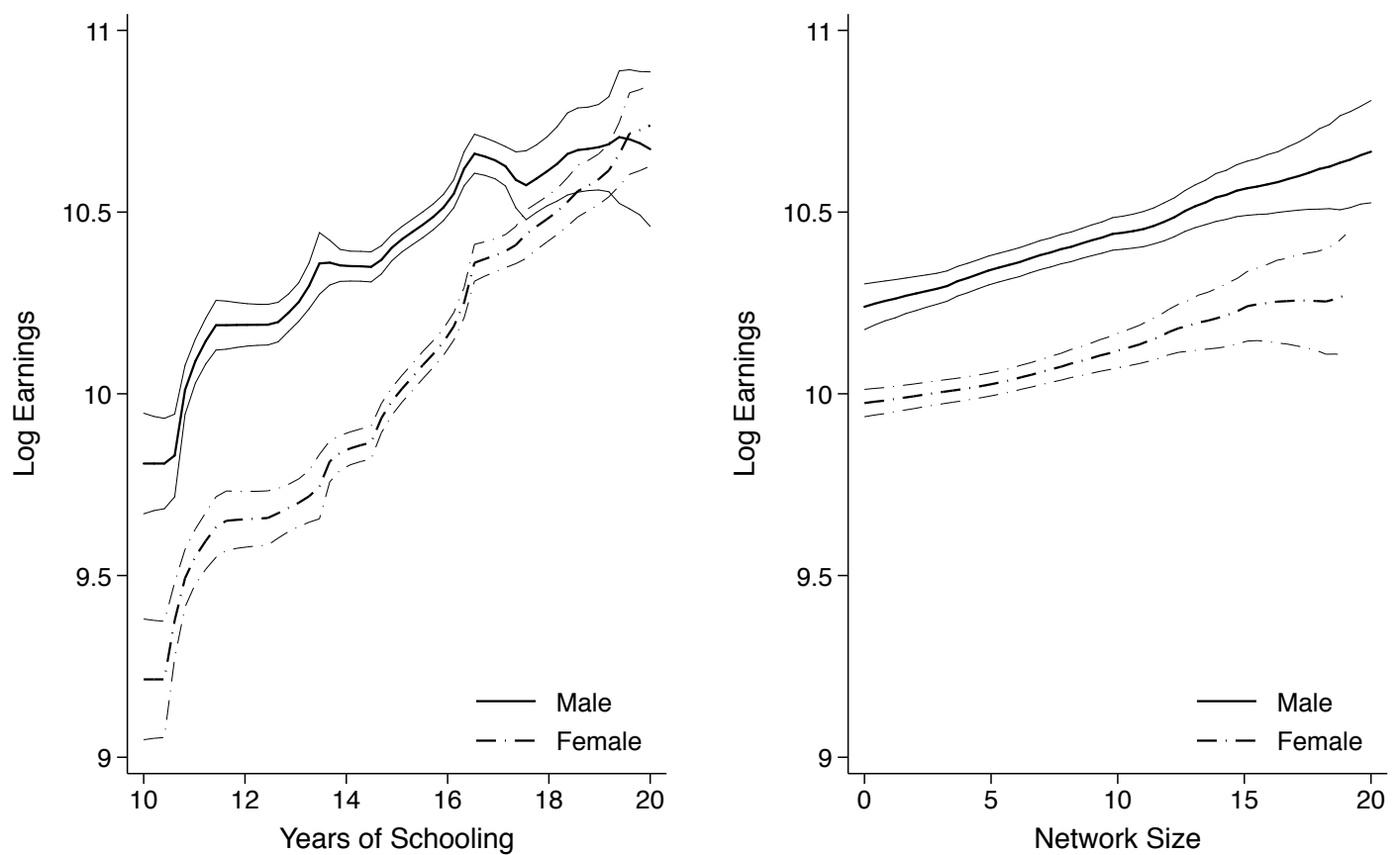

Data: Add Health restricted-use data (estimation sample).

Note: Add Health restricted-use data. Nonparametric plots of log earnings on years of schooling in panel (a) and network size in panel (b). Both series separate out males and females with non-zero earnings.

Figure 2: Social Capital Histograms
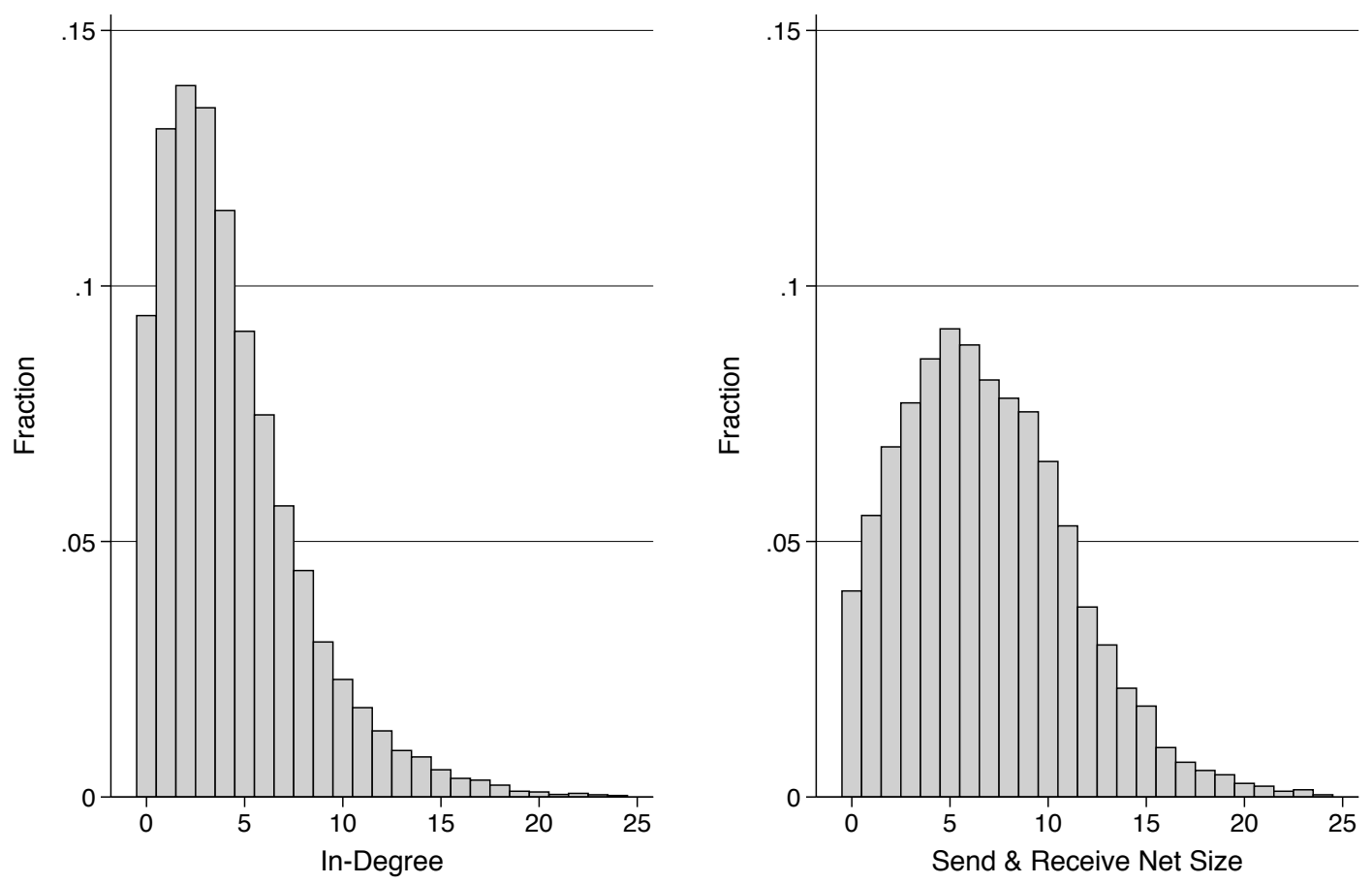

Note: In-degree captures the total number of friendship nominations received by an individual. Network size is measured by counting the total number of people who either sent a nomination to an individual or received a nomination from the individual. 
Figure 3: Education and Social Capital Production
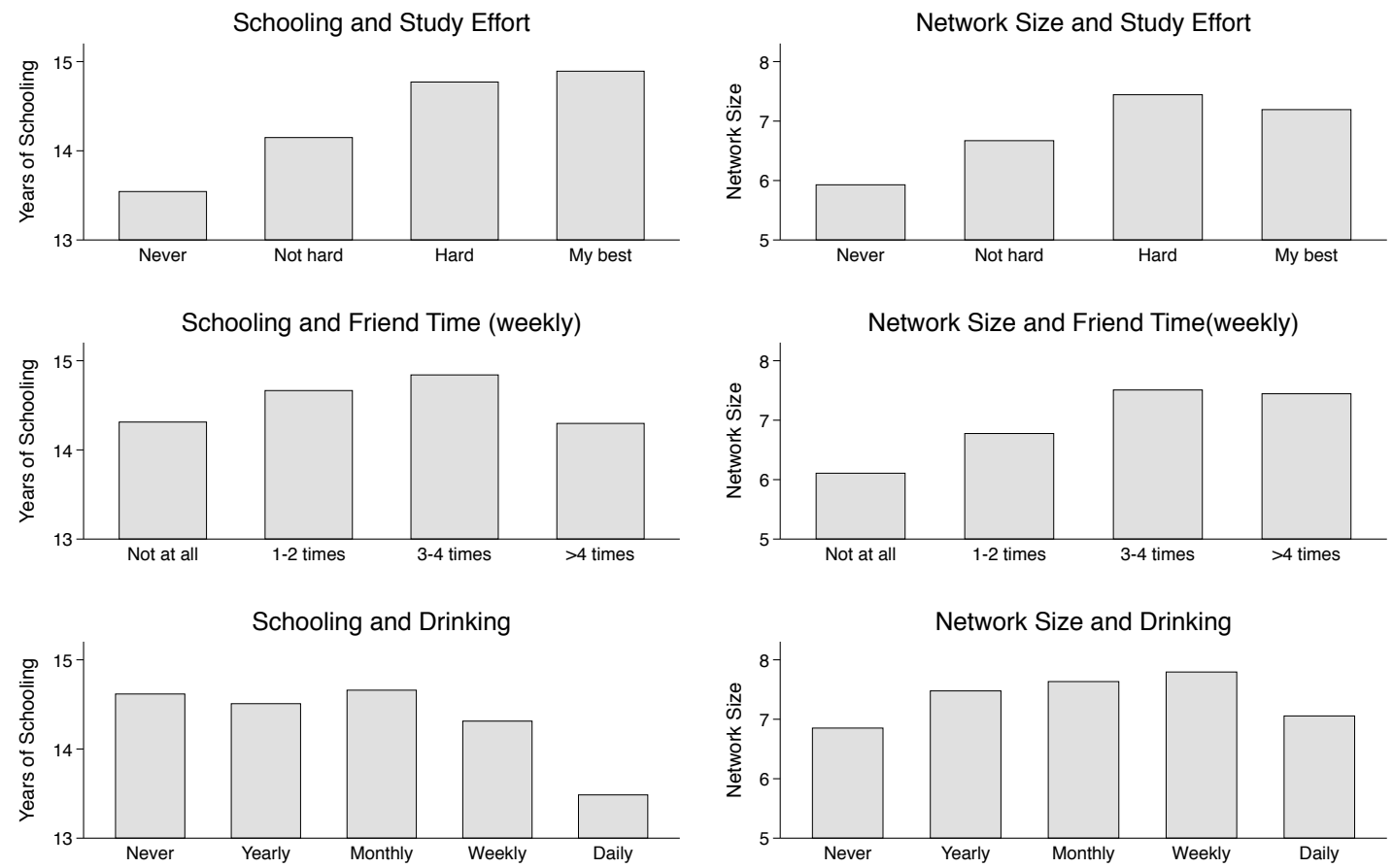

Data: Add Health restricted-use data

Figure 4: Friends in Adulthood on In-degree

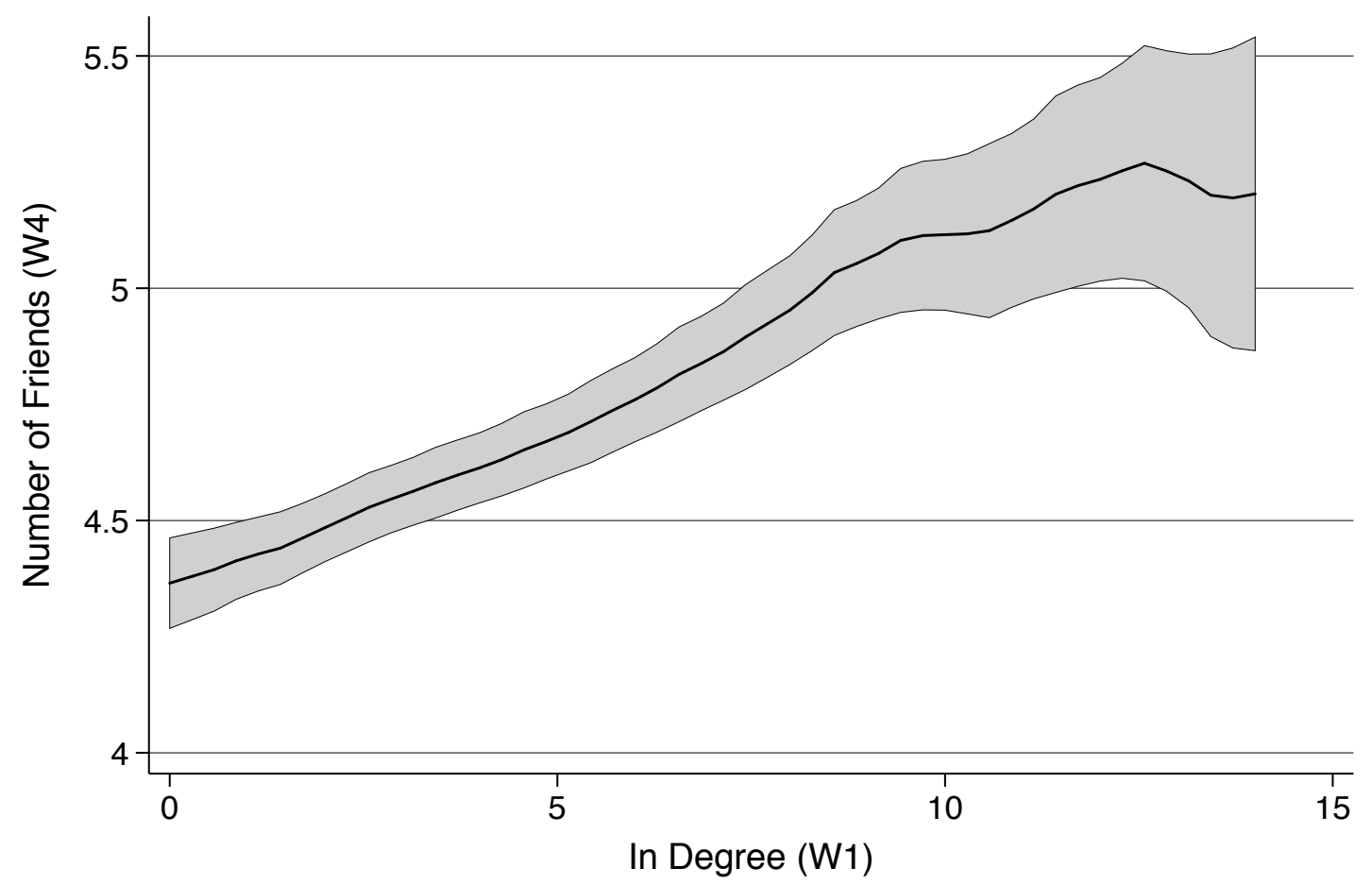


Table 1: Add Health Summary Statistics

\begin{tabular}{|c|c|c|c|c|c|}
\hline & $\begin{array}{c}(1) \\
\text { Total }\end{array}$ & $\begin{array}{c}(2) \\
\text { Hi IQ }\end{array}$ & $\begin{array}{c}(3) \\
\text { Low IQ }\end{array}$ & $\begin{array}{c}(4) \\
\text { Extrovert }\end{array}$ & $\begin{array}{l}(5) \\
\text { Shy }\end{array}$ \\
\hline $\begin{array}{l}\text { Outcomes } \\
\text { Annual Earnings (W4) }\end{array}$ & $\begin{array}{c}38522.3 \\
(45814.7)\end{array}$ & $\begin{array}{c}42109.4 \\
(44699.3)\end{array}$ & $\begin{array}{c}34338.8 \\
(46741.0)\end{array}$ & $\begin{array}{c}37941.4 \\
(38680.8)\end{array}$ & $\begin{array}{c}35966.3 \\
(40573.2)\end{array}$ \\
\hline $\begin{array}{l}\text { Intermediate Outcomes } \\
\text { Yrs of School(W4) }\end{array}$ & $\begin{array}{l}14.80 \\
(2.102)\end{array}$ & $\begin{array}{c}15.37 \\
(1.929)\end{array}$ & $\begin{array}{c}14.14 \\
(2.103)\end{array}$ & $\begin{array}{c}14.84 \\
(2.111)\end{array}$ & $\begin{array}{c}14.76 \\
(2.078)\end{array}$ \\
\hline GPA (W2) & $\begin{array}{c}2.837 \\
(0.742)\end{array}$ & $\begin{array}{c}2.990 \\
(0.734)\end{array}$ & $\begin{array}{c}2.654 \\
(0.710)\end{array}$ & $\begin{array}{l}2.845 \\
(0.735)\end{array}$ & $\begin{array}{c}2.823 \\
(0.755)\end{array}$ \\
\hline In-Degree (W1) & $\begin{array}{c}4.475 \\
(3.670)\end{array}$ & $\begin{array}{c}4.790 \\
(3.838)\end{array}$ & $\begin{array}{c}4.107 \\
(3.426)\end{array}$ & $\begin{array}{c}4.863 \\
(3.813)\end{array}$ & $\begin{array}{c}4.025 \\
(3.344)\end{array}$ \\
\hline In-Degree (grade) & $\begin{array}{c}3.450 \\
(3.115)\end{array}$ & $\begin{array}{c}3.729 \\
(3.239)\end{array}$ & $\begin{array}{l}3.125 \\
(2.931)\end{array}$ & $\begin{array}{c}3.800 \\
(3.293)\end{array}$ & $\begin{array}{c}3.150 \\
(2.822)\end{array}$ \\
\hline Network Size (W1) & $\begin{array}{c}7.150 \\
(4.355)\end{array}$ & $\begin{array}{c}7.590 \\
(4.425)\end{array}$ & $\begin{array}{c}6.637 \\
(4.215)\end{array}$ & $\begin{array}{c}7.684 \\
(4.463)\end{array}$ & $\begin{array}{c}6.675 \\
(4.081)\end{array}$ \\
\hline $\begin{array}{l}\text { Investments } \\
\text { Some Study Effort (W1) }\end{array}$ & $\begin{array}{c}0.517 \\
(0.500)\end{array}$ & $\begin{array}{c}0.537 \\
(0.499)\end{array}$ & $\begin{array}{c}0.492 \\
(0.500)\end{array}$ & $\begin{array}{c}0.517 \\
(0.500)\end{array}$ & $\begin{array}{c}0.489 \\
(0.500)\end{array}$ \\
\hline Very Hard Study Effort (W1) & $\begin{array}{c}0.375 \\
(0.484)\end{array}$ & $\begin{array}{c}0.345 \\
(0.476)\end{array}$ & $\begin{array}{c}0.411 \\
(0.492)\end{array}$ & $\begin{array}{c}0.379 \\
(0.485)\end{array}$ & $\begin{array}{c}0.416 \\
(0.493)\end{array}$ \\
\hline Sometimes Drink (W1) & $\begin{array}{c}0.302 \\
(0.459)\end{array}$ & $\begin{array}{c}0.316 \\
(0.465)\end{array}$ & $\begin{array}{c}0.286 \\
(0.452)\end{array}$ & $\begin{array}{c}0.309 \\
(0.462)\end{array}$ & $\begin{array}{c}0.268 \\
(0.443)\end{array}$ \\
\hline Frequently Drink (W1) & $\begin{array}{c}0.165 \\
(0.372)\end{array}$ & $\begin{array}{c}0.175 \\
(0.380)\end{array}$ & $\begin{array}{c}0.154 \\
(0.361)\end{array}$ & $\begin{array}{c}0.163 \\
(0.369)\end{array}$ & $\begin{array}{c}0.124 \\
(0.330)\end{array}$ \\
\hline Sometimes Hang with Friends (W1) & $\begin{array}{c}0.527 \\
(0.499)\end{array}$ & $\begin{array}{c}0.543 \\
(0.498)\end{array}$ & $\begin{array}{c}0.507 \\
(0.500)\end{array}$ & $\begin{array}{c}0.515 \\
(0.500)\end{array}$ & $\begin{array}{c}0.558 \\
(0.497)\end{array}$ \\
\hline Frequently Hang with Friends (W1) & $\begin{array}{c}0.387 \\
(0.487)\end{array}$ & $\begin{array}{c}0.375 \\
(0.484)\end{array}$ & $\begin{array}{c}0.401 \\
(0.490)\end{array}$ & $\begin{array}{c}0.402 \\
(0.490)\end{array}$ & $\begin{array}{c}0.345 \\
(0.475)\end{array}$ \\
\hline $\begin{array}{l}\text { Predetermined Characteristics } \\
\text { IQ (W1) }\end{array}$ & $\begin{array}{c}101.8 \\
(14.17)\end{array}$ & $\begin{array}{c}112.4 \\
(7.445)\end{array}$ & $\begin{array}{c}89.49 \\
(9.355)\end{array}$ & $\begin{array}{c}102.4 \\
(13.65)\end{array}$ & $\begin{array}{c}100.9 \\
(14.74)\end{array}$ \\
\hline Extrovert (W2) & $\begin{array}{c}0.648 \\
(0.413)\end{array}$ & $\begin{array}{c}0.661 \\
(0.407)\end{array}$ & $\begin{array}{c}0.631 \\
(0.418)\end{array}$ & $\begin{array}{c}1 \\
(0)\end{array}$ & $\begin{array}{c}0 \\
(0)\end{array}$ \\
\hline Peer IQ (WI) & $\begin{array}{c}101.0 \\
(6.773)\end{array}$ & $\begin{array}{l}103.4 \\
(6.343)\end{array}$ & $\begin{array}{c}98.13 \\
(6.135)\end{array}$ & $\begin{array}{c}101.2 \\
(6.672)\end{array}$ & $\begin{array}{c}100.2 \\
(6.873)\end{array}$ \\
\hline Peer Extrovert (W2) & $\begin{array}{c}0.642 \\
(0.134)\end{array}$ & $\begin{array}{c}0.649 \\
(0.144)\end{array}$ & $\begin{array}{c}0.634 \\
(0.121)\end{array}$ & $\begin{array}{c}0.670 \\
(0.103)\end{array}$ & $\begin{array}{c}0.616 \\
(0.113)\end{array}$ \\
\hline IQ Distance & $\begin{array}{c}13.71 \\
(5.925)\end{array}$ & $\begin{array}{c}13.38 \\
(5.394)\end{array}$ & $\begin{array}{c}14.10 \\
(6.469)\end{array}$ & $\begin{array}{c}13.51 \\
(5.554)\end{array}$ & $\begin{array}{c}14.11 \\
(6.051)\end{array}$ \\
\hline Shy Distance & $\begin{array}{c}0.431 \\
(0.173)\end{array}$ & $\begin{array}{c}0.422 \\
(0.179)\end{array}$ & $\begin{array}{c}0.443 \\
(0.166)\end{array}$ & $\begin{array}{c}0.330 \\
(0.103)\end{array}$ & $\begin{array}{c}0.616 \\
(0.113)\end{array}$ \\
\hline Observations & 9148 & 4925 & 4223 & 4406 & 2407 \\
\hline
\end{tabular}




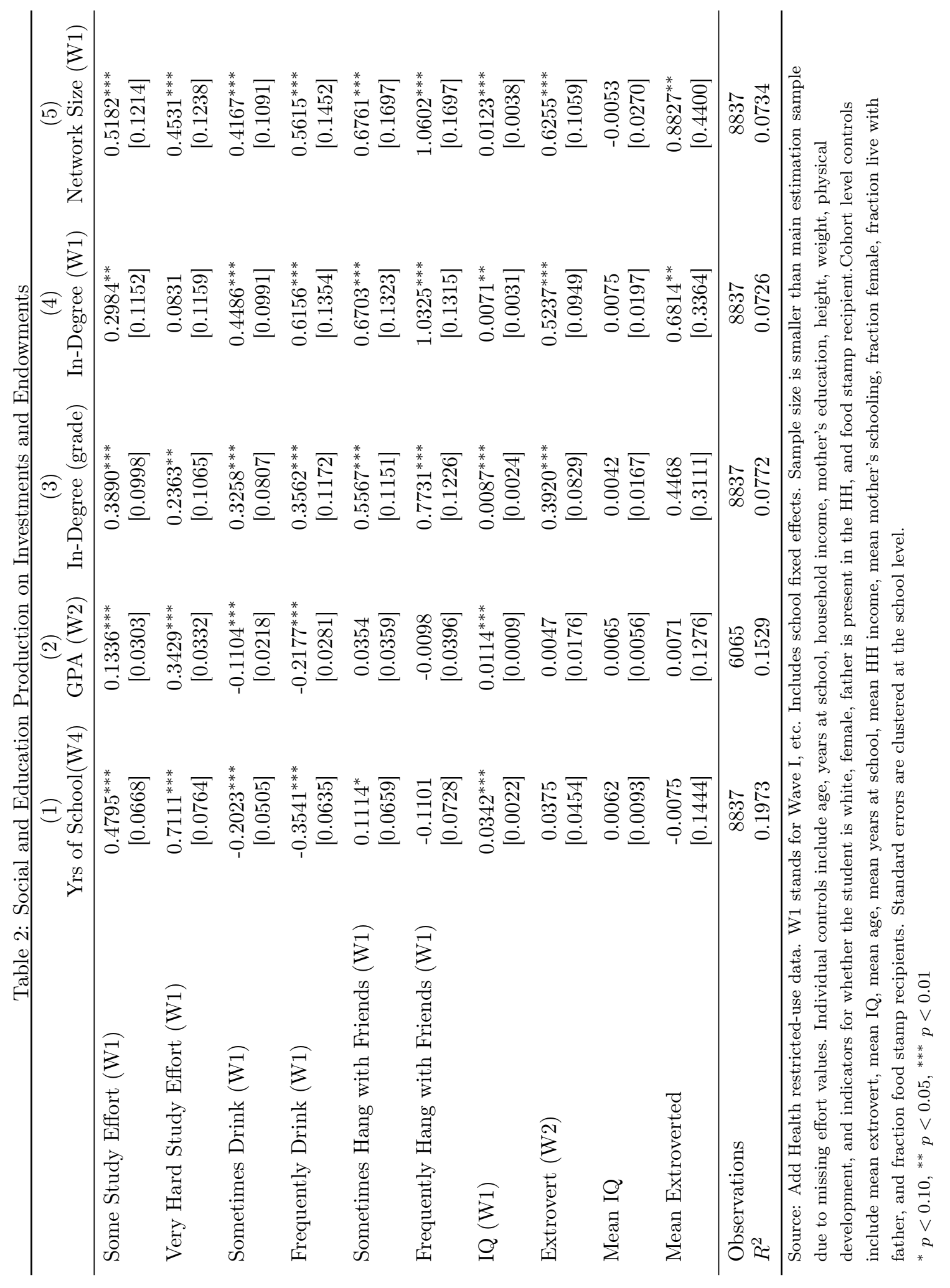


Table 3: Adult Social Capital Production

(1)

Friends(W4)
(2)

Friends(W4)

\begin{tabular}{|c|c|c|}
\hline Yrs of School(W4) & $\begin{array}{c}0.1759^{* * *} \\
{[0.0215]}\end{array}$ & $\begin{array}{c}0.1764^{* * *} \\
{[0.0213]}\end{array}$ \\
\hline In-Degree (W1) & $\begin{array}{c}0.0424^{* * *} \\
{[0.0099]}\end{array}$ & $\begin{array}{c}0.0456^{* * *} \\
{[0.0099]}\end{array}$ \\
\hline Moderate Drinker (W3) & $\begin{array}{l}0.1302^{*} \\
{[0.0747]}\end{array}$ & $\begin{array}{l}0.1534^{*} \\
{[0.0780]}\end{array}$ \\
\hline Frequent Drinker (W3) & $\begin{array}{c}0.5629^{* * *} \\
{[0.1243]}\end{array}$ & $\begin{array}{c}0.5762^{* * *} \\
{[0.1255]}\end{array}$ \\
\hline Sometimes Hang with Friends (W3) & $\begin{array}{c}0.2993^{* * *} \\
{[0.0702]}\end{array}$ & $\begin{array}{c}0.2935^{* * *} \\
{[0.0723]}\end{array}$ \\
\hline Frequently Hang with Friends (W3) & $\begin{array}{c}0.7513^{* * *} \\
{[0.0777]}\end{array}$ & $\begin{array}{c}0.7266^{* * *} \\
{[0.0787]}\end{array}$ \\
\hline Some Study Effort & & $\begin{array}{c}0.0991 \\
{[0.1093]}\end{array}$ \\
\hline Very Hard Study Effort & & $\begin{array}{c}0.2507^{* *} \\
{[0.1080]}\end{array}$ \\
\hline Sometimes Drink & & $\begin{array}{c}-0.2185^{* * *} \\
{[0.0697]}\end{array}$ \\
\hline Frequently Drink & & $\begin{array}{l}-0.1052 \\
{[0.0937]}\end{array}$ \\
\hline Sometimes Hang with Friends & & $\begin{array}{c}0.0906 \\
{[0.1284]}\end{array}$ \\
\hline Frequently Hang with Friends & & $\begin{array}{l}0.3397^{* *} \\
{[0.1323]}\end{array}$ \\
\hline $\mathrm{IQ}(\mathrm{W} 1)$ & $\begin{array}{c}0.0032 \\
{[0.0030]}\end{array}$ & $\begin{array}{c}0.0032 \\
{[0.0029]}\end{array}$ \\
\hline Extrovert (W2) & $\begin{array}{l}0.1370^{*} \\
{[0.0705]}\end{array}$ & $\begin{array}{l}0.1396^{* *} \\
{[0.0687]}\end{array}$ \\
\hline $\begin{array}{l}\text { Observations } \\
R^{2}\end{array}$ & $\begin{array}{c}7597 \\
0.0727\end{array}$ & $\begin{array}{c}7346 \\
0.0777\end{array}$ \\
\hline
\end{tabular}

Source: Add Health restricted-use data. W1 stands for Wave I, etc. Includes school fixed effects. Sample size is smaller than main estimation sample due to missing effort values. Individual controls include age, years at school, household income, mother's education, height, weight, physical development, and indicators for whether the student is white, female, father is present in the $\mathrm{HH}$, and food stamp recipient. Cohort level controls include mean extrovert, mean IQ, mean age, mean years at school, mean HH income, mean mother's schooling, fraction female, fraction live with father, and fraction food stamp recipients. Standard errors are clustered at the school level.

${ }^{*} p<0.10,{ }^{* *} p<0.05,{ }^{* * *} p<0.01$ 
Table 4: First Stage Estimates for Friendship Nominations

\begin{tabular}{lcccc}
\hline & $(1)$ & $(2)$ & $(3)$ & $(4)$ \\
& All & F-F & M-M & F-M \\
\hline Pairwise White Distance & $-0.00754^{* * *}$ & $-0.0118^{* * *}$ & $-0.00801^{* * *}$ & $-0.00516^{* * *}$ \\
Pairwise Female Distance & {$[0.00131]$} & {$[0.00190]$} & {$[0.00150]$} & {$[0.000947]$} \\
& $-0.00625^{* * *}$ & 0 & 0 & 0 \\
Pairwise Age Distance & {$[0.000876]$} & {$[]$.} & {$[]$.} & {$[]$.} \\
& $-0.00237^{* * *}$ & $-0.00367^{* * *}$ & $-0.00300^{* * *}$ & $-0.00143^{* * *}$ \\
Pairwise Years-at-School Distance & {$[0.000360]$} & {$[0.000587]$} & {$[0.000506]$} & {$[0.000237]$} \\
& $-0.00261^{* * *}$ & $-0.00409^{* * *}$ & $-0.00338^{* * *}$ & $-0.00153^{* * *}$ \\
White-Teacher Distance Receiver & {$[0.000261]$} & {$[0.000452]$} & {$[0.000397]$} & {$[0.000165]$} \\
& $0.00382^{* *}$ & $0.00633^{* *}$ & $0.00361^{*}$ & $0.00253^{* * *}$ \\
Total Live with Father Distance & {$[0.00148]$} & {$[0.00260]$} & {$[0.00184]$} & {$[0.000856]$} \\
Total Mother's Edu Distance & {$[0.00000361$} & 0.00000739 & 0.00000752 & 0.000000711 \\
& 0.000000210 & $-9.62 \mathrm{e}-08$ & 0.0000000258 & {$[0.00000385]$} \\
Total Physical Maturity Distance & $0.000000713^{*}$ & -0.000000634 & 0.000000455 & 0.000000224 \\
& {$[0.000000401]$} & {$[0.000000875]$} & {$[0.000000665]$} & {$[0.000000735]$} \\
Grade Cohort Size & $-0.0000197^{* *}$ & $-0.0000327^{* * *}$ & $-0.0000236^{* *}$ & -0.0000114 \\
& {$[0.00000775]$} & {$[0.0000108]$} & {$[0.00000932]$} & {$[0.00000697]$} \\
\hline N & $3,519,584$ & 907,608 & 867,662 & $1,744,314$ \\
F stat of Instruments & 14.88 & 15.92 & 16.23 & 16.23 \\
P-value & 0.0000 & 0.0000 & 0.0000 & 0.0000 \\
\hline
\end{tabular}

Source: Add Health restricted-use data. Includes school fixed effects. Estimation sample includes all of the pairwise combinations of students in the in-home survey with all students in the cohort. Pairwise distance variables are constructed by taking the absolute value of the distance between student $\mathrm{i}$ (sender) and student $\mathrm{j}$ (receiver). Total distance measures sum up the pairwise distances over the receiver $(\mathrm{j})$. Additional controls include receiver covariates (IQ, extraversion, age, white, physical maturity , father in HH, mother's edu,) and peer means of these measures. Sender covariates are not included because nominations from students who were not included in the in-home survey have missing covariates. Standard errors are clustered at the school level. ${ }^{*} p<.1,{ }^{* *} p<0.05,{ }^{* * *} p<0.01$ 
Table 5: First Stage Estimates for Schooling

\begin{tabular}{|c|c|c|}
\hline & $\begin{array}{c}(1) \\
\text { Schooling }\end{array}$ & $\begin{array}{c}(2) \\
\text { GPA }\end{array}$ \\
\hline $\mathrm{IQ}$ & $\begin{array}{c}0.0334^{* * *} \\
{[13.86]}\end{array}$ & $\begin{array}{c}0.0109^{* * *} \\
{[11.47]}\end{array}$ \\
\hline Extrovert & $\begin{array}{c}0.000574 \\
{[0.01]}\end{array}$ & $\begin{array}{c}-0.0188 \\
{[-1.11]}\end{array}$ \\
\hline Total Female Distance & $\begin{array}{c}0.00304^{* * *} \\
{[3.38]}\end{array}$ & $\begin{array}{c}-0.000148 \\
{[-0.21]}\end{array}$ \\
\hline Total White Distance & $\begin{array}{c}-0.000156 \\
{[-0.35]}\end{array}$ & $\begin{array}{c}0.000145 \\
{[0.94]}\end{array}$ \\
\hline Total Yrs at School Distance & $\begin{array}{c}-0.0000980 \\
{[-1.05]}\end{array}$ & $\begin{array}{c}-0.0000194 \\
{[-0.36]}\end{array}$ \\
\hline Total Age Distance & $\begin{array}{c}-0.000900^{* * *} \\
{[-4.47]}\end{array}$ & $\begin{array}{c}-0.0000440 \\
{[-0.45]}\end{array}$ \\
\hline Total Mother's Edu Distance & $\begin{array}{c}-0.000166^{* * *} \\
{[-2.69]}\end{array}$ & $\begin{array}{c}-0.0000364 \\
{[-1.59]}\end{array}$ \\
\hline Total Father in HH Distance & $\begin{array}{c}-0.00108^{* * *} \\
{[-2.66]}\end{array}$ & $\begin{array}{c}-0.000160 \\
{[-0.53]}\end{array}$ \\
\hline Total Physical Maturity Distance & $\begin{array}{c}-0.000977^{* * *} \\
{[-5.34]}\end{array}$ & $\begin{array}{c}-0.000320^{* * *} \\
{[-2.79]}\end{array}$ \\
\hline White-Teacher Distance & $\begin{array}{l}-0.175 \\
{[-1.52]}\end{array}$ & $\begin{array}{c}-0.217^{* * *} \\
{[-5.08]}\end{array}$ \\
\hline Grade Cohort Size & $\begin{array}{c}0.000279 \\
{[0.40]}\end{array}$ & $\begin{array}{c}-0.0000963 \\
{[-0.11]}\end{array}$ \\
\hline Mean Extroverted & $\begin{array}{c}-0.0370 \\
{[-0.25]}\end{array}$ & $\begin{array}{c}0.0167 \\
{[0.13]}\end{array}$ \\
\hline Mean IQ & $\begin{array}{c}0.00292 \\
{[0.29]}\end{array}$ & $\begin{array}{c}0.00392 \\
{[0.71]}\end{array}$ \\
\hline Fraction White & $\begin{array}{c}-0.884^{*} \\
{[-1.81]}\end{array}$ & $\begin{array}{c}-0.00407 \\
{[-0.02]}\end{array}$ \\
\hline Fraction Female & $\begin{array}{c}-0.793^{*} \\
{[-1.68]}\end{array}$ & $\begin{array}{c}-0.0926 \\
{[-0.37]}\end{array}$ \\
\hline Mean Age & $\begin{array}{c}0.582^{* * *} \\
{[9.57]}\end{array}$ & $\begin{array}{c}0.105^{* * *} \\
{[3.63]}\end{array}$ \\
\hline Mean Yrs at School & $\begin{array}{l}-0.0255 \\
{[-0.50]}\end{array}$ & $\begin{array}{c}-0.0311 \\
{[-0.95]}\end{array}$ \\
\hline Fraction Food Stamp Recipient & $\begin{array}{c}-0.773^{* *} \\
{[-2.22]}\end{array}$ & $\begin{array}{l}-0.289 \\
{[-1.34]}\end{array}$ \\
\hline Mean HH Income & $\begin{array}{c}0.000553 \\
{[0.41]}\end{array}$ & $\begin{array}{c}-0.000773 \\
{[-0.84]}\end{array}$ \\
\hline Fraction Father Present & $\begin{array}{l}0.304 \\
{[0.58]}\end{array}$ & $\begin{array}{l}-0.159 \\
{[-0.56]}\end{array}$ \\
\hline Mean Mother's Education & $\begin{array}{c}0.215^{* * *} \\
{[3.02]}\end{array}$ & $\begin{array}{l}0.0194 \\
{[0.40]}\end{array}$ \\
\hline Mean Physical Development & $\begin{array}{c}-0.0217 \\
{[-0.21]}\end{array}$ & $\begin{array}{c}-0.153^{* *} \\
{[-2.26]}\end{array}$ \\
\hline Mean of Dep. Var. & 14.80 & 2.84 \\
\hline R-squared & 0.19 & 0.11 \\
\hline $\mathrm{N}$ & 9,148 & 6,297 \\
\hline F stat of Instruments & 9.83 & 6.42 \\
\hline $\mathrm{P}$-value & 0.000 & 0.000 \\
\hline
\end{tabular}

Source: Add Health restricted-use data. Includes school fixed effects. Individual controls include age, years at school, household income, mother's education, height, weight, physical development, and indicators for whether the student is white, female, and father is present in the household.

Standard errors are clustered at the school level.

${ }^{*} p<0.10,{ }^{* *} p<0.05,{ }^{* * *} p<0.01$ 
Table 6: Wage Equation Estimates on Social Capital Measures

\begin{tabular}{|c|c|c|c|c|c|}
\hline & $\begin{array}{l}(1) \\
\text { OLS }\end{array}$ & $\begin{array}{l}(2) \\
\text { OLS }\end{array}$ & $\begin{array}{l}(3) \\
\text { OLS }\end{array}$ & $\begin{array}{l}(4) \\
\text { OLS }\end{array}$ & $\begin{array}{c}(5) \\
\text { OLS }\end{array}$ \\
\hline Years of schooling & $\begin{array}{c}0.0997^{* * *} \\
{[0.0064]}\end{array}$ & $\begin{array}{c}0.0991^{* * *} \\
{[0.0064]}\end{array}$ & $\begin{array}{c}0.0981^{* * *} \\
{[0.0064]}\end{array}$ & $\begin{array}{c}0.0979^{* * *} \\
{[0.0065]}\end{array}$ & $\begin{array}{c}0.0991^{* * *} \\
{[0.0063]}\end{array}$ \\
\hline Network Size & $\begin{array}{c}0.0111^{* * *} \\
{[0.0025]}\end{array}$ & & & & \\
\hline In Degree & & $\begin{array}{c}0.0174^{* * *} \\
{[0.0031]}\end{array}$ & & & \\
\hline Out-Degree & & $\begin{array}{l}-0.0014 \\
{[0.0034]}\end{array}$ & & & \\
\hline In-Degree (grade) & & & $\begin{array}{c}0.0218^{* * *} \\
{[0.0036]}\end{array}$ & & \\
\hline In Degree (outside grade) & & & $\begin{array}{c}0.0007 \\
{[0.0071]}\end{array}$ & & \\
\hline In-Degree (grade): opposite gender & & & & $\begin{array}{l}0.0113^{*} \\
{[0.0058]}\end{array}$ & \\
\hline In-Degree (grade): same gender & & & & $\begin{array}{c}0.0325^{* * *} \\
{[0.0053]}\end{array}$ & \\
\hline In-Degree (grade): low engagement & & & & & $\begin{array}{r}0.0110^{* *} \\
{[0.0043]}\end{array}$ \\
\hline In-Degree (grade): high engagement & & & & & $\begin{array}{c}0.0332^{* * *} \\
{[0.0073]}\end{array}$ \\
\hline IQ & $\begin{array}{l}-0.0001 \\
{[0.0008]}\end{array}$ & $\begin{array}{l}-0.0001 \\
{[0.0008]}\end{array}$ & $\begin{array}{l}-0.0001 \\
{[0.0008]}\end{array}$ & $\begin{array}{l}-0.0001 \\
{[0.0008]}\end{array}$ & $\begin{array}{l}-0.0000 \\
{[0.0008]}\end{array}$ \\
\hline Extrovert & $\begin{array}{c}0.0328 \\
{[0.0218]}\end{array}$ & $\begin{array}{c}0.0304 \\
{[0.0216]}\end{array}$ & $\begin{array}{c}0.0307 \\
{[0.0216]}\end{array}$ & $\begin{array}{c}0.0326 \\
{[0.0217]}\end{array}$ & $\begin{array}{c}0.0295 \\
{[0.0215]}\end{array}$ \\
\hline $\begin{array}{l}\text { Observations } \\
R^{2}\end{array}$ & $\begin{array}{c}9148 \\
0.0973\end{array}$ & $\begin{array}{c}9148 \\
0.0988\end{array}$ & $\begin{array}{c}9148 \\
0.0994\end{array}$ & $\begin{array}{c}9148 \\
0.0999\end{array}$ & $\begin{array}{c}9148 \\
0.0993\end{array}$ \\
\hline
\end{tabular}

Source: Add Health restricted-use data. Includes school fixed effects. Individual controls include age, years at school, household income, mother's education, height, weight, physical development, and indicators for whether the student is white, female, father is present in the HH, and food stamp recipient.Cohort level controls include mean extrovert, mean IQ, mean age, mean years at school, mean HH income, mean mother's schooling, fraction female, fraction live with father, and fraction food stamp recipients. Standard errors are clustered at the school level.

${ }^{*} p<0.10,{ }^{* *} p<0.05,{ }^{* * *} p<0.01$ 


\begin{tabular}{lcc}
\hline & $(1)$ & $(2)$ \\
& Log Wages $(\mathrm{W} 4)$ & Log Wages $(\mathrm{W} 4)$ \\
\hline Years of schooling & & $0.1040^{* * *}$ \\
IQ & $0.0035^{* * *}$ & {$[0.0064]$} \\
Extrovert & {$[0.0008]$} & -0.0001 \\
& $0.0549^{* *}$ & {$[0.0008]$} \\
Some Study Effort & {$[0.0229]$} & $0.0509^{* *}$ \\
& $0.0728^{* *}$ & {$[0.0227]$} \\
Very Hard Study Effort & {$[0.0300]$} & 0.0235 \\
& $0.0791^{* *}$ & {$[0.0298]$} \\
Sometimes Drink & {$[0.0359]$} & 0.0063 \\
& -0.0245 & {$[0.0354]$} \\
Frequently Drink & {$[0.0229]$} & -0.0033 \\
& -0.0295 & {$[0.0219]$} \\
Sometimes Hang with Friends & {$[0.0331]$} & 0.0074 \\
& $0.0919^{* *}$ & {$[0.0313]$} \\
Frequently Hang with Friends & {$[0.0415]$} & $0.0797^{*}$ \\
& $0.0854^{*}$ & {$[0.0404]$} \\
\hline Observations & {$[0.0448]$} & $0.0964^{* *}$ \\
$R^{2}$ & 8870 & {$[0.0448]$} \\
\hline
\end{tabular}

Source: Add Health restricted-use data. Includes school fixed effects. Sample size is smaller than main estimation sample due to missing effort values. Individual controls include age, years at school, household income, mother's education, height, weight, physical development, and indicators for whether the student is white, female, father is present in the HH, and food stamp recipient. Cohort level controls include mean extrovert, mean IQ, mean age, mean years at school, mean HH income, mean mother's schooling, fraction female, fraction live withfather, and fraction food stamp recipients. Standard errors are clustered at the school level.

${ }^{*} p<.1,{ }^{* *} p<0.05,{ }^{* * *} p<0.01$ 
Table 8: Wage Equation GMM-IV Estimates

\begin{tabular}{|c|c|c|c|c|c|c|c|c|}
\hline & $\begin{array}{l}(1) \\
\text { OLS }\end{array}$ & $\begin{array}{c}(2) \\
\text { IV-GMM }\end{array}$ & $\begin{array}{c}(3) \\
\text { IV-GMM }\end{array}$ & $\begin{array}{c}(4) \\
\text { IV-GMM }\end{array}$ & $\begin{array}{c}(5) \\
\text { IV-GMM }\end{array}$ & $\begin{array}{c}(6) \\
\text { IV-GMM }\end{array}$ & $\begin{array}{c}(7) \\
\text { IV-GMM }\end{array}$ & $\begin{array}{l}(8) \\
\text { OLS }\end{array}$ \\
\hline Years of schooling & $\begin{array}{c}0.0981^{* * *} \\
{[0.0064]}\end{array}$ & $\begin{array}{l}0.1221^{*} \\
{[0.0678]}\end{array}$ & $\begin{array}{c}0.0812^{* * *} \\
{[0.0121]}\end{array}$ & $\begin{array}{c}0.1776^{* * *} \\
{[0.0425]}\end{array}$ & $\begin{array}{c}0.0898^{* * *} \\
{[0.0072]}\end{array}$ & $\begin{array}{l}0.1716^{* *} \\
{[0.0691]}\end{array}$ & $\begin{array}{c}0.0910^{* * *} \\
{[0.0096]}\end{array}$ & \\
\hline In-Degree (grade) & $\begin{array}{c}0.0219^{* * *} \\
{[0.0036]}\end{array}$ & $\begin{array}{c}0.0964^{* *} \\
{[0.0465]}\end{array}$ & $\begin{array}{l}0.1052^{* *} \\
{[0.0423]}\end{array}$ & $\begin{array}{l}0.0417^{*} \\
{[0.0227]}\end{array}$ & $\begin{array}{c}0.0585^{* * *} \\
{[0.0211]}\end{array}$ & $\begin{array}{c}0.0411 \\
{[0.0351]}\end{array}$ & $\begin{array}{l}0.0568^{*} \\
{[0.0307]}\end{array}$ & \\
\hline $\mathrm{IQ}$ & $\begin{array}{l}-0.0001 \\
{[0.0008]}\end{array}$ & $\begin{array}{l}-0.0015 \\
{[0.0023]}\end{array}$ & $\begin{array}{l}-0.0002 \\
{[0.0008]}\end{array}$ & $\begin{array}{c}-0.0038^{* *} \\
{[0.0017]}\end{array}$ & $\begin{array}{l}-0.0004 \\
{[0.0007]}\end{array}$ & $\begin{array}{l}-0.0028 \\
{[0.0023]}\end{array}$ & $\begin{array}{l}-0.0002 \\
{[0.0008]}\end{array}$ & $\begin{array}{c}0.0034^{* * *} \\
{[0.0008]}\end{array}$ \\
\hline Extrovert & $\begin{array}{c}0.0308 \\
{[0.0216]}\end{array}$ & $\begin{array}{l}-0.0014 \\
{[0.0286]}\end{array}$ & $\begin{array}{l}-0.0050 \\
{[0.0273]}\end{array}$ & $\begin{array}{c}0.0268 \\
{[0.0232]}\end{array}$ & $\begin{array}{c}0.0169 \\
{[0.0223]}\end{array}$ & $\begin{array}{c}0.0221 \\
{[0.0256]}\end{array}$ & $\begin{array}{c}0.0157 \\
{[0.0247]}\end{array}$ & $\begin{array}{l}0.0404^{*} \\
{[0.0225]}\end{array}$ \\
\hline First Stage & & $\begin{array}{c}\text { Pairwise } \\
\text { OLS }\end{array}$ & $\begin{array}{c}\text { Pairwise } \\
\text { OLS }\end{array}$ & Aggregate & Aggregate & $\begin{array}{c}\text { Pairwise } \\
\text { Probit }\end{array}$ & $\begin{array}{c}\text { Pairwise } \\
\text { Probit }\end{array}$ & \\
\hline $\begin{array}{l}\text { Edu Endog? } \\
\mathrm{N}\end{array}$ & $\begin{array}{c}\mathrm{N} \\
9,148\end{array}$ & $\begin{array}{c}\mathrm{Y} \\
9,111\end{array}$ & $\begin{array}{c}\mathrm{N} \\
9,111\end{array}$ & $\begin{array}{c}\mathrm{Y} \\
9,147\end{array}$ & $\begin{array}{c}\mathrm{N} \\
9,147\end{array}$ & $\begin{array}{c}\mathrm{Y} \\
9,111\end{array}$ & $\begin{array}{c}\mathrm{N} \\
9,111\end{array}$ & $\begin{array}{c}\mathrm{N} \\
9,148\end{array}$ \\
\hline
\end{tabular}

Source: Add Health restricted-use data. Includes school fixed effects. Individual controls include age, years at school, household income, mother's education, height, weight, physical development, and indicators for whether the student is white, female, father is present in the $\mathrm{HH}$, and food stamp recipient.Cohort level controls include mean extrovert, mean IQ, mean age, mean years at school, mean HH income, mean mother's schooling, fraction female, fraction live with father, and fraction food stamp recipients. Standard errors are clustered at the school level.

${ }^{*} p<0.10,{ }^{* *} p<0.05,{ }^{* * *} p<0.01$ 
Table 9: Social and Study Effort on Endowments

\begin{tabular}{|c|c|c|c|c|c|c|}
\hline & $\begin{array}{c}(1) \\
\text { Some Study }\end{array}$ & $\begin{array}{c}(2) \\
\text { High Study }\end{array}$ & $\begin{array}{c}(3) \\
\text { Some Drink }\end{array}$ & $\begin{array}{c}\qquad(4) \\
\text { Frequent Drink }\end{array}$ & $\begin{array}{c}(5) \\
\text { Some Hang }\end{array}$ & $\begin{array}{c}(6) \\
\text { Frequent Hang }\end{array}$ \\
\hline IQ & $\begin{array}{c}0.0002 \\
{[0.0004]}\end{array}$ & $\begin{array}{l}-0.0006 \\
{[0.0004]}\end{array}$ & $\begin{array}{c}0.0002 \\
{[0.0004]}\end{array}$ & $\begin{array}{l}-0.0005^{*} \\
{[0.0003]}\end{array}$ & $\begin{array}{c}0.0015^{* * *} \\
{[0.0004]}\end{array}$ & $\begin{array}{c}-0.0018^{* * *} \\
{[0.0004]}\end{array}$ \\
\hline Extrovert & $\begin{array}{l}0.0245^{* *} \\
{[0.0120]}\end{array}$ & $\begin{array}{c}-0.0371^{* * *} \\
{[0.0121]}\end{array}$ & $\begin{array}{c}0.0372^{* * *} \\
{[0.0099]}\end{array}$ & $\begin{array}{c}0.0321^{* * *} \\
{[0.0102]}\end{array}$ & $\begin{array}{c}-0.0450^{* * *} \\
{[0.0112]}\end{array}$ & $\begin{array}{c}0.0569^{* * *} \\
{[0.0112]}\end{array}$ \\
\hline Mean IQ & $\begin{array}{c}0.0034 \\
{[0.0023]}\end{array}$ & $\begin{array}{l}-0.0027 \\
{[0.0021]}\end{array}$ & $\begin{array}{c}0.0015 \\
{[0.0026]}\end{array}$ & $\begin{array}{c}0.0019 \\
{[0.0023]}\end{array}$ & $\begin{array}{c}0.0015 \\
{[0.0027]}\end{array}$ & $\begin{array}{l}-0.0011 \\
{[0.0026]}\end{array}$ \\
\hline Mean Extroverted & $\begin{array}{c}0.0451 \\
{[0.0446]}\end{array}$ & $\begin{array}{r}-0.0798^{*} \\
{[0.0466]}\end{array}$ & $\begin{array}{l}-0.0714 \\
{[0.0460]}\end{array}$ & $\begin{array}{l}-0.0095 \\
{[0.0437]}\end{array}$ & $\begin{array}{c}0.0372 \\
{[0.0587]}\end{array}$ & $\begin{array}{l}-0.0055 \\
{[0.0545]}\end{array}$ \\
\hline $\begin{array}{l}\text { Observations } \\
R^{2}\end{array}$ & $\begin{array}{c}8852 \\
0.0125\end{array}$ & $\begin{array}{c}8852 \\
0.0327\end{array}$ & $\begin{array}{c}9133 \\
0.0183\end{array}$ & $\begin{array}{c}9133 \\
0.0427\end{array}$ & $\begin{array}{c}9147 \\
0.0078\end{array}$ & $\begin{array}{c}9147 \\
0.0123\end{array}$ \\
\hline
\end{tabular}

Source: Add Health restricted-use data. W1 stands for Wave I, etc. Includes school fixed effects. Sample size is smaller than main estimation sample due to missing effort values. Individual controls include age, years at school, household income, mother's education, height, weight, physical development, and indicators for whether the student is white, female, father is present in the $\mathrm{HH}$, and food stamp recipient. Cohort level controls include mean extrovert, mean IQ, mean age, mean years at school, mean HH income, mean mother's schooling, fraction female, fraction live with father, and fraction food stamp recipients. Standard errors are clustered at the school level.

${ }^{*} p<0.10,{ }^{* *} p<0.05,{ }^{* * *} p<0.01$ 


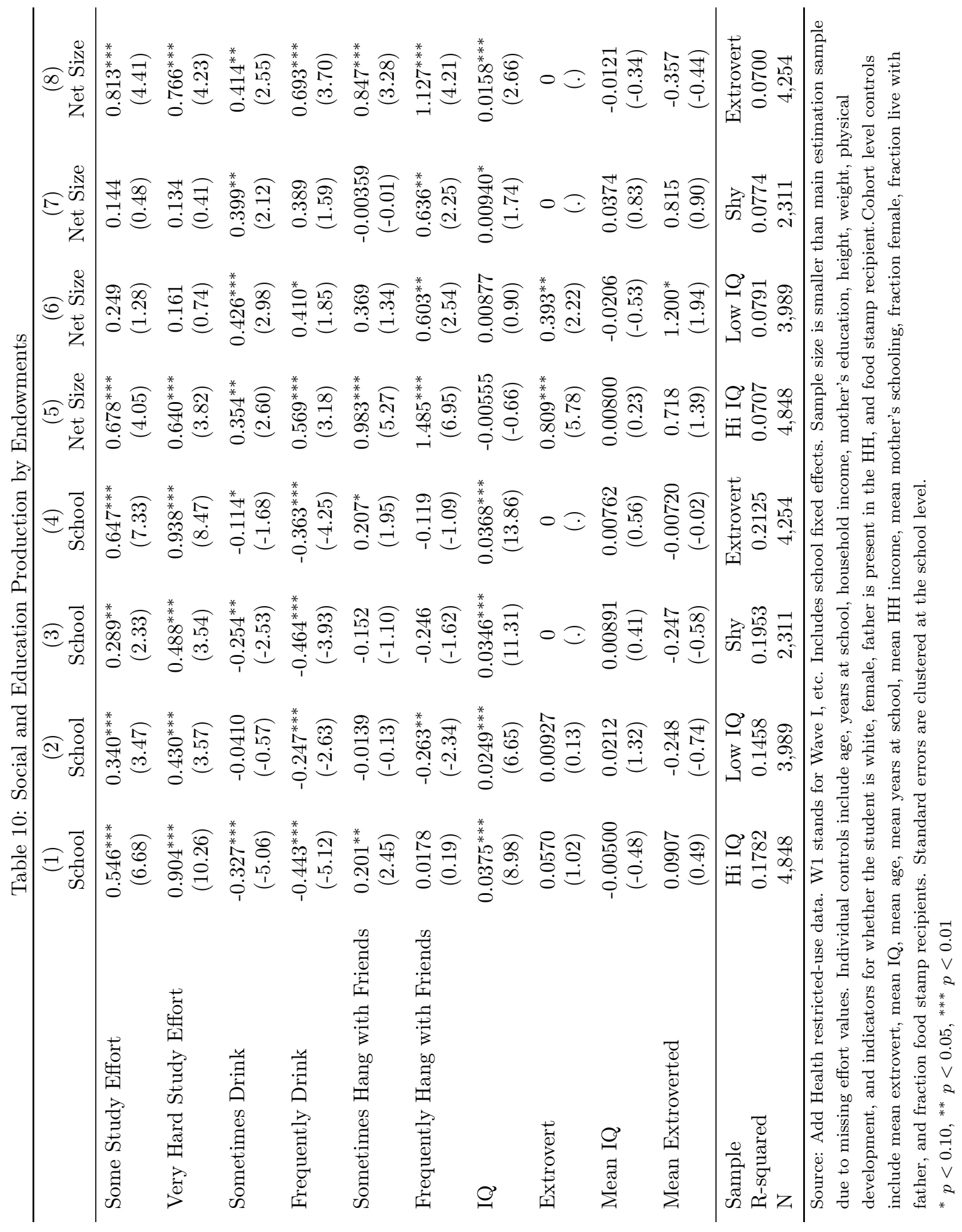


Appendix 
Figure A.1: Education on In Degree
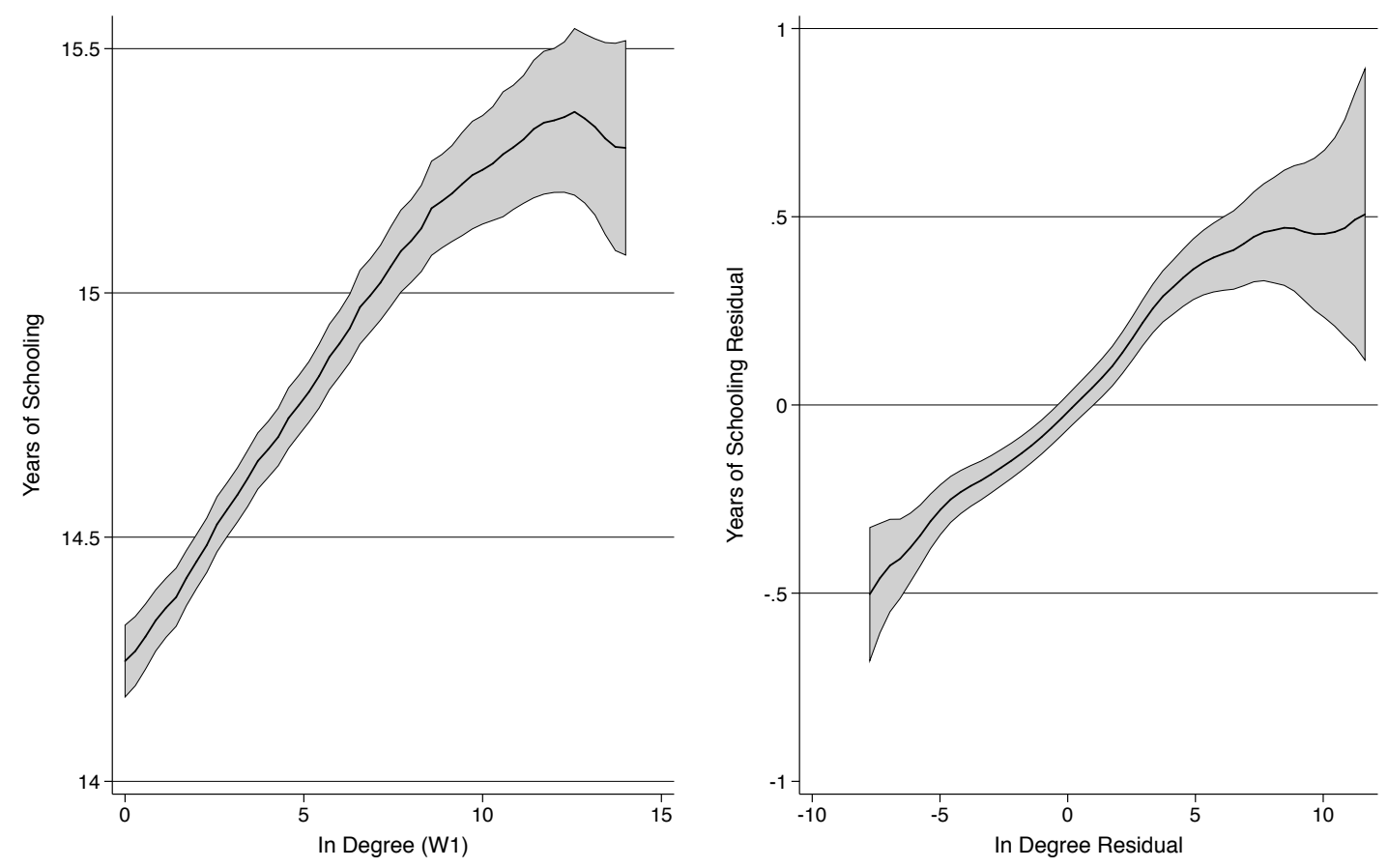

Data: Add Health restricted-use data 
Table A.1: First Stage Estimates for Friendship Nomination cont'd (Receiver Controls)

\begin{tabular}{|c|c|c|c|c|}
\hline & $\begin{array}{l}\text { (1) } \\
\text { All }\end{array}$ & $\begin{array}{l}(2) \\
\text { F-F }\end{array}$ & $\begin{array}{c}(3) \\
\mathrm{M}-\mathrm{M}\end{array}$ & $\begin{array}{c}(4) \\
\text { F-M }\end{array}$ \\
\hline IQ (W1) Receiver & $\begin{array}{l}0.0000327^{* * *} \\
{[0.00000854]}\end{array}$ & $\begin{array}{l}0.0000378^{* *} \\
{[0.0000160]}\end{array}$ & $\begin{array}{c}0.0000188 \\
{[0.0000146]}\end{array}$ & $\begin{array}{l}0.0000340^{* * *} \\
{[0.00000887]}\end{array}$ \\
\hline Extrovert Receiver & $\begin{array}{l}0.00144^{* * *} \\
{[0.000378]}\end{array}$ & $\begin{array}{c}0.000822 \\
{[0.000516]}\end{array}$ & $\begin{array}{c}0.000435 \\
{[0.000410]}\end{array}$ & $\begin{array}{l}0.00229^{* * *} \\
{[0.000470]}\end{array}$ \\
\hline Age (W2) Receiver & $\begin{array}{c}-0.000636^{* * *} \\
{[0.000171]}\end{array}$ & $\begin{array}{c}-0.00111^{* * *} \\
{[0.000298]}\end{array}$ & $\begin{array}{c}-0.000941^{* * *} \\
{[0.000300]}\end{array}$ & $\begin{array}{l}-0.000370^{*} \\
{[0.000195]}\end{array}$ \\
\hline Female Receiver & $\begin{array}{c}0.000968^{* * *} \\
{[0.000330]}\end{array}$ & $\begin{array}{c}0 \\
{[.]}\end{array}$ & $\begin{array}{c}0 \\
{[.]}\end{array}$ & $\begin{array}{l}-0.000448 \\
{[0.000390]}\end{array}$ \\
\hline White Receiver & $\begin{array}{c}0.00163^{*} \\
{[0.000888]}\end{array}$ & $\begin{array}{l}0.00265^{*} \\
{[0.00158]}\end{array}$ & $\begin{array}{c}0.00162 \\
{[0.00114]}\end{array}$ & $\begin{array}{l}0.00102^{* *} \\
{[0.000497]}\end{array}$ \\
\hline Height Receiver & $\begin{array}{c}0.0000879^{* *} \\
{[0.0000343]}\end{array}$ & $\begin{array}{c}0.0000936 \\
{[0.0000649]}\end{array}$ & $\begin{array}{c}0.0000934 \\
{[0.0000596]}\end{array}$ & $\begin{array}{l}0.0000777^{*} \\
{[0.0000429]}\end{array}$ \\
\hline Weight Receiver & $\begin{array}{c}-0.0000456^{* * *} \\
{[0.00000750]}\end{array}$ & $\begin{array}{c}-0.0000558^{* * *} \\
{[0.00000828]}\end{array}$ & $\begin{array}{c}-0.0000286^{* * *} \\
{[0.00000658]}\end{array}$ & $\begin{array}{c}-0.0000518^{* * *} \\
{[0.0000102]}\end{array}$ \\
\hline Physical Maturity Receiver & $\begin{array}{c}0.000883^{* * *} \\
{[0.000218]}\end{array}$ & $\begin{array}{c}0.000531^{* *} \\
{[0.000209]}\end{array}$ & $\begin{array}{c}0.000657^{* * *} \\
{[0.000194]}\end{array}$ & $\begin{array}{l}0.00114^{* * *} \\
{[0.000286]}\end{array}$ \\
\hline Years at School Receiver & $\begin{array}{l}0.00217^{* * *} \\
{[0.000263]}\end{array}$ & $\begin{array}{l}0.00262^{* * *} \\
{[0.000420]}\end{array}$ & $\begin{array}{l}0.00298^{* * *} \\
{[0.000394]}\end{array}$ & $\begin{array}{l}0.00140^{* * *} \\
{[0.000221]}\end{array}$ \\
\hline HH Income receiver & $\begin{array}{l}0.0000207^{* * *} \\
{[0.00000349]}\end{array}$ & $\begin{array}{c}0.0000189^{* * *} \\
{[0.00000680]}\end{array}$ & $\begin{array}{l}0.0000221^{* * *} \\
{[0.00000512]}\end{array}$ & $\begin{array}{l}0.0000213^{* * *} \\
{[0.00000364]}\end{array}$ \\
\hline Food Stamp Recipient receiver & $\begin{array}{c}-0.00191^{* * *} \\
{[0.000489]}\end{array}$ & $\begin{array}{c}-0.00224^{* * *} \\
{[0.000661]}\end{array}$ & $\begin{array}{l}-0.00163^{* *} \\
{[0.000738]}\end{array}$ & $\begin{array}{c}-0.00182^{* * *} \\
{[0.000514]}\end{array}$ \\
\hline Father in $\mathrm{HH}$ receiver & $\begin{array}{c}0.00117^{*} \\
{[0.000646]}\end{array}$ & $\begin{array}{c}0.00167^{*} \\
{[0.000948]}\end{array}$ & $\begin{array}{l}0.00249^{* *} \\
{[0.00105]}\end{array}$ & $\begin{array}{c}0.000441 \\
{[0.000828]}\end{array}$ \\
\hline Mother in HH Receiver & $\begin{array}{c}0.00106^{*} \\
{[0.000572]}\end{array}$ & $\begin{array}{c}-0.0000609 \\
{[0.00121]}\end{array}$ & $\begin{array}{l}0.00217^{* *} \\
{[0.00107]}\end{array}$ & $\begin{array}{c}0.000761 \\
{[0.000609]}\end{array}$ \\
\hline Mother's Educ & $\begin{array}{c}0.0000210 \\
{[0.0000475]}\end{array}$ & $\begin{array}{l}-0.0000185 \\
{[0.0000667]}\end{array}$ & $\begin{array}{c}0.0000610 \\
{[0.0000637]}\end{array}$ & $\begin{array}{c}0.0000224 \\
{[0.0000601]}\end{array}$ \\
\hline HH size receiver & $\begin{array}{l}-0.000211^{* *} \\
{[0.0000959]}\end{array}$ & $\begin{array}{l}-0.000303^{*} \\
{[0.000177]}\end{array}$ & $\begin{array}{l}-0.000309^{*} \\
{[0.000171]}\end{array}$ & $\begin{array}{l}-0.000166 \\
{[0.000104]}\end{array}$ \\
\hline $\mathrm{N}$ & $3,519,584$ & 907,608 & 867,662 & $1,744,314$ \\
\hline F stat of Instruments & 14.88 & 15.92 & 16.23 & 16.23 \\
\hline $\mathrm{P}$-value & 0.0000 & 0.0000 & 0.0000 & 0.0000 \\
\hline
\end{tabular}

Source: Add Health restricted-use data. Includes school fixed effects. Estimation sample includes all of the pairwise combinations of students in the in-home survey with all students in the cohort. Pairwise distance variables are constructed by taking the absolute value of the distance between student $\mathrm{i}$ (sender) and student $\mathrm{j}$ (receiver). Total distance measures sum up the pairwise distances over the receiver (j). Additional controls include receiver covariates (IQ, extraversion, age, white, physical maturity , father in HH, mother's edu,) and peer means of these measures. Sender covariates are not included because nominations from students who were not included in the in-home survey have missing covariates. Standard errors are clustered at the school level. ${ }^{*} p<.1,{ }^{* *} p<0.05,{ }^{* * *} p<0.01$ 
Table A.2: First Stage Estimates for Friendship Nomination cont'd (Peer Means)

\begin{tabular}{|c|c|c|c|c|}
\hline & $\begin{array}{l}\text { (1) } \\
\text { All }\end{array}$ & $\begin{array}{l}(2) \\
\text { F-F }\end{array}$ & $\begin{array}{c}(3) \\
\text { M-M }\end{array}$ & $\begin{array}{c}(4) \\
\text { F-M }\end{array}$ \\
\hline Mean IQ & $\begin{array}{c}0.000152 \\
{[0.000113]}\end{array}$ & $\begin{array}{c}0.000148 \\
{[0.000171]}\end{array}$ & $\begin{array}{c}0.000230^{*} \\
{[0.000138]}\end{array}$ & $\begin{array}{c}0.000134 \\
{[0.000114]}\end{array}$ \\
\hline Mean Extroverted & $\begin{array}{c}0.00184 \\
{[0.00176]}\end{array}$ & $\begin{array}{c}0.00138 \\
{[0.00295]}\end{array}$ & $\begin{array}{c}0.00238 \\
{[0.00191]}\end{array}$ & $\begin{array}{c}0.00154 \\
{[0.00171]}\end{array}$ \\
\hline Fraction White & $\begin{array}{c}0.0150 \\
{[0.00967]}\end{array}$ & $\begin{array}{l}0.00781 \\
{[0.0124]}\end{array}$ & $\begin{array}{c}0.0248^{* *} \\
{[0.0117]}\end{array}$ & $\begin{array}{c}0.0146 \\
{[0.00974]}\end{array}$ \\
\hline Fraction Female & $\begin{array}{l}-0.00433 \\
{[0.00899]}\end{array}$ & $\begin{array}{c}-0.0431^{* * *} \\
{[0.0141]}\end{array}$ & $\begin{array}{c}0.0320^{* * *} \\
{[0.0103]}\end{array}$ & $\begin{array}{r}-0.00287 \\
{[0.0100]}\end{array}$ \\
\hline Mean Age & $\begin{array}{c}-0.000811 \\
{[0.00120]}\end{array}$ & $\begin{array}{c}-0.000564 \\
{[0.00206]}\end{array}$ & $\begin{array}{c}-0.00171 \\
{[0.00140]}\end{array}$ & $\begin{array}{r}-0.000450 \\
{[0.00112]}\end{array}$ \\
\hline Mean Yrs at School & $\begin{array}{c}-0.000143 \\
{[0.00120]}\end{array}$ & $\begin{array}{c}-0.0000907 \\
{[0.00238]}\end{array}$ & $\begin{array}{c}-0.000441 \\
{[0.00142]}\end{array}$ & $\begin{array}{c}0.0000686 \\
{[0.00112]}\end{array}$ \\
\hline Fraction Food Stamp Recipient & $\begin{array}{c}0.00272 \\
{[0.00409]}\end{array}$ & $\begin{array}{c}-0.00129 \\
{[0.00674]}\end{array}$ & $\begin{array}{c}0.00399 \\
{[0.00566]}\end{array}$ & $\begin{array}{c}0.00368 \\
{[0.00348]}\end{array}$ \\
\hline Mean HH Income & $\begin{array}{l}0.0000243^{*} \\
{[0.0000133]}\end{array}$ & $\begin{array}{c}0.0000380 \\
{[0.0000354]}\end{array}$ & $\begin{array}{c}0.0000213 \\
{[0.0000200]}\end{array}$ & $\begin{array}{c}0.0000180 \\
{[0.0000112]}\end{array}$ \\
\hline Fraction Father Present & $\begin{array}{c}-0.0102 \\
{[0.00881]}\end{array}$ & $\begin{array}{c}-0.00654 \\
{[0.0131]}\end{array}$ & $\begin{array}{l}-0.0145 \\
{[0.0119]}\end{array}$ & $\begin{array}{l}-0.00988 \\
{[0.00895]}\end{array}$ \\
\hline Mean Mother's Education & $\begin{array}{c}0.00110 \\
{[0.00120]}\end{array}$ & $\begin{array}{c}0.00159 \\
{[0.00193]}\end{array}$ & $\begin{array}{l}0.000527 \\
{[0.00141]}\end{array}$ & $\begin{array}{c}0.00112 \\
{[0.00126]}\end{array}$ \\
\hline Mean Physical Development & $\begin{array}{c}-0.00136 \\
{[0.00113]}\end{array}$ & $\begin{array}{c}0.00179 \\
{[0.00195]}\end{array}$ & $\begin{array}{c}-0.00325^{* *} \\
{[0.00152]}\end{array}$ & $\begin{array}{l}-0.00189 \\
{[0.00123]} \\
\end{array}$ \\
\hline $\begin{array}{l}\mathrm{N} \\
\text { F stat of Instruments } \\
\text { P-value }\end{array}$ & $\begin{array}{c}3,519,584 \\
14.88 \\
0.0000\end{array}$ & $\begin{array}{c}907,608 \\
15.92 \\
0.0000\end{array}$ & $\begin{array}{c}867,662 \\
16.23 \\
0.0000\end{array}$ & $\begin{array}{c}1,744,314 \\
16.23 \\
0.0000\end{array}$ \\
\hline
\end{tabular}

Source: Add Health restricted-use data. Includes school fixed effects. Estimation sample includes all of the pairwise combinations of students in the in-home survey with all students in the cohort. Pairwise distance variables are constructed by taking the absolute value of the distance between student $\mathrm{i}$ (sender) and student $\mathrm{j}$ (receiver). Total distance measures sum up the pairwise distances over the receiver $(\mathrm{j})$. Additional controls include receiver covariates (IQ, extraversion, age, white, physical maturity , father in HH, mother's edu,) and peer means of these measures. Sender covariates are not included because nominations from students who were not included in the in-home survey have missing covariates. Standard errors are clustered at the school level. ${ }^{*} p<.1,{ }^{* *} p<0.05,{ }^{* * *} p<0.01$ 
Table A.3: Test for Coordination in Friendship Formation

\begin{tabular}{|c|c|c|}
\hline & $\begin{array}{c}(1) \\
\text { School Sample }\end{array}$ & $\begin{array}{c}(2) \\
\text { In Home Sample }\end{array}$ \\
\hline Pairwise White Distance & $\begin{array}{c}-0.00881^{* * *} \\
{[0.00107]}\end{array}$ & $\begin{array}{c}-0.00948^{* * *} \\
{[0.00168]}\end{array}$ \\
\hline Pairwise Female Distance & $\begin{array}{c}-0.00565^{* * *} \\
{[0.000484]}\end{array}$ & $\begin{array}{c}-0.00616^{* * *} \\
{[0.000866]}\end{array}$ \\
\hline Pairwise Age Distance & $\begin{array}{c}-0.00205^{* * *} \\
{[0.000198]}\end{array}$ & $\begin{array}{c}-0.00263^{* * *} \\
{[0.000342]}\end{array}$ \\
\hline Pairwise Years-at-School Distance & $\begin{array}{c}-0.00294^{* * *} \\
{[0.000245]}\end{array}$ & $\begin{array}{c}-0.00352^{* * *} \\
{[0.000361]}\end{array}$ \\
\hline Total White Distance (Sender) & $\begin{array}{c}0.0000181^{* * *} \\
{[0.00000338]}\end{array}$ & $\begin{array}{c}0.0000167^{* * *} \\
{[0.00000431]}\end{array}$ \\
\hline Total Female Distance (Sender) & $\begin{array}{c}-0.0000267^{* * *} \\
{[0.00000517]}\end{array}$ & $\begin{array}{c}-0.0000340^{* * *} \\
{[0.00000711]}\end{array}$ \\
\hline Total Age Distance (Sender) & $\begin{array}{l}0.00000210^{* * *} \\
{[0.000000547]}\end{array}$ & $\begin{array}{l}0.00000344^{* * *} \\
{[0.000000865]}\end{array}$ \\
\hline Total Yrs at School Distance (Sender) & $\begin{array}{c}0.00000243^{* * *} \\
{[0.000000595]}\end{array}$ & $\begin{array}{l}0.00000275^{* * *} \\
{[0.000000846]}\end{array}$ \\
\hline Total White Distance (Receiver) & $\begin{array}{c}0.0000180^{* * *} \\
{[0.00000338]}\end{array}$ & $\begin{array}{c}0.0000166^{* * *} \\
{[0.00000458]}\end{array}$ \\
\hline Total Female Distance (Receiver) & $\begin{array}{l}-0.0000107^{* *} \\
{[0.00000476]}\end{array}$ & $\begin{array}{c}-0.0000114 \\
{[0.00000692]}\end{array}$ \\
\hline Total Age Distance (Receiver) & $\begin{array}{c}0.00000188^{* * *} \\
{[0.000000564]}\end{array}$ & $\begin{array}{l}0.00000415^{* * *} \\
{[0.000000961]}\end{array}$ \\
\hline Total Yrs at School Distance (Receiver) & $\begin{array}{l}0.00000190^{* * *} \\
{[0.000000604]}\end{array}$ & $\begin{array}{c}0.00000213^{* *} \\
{[0.000000844]}\end{array}$ \\
\hline $\begin{array}{l}\mathrm{N} \\
\text { F stat of Sender Homophily } \\
\text { P-value }\end{array}$ & $\begin{array}{c}21,944,154 \\
18.51 \\
0.0000\end{array}$ & $\begin{array}{l}3,524,859 \\
13.82 \\
0.0000\end{array}$ \\
\hline
\end{tabular}

Source: Add Health restricted-use data. Includes school fixed effects. The estimation sample in Column 1 consists of all of the pairwise combinations of students within a given cohort, which is derived from the school survey of all students. The in school sample is larger than our main analytic sample (Column 2) because because not all students surveyed in school were selected for the in home survey, which included additional survey questions. To make estimates comparable, we limit covariates to variables that can be constructed from questions in the school survey. Controls include sender and receiver covariates (female, age, white, yrs at school, and peer means of these measures. Pairwise distance variables are constructed by taking the absolute value of the distance between student $\mathrm{i}$ (sender) and student $\mathrm{j}$ (receiver). Variables labeled as total distance (receiver) sum up the pairwise distances over the receiver (j). Variables labeled as total distance (sender) sum up the pairwise distances over the sender (i)

Standard errors are clustered at the school level.

${ }^{*} p<.1,{ }^{* *} p<0.05,{ }^{* * *} p<0.01$ 
Table A.4: First Stage Estimates

\begin{tabular}{|c|c|c|c|c|}
\hline & $\begin{array}{c}(1) \\
\text { Schooling }\end{array}$ & $\begin{array}{c}(2) \\
\text { GPA }\end{array}$ & $\begin{array}{c}(3) \\
\text { In-deg }\end{array}$ & $\begin{array}{c}(4) \\
\text { In-grade }\end{array}$ \\
\hline \multirow[t]{2}{*}{ IQ } & $0.033^{* * *}$ & $0.011^{* * *}$ & 0.004 & $0.007^{* * *}$ \\
\hline & {$[0.002]$} & {$[0.001]$} & {$[0.003]$} & {$[0.002]$} \\
\hline \multirow[t]{2}{*}{ Extrovert } & 0.001 & -0.019 & $0.582^{* * *}$ & $0.434^{* * *}$ \\
\hline & {$[0.044]$} & {$[0.017]$} & {$[0.091]$} & {$[0.081]$} \\
\hline \multirow[t]{2}{*}{ Total Female Distance } & $0.003^{* * *}$ & -0.000 & $0.008^{* * *}$ & $0.008^{* * *}$ \\
\hline & {$[0.001]$} & {$[0.001]$} & {$[0.002]$} & {$[0.002]$} \\
\hline \multirow[t]{2}{*}{ Total White Distance } & -0.000 & 0.000 & $-0.002^{* * *}$ & $-0.001^{* * *}$ \\
\hline & {$[0.000]$} & {$[0.000]$} & {$[0.000]$} & {$[0.000]$} \\
\hline \multirow[t]{2}{*}{ Total Yrs at School Distance } & -0.000 & -0.000 & $-0.001^{* * *}$ & $-0.001^{* * *}$ \\
\hline & {$[0.000]$} & {$[0.000]$} & {$[0.000]$} & {$[0.000]$} \\
\hline \multirow[t]{2}{*}{ Total Age Distance } & $-0.001^{* * *}$ & -0.000 & $-0.001^{*}$ & $-0.001^{* *}$ \\
\hline & {$[0.000]$} & {$[0.000]$} & {$[0.000]$} & {$[0.000]$} \\
\hline \multirow{2}{*}{ Total Mother's Edu Distance } & $-0.000^{* * *}$ & -0.000 & 0.000 & 0.000 \\
\hline & {$[0.000]$} & {$[0.000]$} & {$[0.000]$} & {$[0.000]$} \\
\hline \multirow[t]{2}{*}{ Total Father in HH Distance } & $-0.001^{* * *}$ & -0.000 & $-0.002^{* *}$ & $-0.002^{*}$ \\
\hline & [0.000] & {$[0.000]$} & {$[0.001]$} & {$[0.001]$} \\
\hline \multirow[t]{2}{*}{ Total Physical Maturity Distance } & $-0.001^{* * *}$ & $-0.000^{* * *}$ & 0.000 & 0.000 \\
\hline & {$[0.000]$} & {$[0.000]$} & {$[0.000]$} & {$[0.000]$} \\
\hline \multirow[t]{2}{*}{ White-Teacher Distance } & -0.175 & $-0.217^{* * *}$ & -0.139 & $-0.251^{*}$ \\
\hline & {$[0.115]$} & [0.043] & {$[0.155]$} & {$[0.138]$} \\
\hline \multirow[t]{2}{*}{ Grade Cohort Size } & 0.000 & -0.000 & -0.002 & -0.002 \\
\hline & {$[0.001]$} & [0.001] & {$[0.002]$} & {$[0.002]$} \\
\hline \multirow{2}{*}{ Mean Extroverted } & -0.037 & 0.017 & $0.682^{*}$ & 0.471 \\
\hline & {$[0.147]$} & {$[0.124]$} & {$[0.347]$} & {$[0.316]$} \\
\hline \multirow[t]{2}{*}{ Mean IQ } & 0.003 & 0.004 & 0.019 & 0.017 \\
\hline & {$[0.010]$} & {$[0.005]$} & {$[0.017]$} & {$[0.015]$} \\
\hline \multirow[t]{2}{*}{ Fraction White } & $-0.884^{*}$ & -0.004 & 0.541 & -0.105 \\
\hline & {$[0.488]$} & {$[0.259]$} & {$[1.065]$} & {$[0.992]$} \\
\hline \multirow[t]{2}{*}{ Fraction Female } & $-0.793^{*}$ & -0.093 & 0.548 & $1.384^{*}$ \\
\hline & {$[0.471]$} & {$[0.251]$} & {$[0.893]$} & {$[0.811]$} \\
\hline \multirow[t]{2}{*}{ Mean Age } & $0.582^{* * *}$ & $0.105^{* * *}$ & $0.311^{* * *}$ & 0.051 \\
\hline & {$[0.061]$} & {$[0.029]$} & {$[0.111]$} & {$[0.097]$} \\
\hline \multirow[t]{2}{*}{ Mean Yrs at School } & -0.025 & -0.031 & -0.079 & -0.077 \\
\hline & {$[0.051]$} & [0.033] & {$[0.124]$} & {$[0.110]$} \\
\hline \multirow[t]{2}{*}{ Fraction Food Stamp Recipient } & $-0.773^{* *}$ & -0.289 & 1.086 & 0.491 \\
\hline & {$[0.348]$} & {$[0.216]$} & {$[0.861]$} & {$[0.777]$} \\
\hline \multirow[t]{2}{*}{ Mean HH Income } & 0.001 & -0.001 & 0.001 & 0.001 \\
\hline & {$[0.001]$} & {$[0.001]$} & {$[0.002]$} & {$[0.002]$} \\
\hline \multirow[t]{2}{*}{ Fraction Father Present } & 0.304 & -0.159 & -1.066 & -0.762 \\
\hline & {$[0.524]$} & {$[0.285]$} & [1.251] & {$[1.043]$} \\
\hline \multirow[t]{2}{*}{ Mean Mother's Education } & $0.215^{* * *}$ & 0.019 & 0.089 & 0.169 \\
\hline & {$[0.071]$} & {$[0.049]$} & {$[0.158]$} & {$[0.138]$} \\
\hline \multirow[t]{2}{*}{ Mean Physical Development } & -0.022 & $-0.153^{* *}$ & -0.076 & -0.310 \\
\hline & [0.105] & {$[0.068]$} & {$[0.263]$} & {$[0.250]$} \\
\hline Mean of Dep. Var. & 14.80 & 2.84 & 4.47 & 3.45 \\
\hline $\mathrm{N}$ & 9,148 & 6,297 & 9,148 & 9,148 \\
\hline F stat of Instruments & 9.83 & 6.42 & 14.68 & 17.30 \\
\hline $\mathrm{P}$-value & 0.000 & 0.000 & 0.000 & 0.000 \\
\hline
\end{tabular}

Source: Add Health restricted-use data. W1 stands for Wave I, etc. Includes school fixed effects. Individual controls include age, years at school, household income, mother's education, height, weight, physical development, and indicators for whether the student is white, female, and father is present in the household. Standard errors ar£dlustered at the school level.

${ }^{*} p<0.10,{ }^{* *} p<0.05,{ }^{* * *} p<0.01$ 
Table A.5: Variance Covariance Matrix of Network Measures

In Degree In Degree

(within-grade)
High Engagement Nominations

(within-grade)

In Degree $\quad 11.60$

In Degree (within-grade) 8.99

High Engagement Nominations (within-grade) $\quad 3.16$

8.28

2.33

1.94

Note: This table presents the variance covariance matrix of residualized in-degree, in-degree (within grade), and within grade in degree (restricting to high engagement nominations). 
Table A.6: Adult Social Capital on In Degree

\begin{tabular}{lccccc}
\hline & $(1)$ & $(2)$ & $(3)$ & $(4)$ & $(5)$ \\
& Extraversion(W4) & Friends(W4) & Depress(W4) & Ever Marry(W4) & Work(W4) \\
\hline Years of schooling & $0.0319^{*}$ & $0.1744^{* * *}$ & $-0.1453^{* * *}$ & 0.0021 & $0.0117^{* * *}$ \\
& {$[0.0180]$} & {$[0.0197]$} & {$[0.0170]$} & {$[0.0028]$} & {$[0.0017]$} \\
In Degree & $0.0804^{* * *}$ & $0.0494^{* * *}$ & 0.0059 & 0.0025 & 0.0010 \\
& {$[0.0089]$} & {$[0.0093]$} & {$[0.0070]$} & {$[0.0015]$} & {$[0.0007]$} \\
IQ & $-0.0090^{* *}$ & $0.0051^{* *}$ & $-0.0052^{* *}$ & $-0.0010^{* *}$ & 0.0002 \\
& {$[0.0037]$} & {$[0.0025]$} & {$[0.0020]$} & {$[0.0004]$} & {$[0.0002]$} \\
Extrovert & $1.3863^{* * *}$ & $0.1165^{*}$ & $-0.1640^{* *}$ & 0.0205 & -0.0067 \\
& {$[0.0760]$} & {$[0.0664]$} & {$[0.0696]$} & {$[0.0134]$} & {$[0.0058]$} \\
\hline Mean of Dep. Var. & 13.26 & 4.76 & 2.47 & 0.50 & 0.93 \\
R-squared & 0.06 & 0.05 & 0.04 & 0.04 & 0.03 \\
N & 9,141 & 9,037 & 9,148 & 9,143 & 9,823 \\
\hline
\end{tabular}

Source: Add Health restricted-use data. Includes school fixed effects. Extraversion and the CESD

Depression scores are variables constructed by ADD Health. Adult Friendships refers to the number of reported friends in Wave 4. Additional controls include age, years at school, household income, mother's education, height, weight, physical development, and indicators for whether the student is white, female, and father is present in the household. Cohort level controls include mean extrovert, mean IQ, mean age, mean years at school, mean HH income, mean mother's schooling, fraction female, fraction live withfather, and fraction food stamp recipients. Standard errors are clustered at the school level.

${ }^{*} p<.1,{ }^{* *} p<0.05,{ }^{* * *} p<0.01$ 


\section{Appendix 1: Equilibrium}

There may be multiple equilibria in (11), but if we can show that (11) is a contraction mapping, then there is a unique equilibrium. In particular, suppose the function $g_{s}$ takes a partial linear form

$$
\begin{aligned}
& g_{s}\left(r_{e} a_{i}(X)-r_{s} \sum_{j \neq i} p_{j i}(X) \mathbb{E}\left[S_{j} \mid X\right], X_{i}, v_{i}\right) \\
= & r_{e} a_{i}(X)-r_{s} \sum_{j \neq i} p_{j i}(X) \mathbb{E}\left[S_{j} \mid X\right]+u\left(X_{i}\right)+v_{i}
\end{aligned}
$$

Define the $n \times n$ matrix $p(X)$ by

$$
p(X)=\left[\begin{array}{cccc}
0 & p_{21}(X) & \cdots & p_{n 1}(X) \\
p_{12}(X) & 0 & \cdots & p_{n 2}(X) \\
\vdots & \vdots & \ddots & \vdots \\
p_{1 n}(X) & p_{2 n}(X) & \cdots & 0
\end{array}\right]
$$

Assume $\left|r_{s} \lambda_{\max }(p(X))\right|<1$, where $\lambda_{\max }(p(X))$ is the largest eigenvalue of the matrix $p(X)$. Then (11) has a unique equilibrium.

\section{Appendix 2: Empirical Implications}

\section{Proof of Proposition 1 (individual characteristics)}

Proof. Part (1): We first examine the effect of $X_{i}$ on socializing and in-degree. Recall that in equilibrium the optimal socializing $S_{i}^{*}$ satisfies the first-order condition

$$
\frac{\partial V_{s}}{\partial S_{i}}\left(S_{i}^{*}, X_{i}, v_{i}\right)=r_{e} a_{i}(X)-r_{s} \sum_{j \neq i} p_{j i}(X) \mathbb{E}\left[S_{j}^{*} \mid X\right]
$$

Take the derivative of both sides with respect to $X_{i}$

$$
\begin{aligned}
& \frac{\partial^{2} V_{s}}{\partial S_{i}^{2}}\left(S_{i}^{*}, X_{i}, v_{i}\right) \frac{\partial S_{i}^{*}}{\partial X_{i}}+\frac{\partial^{2} V_{s}}{\partial S_{i} \partial X_{i}}\left(S_{i}^{*}, X_{i}, v_{i}\right) \\
= & r_{e} \frac{\partial a_{i}}{\partial X_{i}}(X)-r_{s} \sum_{j \neq i} \frac{\partial p_{j i}}{\partial X_{i}}(X) \mathbb{E}\left[S_{j}^{*} \mid X\right]-r_{s} \sum_{j \neq i} p_{j i}(X) \frac{\partial \mathbb{E}\left[S_{j}^{*} \mid X\right]}{\partial X_{i}}
\end{aligned}
$$


from which we can derive

$$
\begin{array}{r}
\frac{\partial S_{i}^{*}}{\partial X_{i}}=-\left(\frac{\partial^{2} V_{s}}{\partial S_{i}^{2}}\left(S_{i}^{*}, X_{i}, v_{i}\right)\right)^{-1} \cdot\left(\frac{\partial^{2} V_{s}}{\partial S_{i} \partial X_{i}}\left(S_{i}^{*}, X_{i}, v_{i}\right)-r_{e} \frac{\partial a_{i}}{\partial X_{i}}(X)\right. \\
\left.+r_{s} \sum_{j \neq i} \frac{\partial p_{j i}}{\partial X_{i}}(X) \mathbb{E}\left[S_{j}^{*} \mid X\right]+r_{s} \sum_{j \neq i} p_{j i}(X) \frac{\partial \mathbb{E}\left[S_{j}^{*} \mid X\right]}{\partial X_{i}}\right)
\end{array}
$$

By assumption $\frac{\partial^{2} V_{s}}{\partial S_{i}^{2}}\left(S_{i}^{*}, X_{i}, v_{i}\right)<0$, so the sign of $\frac{\partial S_{i}^{*}}{\partial X_{i}}$ is given by the sign of

$$
\frac{\partial^{2} V_{s}}{\partial S_{i} \partial X_{i}}\left(S_{i}^{*}, X_{i}, v_{i}\right)-r_{e} \frac{\partial a_{i}}{\partial X_{i}}(X)+r_{s} \sum_{j \neq i} \frac{\partial p_{j i}}{\partial X_{i}}(X) \mathbb{E}\left[S_{j}^{*} \mid X\right]+r_{s} \sum_{j \neq i} p_{j i}(X) \frac{\partial \mathbb{E}\left[S_{j}^{*} \mid X\right]}{\partial X_{i}}
$$

In other words, this means that the sign of $\frac{\partial S_{i}^{*}}{\partial X_{i}}$ will depend on how $X_{i}$ affects the marginal enjoyment of socializing $\frac{\partial^{2} V_{s}}{\partial S_{i} \partial X_{i}}\left(S_{i}^{*}, X_{i}, v_{i}\right)$, the marginal productivity of studying $r_{e} \frac{\partial a_{i}}{\partial X_{i}}(X)$, the marginal productivity of time spent socializing $r_{s} \sum_{j \neq i} \frac{\partial p_{j i}}{\partial X_{i}}(X) \mathbb{E}\left[S_{j}^{*} \mid X\right]$, and any equilibrium changes in socializing $r_{s} \sum_{j \neq i} p_{j i}(X) \frac{\partial \mathbb{E}\left[S_{j}^{*} \mid X\right]}{\partial X_{i}}$. Without further assumptions, we do not know the signs of these terms, nor their relative magnitude, so the sign of $\frac{\partial S_{i}^{*}}{\partial X_{i}}$ is in general ambiguous: we have no clear prediction about how the optimal socializing changes in $X_{i}$.

For the effect of $X_{i}$ on in-degree $D_{i}$, by (4) $D_{i}$ satisfies

$$
\mathbb{E}\left(D_{i} \mid H_{j}, H_{i}, S_{j}, S_{i}, X, v_{i}, \eta_{i}\right)=\sum_{j \neq i} p_{j i}(X) S_{j}^{*} S_{i}^{*}
$$

Taking the derivative with respect to $X_{i}$ we get

$\frac{\partial \mathbb{E}\left(D_{i} \mid H_{j}, H_{i}, S_{j}, S_{i}, X, v_{i}, \eta_{i}\right)}{\partial X_{i}}=\sum_{j \neq i} \frac{\partial p_{j i}}{\partial X_{i}}(X) S_{j}^{*} S_{i}^{*}+\sum_{j \neq i} p_{j i}(X) \frac{\partial S_{j}^{*}}{\partial X_{i}} S_{i}^{*}+\sum_{j \neq i} p_{j i}(X) S_{j}^{*} \frac{\partial S_{i}^{*}}{\partial X_{i}}$

In other words, the effect of $X_{i}$ on the expected in-degree will depend on how $X_{i}$ affects the the marginal productivity of time spent socializing $\left(\sum_{j \neq i} \frac{\partial p_{j i}}{\partial X_{i}}(X) S_{j}^{*} S_{i}^{*}\right)$ and the optimal socializing decisions of $i\left(\sum_{j \neq i} p_{j i}(X) S_{j}^{*} \frac{\partial S_{i}^{*}}{\partial X_{i}}\right)$ and others $\left(\sum_{j \neq i} p_{j i}(X) \frac{\partial S_{j}^{*}}{\partial X_{i}} S_{i}^{*}\right)$. From the discussion above, we don't know the sign of $\frac{\partial S_{i}^{*}}{\partial X_{i}}$. The effects of $X_{i}$ on $p_{j i}(X)$ and $S_{j}^{*}$ are also ambiguous. We conclude that the effect of $X_{i}$ on the expected in-degree is ambiguous.

Part (2): Similarly, we can examine the effect of $X_{i}$ on studying and education. Because the optimal studying is given by $H_{i}^{*}=1-S_{i}^{*}-L_{i}^{*}$, we only need to consider the effect of $X_{i}$ on the optimal leisure $L_{i}^{*}$. Recall that the optimal leisure $L_{i}^{*}$ satisfies the first-order 
condition in (6)

$$
\frac{\partial V_{l}}{\partial L_{i}}\left(L_{i}^{*}, X_{i}, \eta_{i}\right)=r_{e} a_{i}(X)
$$

Take the first derivative of both sides with respect to $X_{i}$

$$
\frac{\partial^{2} V_{l}}{\partial L_{i}^{2}}\left(L_{i}^{*}, X_{i}, \eta_{i}\right) \frac{\partial L_{i}^{*}}{\partial X_{i}}+\frac{\partial^{2} V_{l}}{\partial L_{i} \partial X_{i}}\left(L_{i}^{*}, X_{i}, \eta_{i}\right)=r_{e} \frac{\partial a_{i}}{\partial X_{i}}(X)
$$

from which we derive

$$
\frac{\partial L_{i}^{*}}{\partial X_{i}}=-\left(\frac{\partial^{2} V_{l}}{\partial L_{i}^{2}}\left(L_{i}^{*}, X_{i}, \eta_{i}\right)\right)^{-1}\left(\frac{\partial^{2} V_{l}}{\partial L_{i} \partial X_{i}}\left(L_{i}^{*}, X_{i}, \eta_{i}\right)-r_{e} \frac{\partial a_{i}}{\partial X_{i}}(X)\right)
$$

Because $\frac{\partial^{2} V_{l}}{\partial L_{i}^{2}}\left(L_{i}^{*}, X_{i}, \eta_{i}\right)<0$ by assumption, the sign of $\frac{\partial L_{i}^{*}}{\partial X_{i}}$ is given by the sign of

$$
\frac{\partial^{2} V_{l}}{\partial L_{i} \partial X_{i}}\left(L_{i}^{*}, X_{i}, \eta_{i}\right)-r_{e} \frac{\partial a_{i}}{\partial X_{i}}(X)
$$

Without further assumptions, we do not know how $X_{i}$ affects the marginal enjoyment of leisure $\frac{\partial^{2} V_{l}}{\partial L_{i} \partial X_{i}}\left(L_{i}^{*}, X_{i}, \eta_{i}\right)$, nor the marginal productivity of studying $r_{e} \frac{\partial a_{i}}{\partial X_{i}}(X)$. so the effect of $X_{i}$ on the optimal leisure is ambiguous. Combining with the ambiguous effect of $X_{i}$ on the optimal socializing $S_{i}^{*}$, we conclude that the effect of $X_{i}$ on the optimal studying $H_{i}^{*}$ is ambiguous as well.

For the effect of $X_{i}$ on education $E_{i}$, by (3) $E_{i}$ satisfies

$$
\mathbb{E}\left[E_{i} \mid H_{i}, S_{i}, X, v_{i}, \eta_{i}\right]=a_{i}(X) H_{i}^{*}
$$

Take the derivative with respect to $X_{i}$

$$
\frac{\partial \mathbb{E}\left[E_{i} \mid H_{i}, S_{i}, X, v_{i}, \eta_{i}\right]}{\partial X_{i}}=\frac{\partial a_{i}}{\partial X_{i}}(X) H_{i}^{*}+a_{i}(X) \frac{\partial H_{i}^{*}}{\partial X_{i}}
$$

This implies that the effect of $X_{i}$ on the expected education will depend on how $X_{i}$ affects the marginal productivity of studying $\frac{\partial a_{i}}{\partial X_{i}}(X) H_{i}^{*}$ and the optimal amount of studying $a_{i}(X) \frac{\partial H_{i}^{*}}{\partial X_{i}}$. Because the latter effect is ambiguous, we have no clear prediction how $X_{i}$ affects the expected education. The proof is complete.

Discussion: the effects of IQ and extroversion on socializing, studying, and their outcomes in-degree and education.

(1) The effects of IQ and extroversion on socializing and in-degree. With some additional assumptions, we can speculate on the roles of IQ and extroversion on so- 
cializing. For simplicity, suppose that the equilibrium effect $r_{s} \sum_{j \neq i} p_{j i}(X) \frac{\partial \mathbb{E}\left[S_{j}^{*} \mid X\right]}{\partial X_{i}}$ is relatively small compared with the other effects of $X_{i}$. For IQ, it is reasonable to assume that $\frac{\partial a_{i}}{\partial X_{i}}(X)>0$ i.e., higher IQ students are more efficient in studying relative to lower IQ students. If we assume that intelligence has no effect on the marginal enjoyment of socializing $\left(\frac{\partial^{2} V_{s}}{\partial S_{i} \partial X_{i}}\left(S_{i}^{*}, X_{i}, v_{i}\right)=0\right)$ and no effect on the marginal productivity of time spent socializing $\left(\sum_{j \neq i} \frac{\partial p_{j i}}{\partial X_{i}}(X) \mathbb{E}\left[S_{j}^{*} \mid X\right]=0\right)$, then time spent socializing would be decreasing in intelligence. This negative effect would be reinforced if we were to assume that higher IQ individuals derive less enjoyment from socializing $\left(\frac{\partial^{2} V_{s}}{\partial S_{i} \partial X_{i}}\left(S_{i}^{*}, X_{i}, v_{i}\right)<0\right)$ or are less productive in socializing $\left(\sum_{j \neq i} \frac{\partial p_{j i}}{\partial X_{i}}(X) \mathbb{E}\left[S_{j}^{*} \mid X\right]<0\right)$. This would be consistent with the idea of the "nerdy" students who are not popular and prefer to spend their time studying.

However, socializing could be increasing in intelligence if either the marginal enjoyment of socializing or the marginal productivity of socializing is increasing in intelligence (for example high IQ is attractive trait in friendships). The sign of $\frac{\partial S_{i}^{*}}{\partial X_{i}}$ would then depend on the relative efficiency in studying vs socializing. If $\frac{\partial^{2} V_{s}}{\partial S_{i} \partial X_{i}}\left(S_{i}^{*}, X_{i}, v_{i}\right)+r_{s} \sum_{j \neq i} \frac{\partial p_{j i}}{\partial X_{i}}(X) \mathbb{E}\left[S_{j}^{*} \mid X\right]>$ $r_{e} \frac{\partial a_{i}}{\partial X_{i}}(X)$, i.e., the student is more productive in socializing, then socializing would be increasing in intelligence.

The effect of extroversion on socializing is less ambiguous. To evaluate the effect of being an extrovert on socializing, we can assume that an individual's level of extroversion does not affect their studying productivity $\left(\frac{\partial a_{i}}{\partial X_{i}}(X)=0\right)$. On the other hand, being an extrovert is likely to increase the marginal enjoyment of socializing $\left(\frac{\partial^{2} V_{s}}{\partial S_{i} \partial X_{i}}\left(S_{i}^{*}, X_{i}, v_{i}\right)>0\right)$ and the productivity of socializing $\left(\sum_{j \neq i} \frac{\partial p_{j i}}{\partial X_{i}}(X) \mathbb{E}\left[S_{j}^{*} \mid X\right]>0\right)$. Socializing would then be unambiguously increasing in extroversion.

To further speculate on the effects of IQ and extroversion on in-degree, we assume that the spillover effects of $i$ 's IQ and extroversion on the socializing decisions of others $\sum_{j \neq i} p_{j i}(X) \frac{\partial S_{j}^{*}}{\partial X_{i}} S_{i}^{*}$ are relatively small compared to the other effects. If we assume that intelligence has no effect on the marginal productivity of socializing $\left(\sum_{j \neq i} \frac{\partial p_{j i}}{\partial X_{i}}(X) S_{j}^{*} S_{i}^{*}=0\right)$, then whether the expected in-degree is increasing in intelligence or not is determiend by whether the optimal socializing is increasing in intelligence or not $\left(\frac{\partial S_{i}^{*}}{\partial X_{i}}\right)$.

For extroversion, we can assume that being extrovert increases the productivity of socializing $\left(\sum_{j \neq i} \frac{\partial p_{j i}}{\partial X_{i}}(X) S_{j}^{*} S_{i}^{*}>0\right)$. Under the previous assumptions, the optimal socializing is unambiguously increasing in extroversion, so the expected in-degree is also increasing in extroversion.

(2) The effects of IQ and extroversion on studying and education. To investigate the effects of IQ and extroversion on studying, we first investigate their effects on leisure. For IQ, we can assume that individuals' level of intelligence increases their studying productivity $\left(\frac{\partial a_{i}}{\partial X_{i}}(X)>0\right)$, but does not affect their marginal utility from leisure $\left(\frac{\partial^{2} V_{l}}{\partial L_{i} \partial X_{i}}\left(L_{i}^{*}, X_{i}, \eta_{i}\right)=0\right)$. 
Leisure would then be decreasing in intelligence: smarter students spend less time on leisure activities $\left(\frac{\partial L_{i}^{*}}{\partial X_{i}}>0\right)$.

For extroversion, it is reasonable to assume that the level of extroversion does not affect studying productivity $\left(\frac{\partial a_{i}}{\partial X_{i}}(X)=0\right)$ nor marginal utility from leisure $\left(\frac{\partial^{2} V_{l}}{\partial L_{i} \partial X_{i}}\left(L_{i}^{*}, X_{i}, \eta_{i}\right)=\right.$ $0)$, so extrovert students have the same level of leisure as other students $\left(\frac{\partial L_{i}^{*}}{\partial X_{i}}=0\right)$. extroversion has no effect on the leisure decision.

Combining the effects of IQ and extroversion on socializing and leisure, we can infer their effects on studying. For the effect of IQ on studying, smarter students spend less time on leisure, but whether they study more depend on how their socializing decisions change in intelligence. If socializing is decreasing in intelligence, then smarter students definitely spend more time studying. On the contrary, if socializing is increasing in intelligence, whether smarter students reduce the time spent studying depends on whether the increase in their time spent socializing is large enough so that it exceeds the reduction in leisure time.

For the effect of extroversion on studying, because extrovert students socialize more while they have the same amount of leisure as other students, they spend less time on studying.

Lastly, we consider the effects of IQ and extroversion on education. For IQ, we can assume that the studying productivity increases in intelligence $\left(\frac{\partial a_{i}}{\partial X_{i}}(X)>0\right)$. If the optimal studying is also increasing in intelligence $\left(\frac{\partial H_{i}^{*}}{\partial X_{i}}>0\right)$, then smarter students generally have higher level of education. On the other hand, if the optimal studying is decreasing in intelligence $\left(\frac{\partial H_{i}^{*}}{\partial X_{i}}<0\right)$ because smarter students are relatively more productive in socializing than studying, then the level of education could increase more slowly in intelligence or even decrease in intelligence.

For the effect of extroversion on education, if we assume that extroversion has no effect on the studying productivity $\left(\frac{\partial a_{i}}{\partial X_{i}}(X)=0\right)$, then more extrovert students have lower level of education because they spend less time studying $\left(\frac{\partial H_{i}^{*}}{\partial X_{i}}<0\right)$.

To sum up, the predictions for extrovert students are clearer: they spend more time socializing and less time studying. Consequently, they have more social capital and less education. The effects of IQ is more ambiguous. Smarter students could study more and socialize less, or study less and socialize more, depending on their relative productivity in studying and socializing. But they always have less leisure. Smarter students in general have higher level of education, but this is not always true. They also have more social capital if they socialize more and less social capital if they socialize less. 


\section{Proof of Proposition 2 (homophily measures)}

Proof. Part (1): First we examine the effect of homophily measures on socializing and indegree. From (12) the optimal socializing is given by

$$
S_{i}^{*}=g_{s}\left(r_{e} a_{i}(X)-r_{s} \sum_{j \neq i} p_{j i}(X) \mathbb{E}\left[S_{j}^{*} \mid X\right], X_{i}, v_{i}\right)
$$

where $g_{s}$ is decreasing in the first argument. Let $d_{j i}=\left|X_{j}-X_{i}\right|$ be the social distance between $j$ and $i$. It is reasonable to assume that the productivity of socializing is decreasing in social distance $\left(\frac{\partial p_{j i}}{\partial d_{j i}}(X)<0\right)$ due to the homophily effect. For simplicity, we also assume that $p_{j i}(X)$ depends on $X$ only through the social distance $d_{j i}$ and the receiver $i$ 's characteristics $X_{i}$.

We consider the effect on $i$ 's socializing decision when we change her social distance to another student $j$ via changing $j$ 's characteristics $X_{j}$. For any $j \neq i$, take the derivative of both sides of (19) with respective to $d_{j i}$, assuming that $X_{i}$ is fixed while $X_{j}$ varies

$$
\begin{aligned}
\frac{\partial S_{i}^{*}}{\partial d_{j i}}= & \partial_{1} g_{s}\left(r_{e} a_{i}(X)-r_{s} \sum_{j \neq i} p_{j i}(X) \mathbb{E}\left[S_{j}^{*} \mid X\right], X_{i}, v_{i}\right) \\
& \cdot\left(r_{e} \frac{\partial a_{i}}{\partial d_{j i}}(X)-r_{s} \frac{\partial p_{j i}}{\partial d_{j i}}(X) \mathbb{E}\left[S_{j}^{*} \mid X\right]\right. \\
& \left.-r_{s} p_{j i}(X) \frac{\partial \mathbb{E}\left[S_{j}^{*} \mid X\right]}{\partial d_{j i}}-r_{s} \sum_{k \neq i, j} p_{k i}(X) \frac{\partial \mathbb{E}\left[S_{k}^{*} \mid X\right]}{\partial d_{j i}}\right),
\end{aligned}
$$

where $\partial_{1} g_{s}$ is the derivative of $g_{s}$ with respect to the first argument. Here we have used the assumption that changing the social distance between $j$ and $i$ (by varying $X_{j}$ ) has no effect on the socializing productivity of $k$ and $i\left(\frac{\partial p_{k i}}{\partial d_{j i}}(X)=0\right)$. Because $\partial_{1} g_{s}\left(\cdot, X_{i}, v_{i}\right)<0$ by assumption, the sign of $\frac{\partial S_{i}^{*}}{\partial d_{j i}}$ is determined by the sign of

$$
-r_{e} \frac{\partial a_{i}}{\partial d_{j i}}(X)+r_{s} \frac{\partial p_{j i}}{\partial d_{j i}}(X) \mathbb{E}\left[S_{j}^{*} \mid X\right]+r_{s} p_{j i}(X) \frac{\partial \mathbb{E}\left[S_{j}^{*} \mid X\right]}{\partial d_{j i}}+r_{s} \sum_{k \neq i, j} p_{k i}(X) \frac{\partial \mathbb{E}\left[S_{k}^{*} \mid X\right]}{\partial d_{j i}}
$$

We can see that the effect of $d_{j i}$ on $S_{i}^{*}$ depends on how $d_{j i}$ affects the studying productivity of $i\left(r_{e} \frac{\partial a_{i}}{\partial d_{j i}}(X)\right)$, the socializing productivity of $j$ and $i\left(r_{s} \frac{\partial p_{j i}}{\partial d_{j i}}(X) \mathbb{E}\left[S_{j}^{*} \mid X\right]\right)$, and the expected amounts of socializing of $j\left(r_{s} p_{j i}(X) \frac{\partial \mathbb{E}\left[S_{j}^{*} \mid X\right]}{\partial d_{j i}}\right)$ and others $\left(r_{s} \sum_{k \neq i, j} p_{k i}(X) \frac{\partial \mathbb{E}\left[S_{k}^{*} \mid X\right]}{\partial d_{j i}}\right)$ in equilibrium.

To speculate on the sign of $\frac{\partial S_{i}^{*}}{\partial d_{j i}}$, we need to impose further assumptions about the terms 
in (20). While the social distance between $j$ and $i$ may affect the studying productivity of $i$, because this change occurs through a varying $X_{j}$ we can assume that the effect is negligible $\left(\frac{\partial a_{i}}{\partial d_{j i}}(X)=0\right)$. Recall that the socializing productivity of $j$ and $i$ is decreasing in their social distance $\left(\frac{\partial p_{j i}}{\partial d_{j i}}(X)<0\right)$. Without taking into account the equilibrium effects (the last two terms in (20)), the first two terms in (20) tend to suggest that the time $i$ spends socializing is decreasing in her social distance to $j\left(\frac{\partial S_{i}^{*}}{\partial d_{j i}}<0\right)$.

Next we investigate the equilibrium effects. From (19) the expected time $j$ spends socializing is

$$
\mathbb{E}\left[S_{j}^{*} \mid X\right]=\mathbb{E}\left[g_{s}\left(r_{e} a_{j}(X)-r_{s} \sum_{k \neq j} p_{k j}(X) \mathbb{E}\left[S_{k}^{*} \mid X\right], X_{j}, v_{j}\right) \mid X\right]
$$

Take the derivative with respect to $d_{j i}$ (assuming that $X_{j}$ varies and $X_{i}$ is fixed)

$$
\begin{aligned}
\frac{\partial \mathbb{E}\left[S_{j}^{*} \mid X\right]}{\partial d_{j i}}= & \mathbb{E}\left[\partial_{1} g_{s}\left(r_{e} a_{j}(X)-r_{s} \sum_{k \neq j} p_{k j}(X) \mathbb{E}\left[S_{k}^{*} \mid X\right], X_{j}, v_{j}\right) \mid X\right] \\
& \cdot\left(r_{e} \frac{\partial a_{j}}{\partial d_{j i}}(X)-r_{s} \sum_{k \neq j} \frac{\partial p_{k j}}{\partial d_{j i}}(X) \mathbb{E}\left[S_{k}^{*} \mid X\right]-r_{s} \sum_{k \neq j} p_{k j}(X) \frac{\partial \mathbb{E}\left[S_{k}^{*} \mid X\right]}{\partial d_{j i}}\right) \\
& +\mathbb{E}\left[\partial_{2} g_{s}\left(r_{e} a_{j}(X)-r_{s} \sum_{k \neq j} p_{k j}(X) \mathbb{E}\left[S_{k}^{*} \mid X\right], X_{j}, v_{j}\right) \mid X\right] \cdot \frac{\partial X_{j}}{\partial d_{j i}}
\end{aligned}
$$

where $\partial_{2} g_{s}$ is the derivative of $g_{s}$ with respect to the second argument. We can see that the effect of $d_{j i}$ on $\mathbb{E}\left[S_{j}^{*} \mid X\right]$ is in general ambiguous because if we change the distance $d_{j i}$ by changing $j$ 's characteristics $X_{j}$, then this will affect $j$ 's studying productivity $\left(\frac{\partial a_{j}}{\partial d_{j i}}(X) \neq 0\right)$ and socializing preference $\left(\partial_{2} g_{s} \neq 0\right)$ in addition to the effects on $j$ 's socializing productivity with others $\left(r_{s} \sum_{k \neq j} \frac{\partial p_{k j}}{\partial d_{j i}}(X) \mathbb{E}\left[S_{k}^{*} \mid X\right]\right)$ and the equilibrium socializing decisions of others $\left(r_{s} \sum_{k \neq j} p_{k j}(X) \frac{\partial \mathbb{E}\left[S_{k}^{*} \mid X\right]}{\partial d_{j i}}\right)$. Note that the former two effects are first order and cannot be neglected. These effects are also ambiguous because they depend on which individual characteristic in $X_{j}$ we shift when changing the distance $d_{j i}$. It is also hard to predict the effect of the social distance between $j$ and $i$ on the socializing productivity between $k$ and $j\left(\frac{\partial p_{k j}}{\partial d_{j i}}(X)\right)$ because when we change the characteristics of $j$ it is unclear how the social distance between $k$ and $j$ will change accordingly: it will depend on the characteristics of $k$. Without further information about these effects, the effect of $d_{j i}$ on $j$ 's expected time spent socializing $\left(\frac{\partial \mathbb{E}\left[S_{j}^{*} \mid X\right]}{\partial d_{j i}}\right)$ is ambiguous.

The effect of $d_{j i}$ on another student $k$ 's expected socializing $\left(\frac{\partial \mathbb{E}\left[S_{k}^{*} \mid X\right]}{\partial d_{j i}}\right)$ is also ambiguous. 
This is because for any $k \neq i, j, \mathbb{E}\left[S_{k}^{*} \mid X\right]$ is given by

$$
\mathbb{E}\left[S_{k}^{*} \mid X\right]=\mathbb{E}\left[g_{s}\left(r_{e} a_{k}(X)-r_{s} \sum_{l \neq k} p_{l k}(X) \mathbb{E}\left[S_{l}^{*} \mid X\right], X_{k}, v_{k}\right) \mid X\right]
$$

Take the derivative with respect to $d_{j i}$ (assuming again that $X_{j}$ varies and $X_{i}$ is fixed)

$$
\begin{aligned}
\frac{\partial \mathbb{E}\left[S_{k}^{*} \mid X\right]}{\partial d_{j i}}= & \mathbb{E}\left[\partial_{1} g_{s}\left(r_{e} a_{k}(X)-r_{s} \sum_{l \neq k} p_{l k}(X) \mathbb{E}\left[S_{l}^{*} \mid X\right], X_{k}, v_{k}\right) \mid X\right] \\
& \cdot\left(-r_{s} \frac{\partial p_{j k}}{\partial d_{j i}}(X) \mathbb{E}\left[S_{j}^{*} \mid X\right]-r_{s} \sum_{l \neq k} p_{l k}(X) \frac{\partial \mathbb{E}\left[S_{l}^{*} \mid X\right]}{\partial d_{j i}}\right)
\end{aligned}
$$

Here we have used the assumptions that the social distance between $j$ and $i$ has no effect on the studying productivity of $k\left(\frac{\partial a_{k}}{\partial d_{j i}}(X)=0\right)$ and no effect on the socializing productivity of $l$ and $k\left(\frac{\partial p_{l k}}{\partial d_{j i}}(X)=0\right)$ for all $l \neq j, k$. Note that the distance $d_{j i}$ can affect the socializing productivity of $j$ and $k$, and this effect is ambiguous because we don't know how the social distance between $j$ and $k$ will change accordingly. There are also equilibrium effects on the socializing decisions of others $\left(r_{s} \sum_{l \neq k} p_{l k}(X) \frac{\partial \mathbb{E}\left[S_{l}^{*} \mid X\right]}{\partial d_{j i}}\right)$, whose signs are hard to predict. Therefore, the effect of $d_{j i}$ on $\mathbb{E}\left[S_{k}^{*} \mid X\right]$ is ambiguous.

In sum, if we ignore the equilibrium effects, we can expect that $i$ 's socializing is decreasing in her social distance to $j$. In fact, this result can be extended to a more general setting where we change the characteristics of several other students. Without the equilibrium effects, $i$ will choose to socialize more if her overall social distance to other students decreases so that her overall socializing productivity $\left(r_{s} \sum_{j \neq i} p_{j i}(X) \mathbb{E}\left[S_{j}^{*} \mid X\right]\right)$ becomes higher.

However, we can't conclude that if we put $i$ in a new group of students who are socially closer to her then $i$ will socialize more. A group of students with different characteristics in general have different productivity in studying and socializing and different utility preference for socializing, thereby leading to an equilibrium with different amounts of optimal socializing. As a result of coordination, these equilibrium effects will affect $i$ 's socializing decision. The direction of these effects is ambiguous.

As for the effect of social distance on in-degree, take the derivative of (16) with respect to $d_{j i}$

$$
\frac{\partial \mathbb{E}\left(D_{i} \mid H_{j}, H_{i}, S_{j}, S_{i}, X, v_{i}, \eta_{i}\right)}{\partial d_{j i}}=\frac{\partial p_{j i}}{\partial d_{j i}}(X) S_{j}^{*} S_{i}^{*}+\sum_{k \neq i} p_{k i}(X) S_{k}^{*} \frac{\partial S_{i}^{*}}{\partial d_{j i}}+\sum_{k \neq i} p_{k i}(X) \frac{\partial S_{k}^{*}}{\partial d_{j i}} S_{i}^{*}
$$

where we have used the assumption that $\frac{\partial p_{k i}}{\partial d_{j i}}(X)=0$ for all $k \neq i, j$. This shows that the effect of the social distance $d_{j i}$ on $i$ 's expected in-degree depends on how $d_{j i}$ affects 
the the socializing productivity of $j$ and $i\left(\frac{\partial p_{j i}}{\partial X_{i}}(X) S_{j}^{*} S_{i}^{*}\right)$, the socializing decision of $i$ $\left(\sum_{k \neq i} p_{k i}(X) S_{k}^{*} \frac{\partial S_{i}^{*}}{\partial d_{j i}}\right)$, and the socializing decisions of others $\left(\sum_{k \neq i} p_{k i}(X) \frac{\partial S_{k}^{*}}{\partial d_{j i}} S_{i}^{*}\right)$. Note that the third effect comes from the fact that friendship formation requires coordination. By assumption, the socializing productivity is decreasing in social distance $\left(\frac{\partial p_{j i}}{\partial d_{j i}}(X)<0\right)$. The effect of social distance $d_{j i}$ on $i$ 's socializing $\left(\frac{\partial S_{i}^{*}}{\partial d_{j i}}\right)$ can be ambiguous if we take into account the equilibrium effects. The effects of $d_{j i}$ on others' socializing decisions are also ambiguous. Therefore, even if we ignore the equilibrium effects in $i$ 's socializing and believe that that $i$ socializes more if her social distance to $j$ decreases, the effect of $d_{j i}$ on $i$ 's expected in-degree is still ambiguous, unless there is no coordination.

Part (2): Next we examine the effect of homophily measures on studying and education. Similarly to part (1), we start with the simple case where we change $i$ 's social distance to another student $j\left(d_{j i}\right)$ by changing the characteristics of $j\left(X_{j}\right)$. From (8) and (10), the optimal studying is given by

$$
H_{i}^{*}=1-S_{i}^{*}-L_{i}^{*}
$$

where $L_{i}^{*}$ is the optimal leisure

$$
L_{i}^{*}=g_{l}\left(r_{e} a_{i}(X), X_{i}, \eta_{i}\right)
$$

Given the results in part (1), it is enough to consider how the optimal leisure of $i$ changes in her social distance to $j$. Take the derivative of both sides of $(21)$ with respect to $d_{j i}$

$$
\frac{\partial L_{i}^{*}}{\partial d_{j i}}=\partial_{1} g_{l}\left(r_{e} a_{i}(X), X_{i}, \eta_{i}\right) \cdot r_{e} \frac{\partial a_{i}}{\partial d_{j i}}(X)
$$

where $\partial_{1} g_{l}$ is the derivative of $g_{l}$ with respect to the first argument. Similarly to part (1), we assume that changing the social distance between $i$ and $j$ by changing $j$ 's characteristics has no effect on the studying productivity of $i\left(\frac{\partial a_{i}}{\partial d_{j i}}(X)=0\right)$. This implies that the social distance $d_{j i}$ has no effect on the optimal leisure of $i\left(\frac{\partial L_{i}^{*}}{\partial d_{j i}}=0\right)$.

Therefore, the effect of the social distance $d_{j i}$ on studying is the opposite of the effect on socializing

$$
\frac{\partial H_{i}^{*}}{\partial d_{j i}}=-\frac{\partial S_{i}^{*}}{\partial d_{j i}}
$$

From part (1), if we ignore the equilibrium effects, $i$ 's socializing is decreasing in the social distance $d_{j i}$, so her studying is increasing in $d_{j i}$. With the equilibrium effects, however, the effect of $d_{j i}$ on socializing becomes ambiguous, so does the effect on studying.

As for the effect of the social distance $d_{j i}$ on $i$ 's education, take the derivative of (18) 
with respect to $d_{j i}$

$$
\frac{\partial \mathbb{E}\left[E_{i} \mid H_{i}, S_{i}, X, v_{i}, \eta_{i}\right]}{\partial d_{j i}}=\frac{\partial a_{i}}{\partial d_{j i}}(X) H_{i}^{*}+a_{i}(X) \frac{\partial H_{i}^{*}}{\partial d_{j i}}
$$

By assumption $\frac{\partial a_{i}}{\partial d_{j i}}(X)=0$, so the effect of $d_{j i}$ on $i$ 's expected education depends only on how $d_{j i}$ affects the time $i$ spends studying $\left(\frac{\partial H_{i}^{*}}{\partial d_{j i}}\right) .{ }^{46}$ If we ignore the equilibrium effects in socializing, studying is increasing in the social distance $d_{j i}$, so is the expected education. With the equilibrium effects, however, the effects of $d_{j i}$ on studying and expected education are ambiguous. The proof is complete.

\section{Proof of Proposition 3 (coordination)}

Proof. Without coordination, the probability that $j$ nominates $i$ as a friends is

$$
\operatorname{Pr}\left(D_{j i}=1 \mid X\right)=p\left(X_{j}, X_{i}\right) \mathbb{E}\left[S_{i}^{*} \mid X\right]
$$

Under our specification, the utility from socializing $V_{s}\left(S_{i}, X_{i}, v_{i}\right)$ and thus the function $g_{s}\left(\cdot, X_{i}, v_{i}\right)$ do not directly depend on the homophily measures of students other than $i$ (e.g. $\left|X_{j}-X_{k}\right|$ for all $j, k \neq i$ ). If coordination does not matter, the optimal socializing $S_{i}^{*}$ will not depend on the homophily measures of other students. Hence, the link probability $\operatorname{Pr}\left(D_{j i}=1 \mid X\right)$ in $(22)$ will not depend on the homophily measures of the sender $j$ with respect to other students. By examining whether $\operatorname{Pr}\left(D_{j i}=1 \mid X\right)$ depends on the homophily measures of the sender $j$, we can test whether there is coordination in the social capital production. The proof is complete.

\section{Proof of Proposition 4 (OLS bias)}

Proof. Write the log earnings equation as

$$
\ln Y_{i}=r^{\prime} K_{i}+\beta^{\prime} X_{i}+\varepsilon_{i}
$$

where $K_{i}=\left(E_{i}, D_{i}\right)^{\prime}$ represents the vector of education and in-degree, $r=\left(r_{e}, r_{s}\right)^{\prime}$ represents the vector of returns to education and in-degree, $X_{i}$ represents the vector of exogenous covariates, and $\varepsilon_{i}$ represents the error term. Assume that $\mathbb{E}\left(\varepsilon_{i}\right)=0$. The endogeneity of $K_{i}$ and exogeneity of $X_{i}$ mean that $\mathbb{E}\left(K_{i} \varepsilon_{i}\right) \neq 0$ and $\mathbb{E}\left(X_{i} \varepsilon_{i}\right)=0$.

\footnotetext{
${ }^{46}$ Unlike friendship formation, there is no coordination in the production of education.
} 
The OLS estimator of $r$ is given by

$$
\hat{r}=\left(\sum_{i=1}^{n} \tilde{K}_{i} K_{i}^{\prime}\right)^{-1} \sum_{i=1}^{n} \tilde{K}_{i} \ln Y_{i}
$$

where $\tilde{K}_{i}=K_{i}-\left(\sum_{i=1}^{n} K_{i} X_{i}^{\prime}\right)\left(\sum_{i=1}^{n} X_{i} X_{i}^{\prime}\right)^{-1} X_{i}$ is the residual of $K_{i}$ after partialing out $X_{i}$. Because $\sum_{i=1}^{n} \tilde{K}_{i} X_{i}^{\prime}=0$ we can derive

$$
\hat{r}-r=\left(\sum_{i=1}^{n} \tilde{K}_{i} K_{i}^{\prime}\right)^{-1} \sum_{i=1}^{n} \tilde{K}_{i} \varepsilon_{i}
$$

By the Law of Large Numbers and the exogeneity of $X_{i}\left(\mathbb{E}\left(X_{i} \varepsilon_{i}\right)=0\right)$, we obtain

$$
\hat{r}-r \stackrel{p}{\rightarrow}\left(\mathbb{E}\left(K_{i} K_{i}^{\prime}\right)-\mathbb{E}\left(K_{i} X_{i}^{\prime}\right) \mathbb{E}\left(X_{i} X_{i}^{\prime}\right)^{-1} \mathbb{E}\left(X_{i} K_{i}^{\prime}\right)\right)^{-1} \mathbb{E}\left(K_{i} \varepsilon_{i}\right)
$$

as $n \rightarrow \infty$. Because $\mathbb{E}\left(K_{i} \varepsilon_{i}\right) \neq 0$ due to the endogeneity of $K_{i}$, the right-hand side is nonzero. It gives the asymptotic bias in the OLS estimator of $r$.

The bias in $\hat{r}$ depends on both the correlation between $K_{i}$ and $\varepsilon_{i}\left(\mathbb{E}\left(K_{i} \varepsilon_{i}\right)\right)$ and the inverse of the matrix

$$
\mathbb{E}\left(K_{i} K_{i}^{\prime}\right)-\mathbb{E}\left(K_{i} X_{i}^{\prime}\right) \mathbb{E}\left(X_{i} X_{i}^{\prime}\right)^{-1} \mathbb{E}\left(X_{i} K_{i}^{\prime}\right)
$$

Notice that this matrix is positive definite, ${ }^{47}$ so is its inverse. Unlike the case with a single endogenous variable, unless the matrix (24) is diagonal, the OLS bias in the returns to indegree does not necessarily have the same sign as the correlation between in-degree and the error term $\varepsilon_{i}$, and the same for education. Without knowledge about the matrix (24), even if the correlations between education, in-degree and $\varepsilon_{i}$ are known, the OLS biases in the returns to education and in-degree can be ambiguous. The proof is complete.

\section{Discussion: OLS bias in our sample}

Observe that the matrix (24) involves the observables $K_{i}$ and $X_{i}$ only. In a given data set, this matrix can be estimated. Hence, we can predict the OLS bias if we can speculate on the correlation between $K_{i}$ and $\varepsilon_{i}$.

Note that the off-diagonal elements in the matrix (24) are determined by the correlation

\footnotetext{
${ }^{47}$ This is because

$$
\begin{aligned}
& \mathbb{E}\left(K_{i} K_{i}^{\prime}\right)-\mathbb{E}\left(K_{i} X_{i}^{\prime}\right) \mathbb{E}\left(X_{i} X_{i}^{\prime}\right)^{-1} \mathbb{E}\left(X_{i} K_{i}^{\prime}\right) \\
= & \mathbb{E}\left(\left(K_{i}-\mathbb{E}\left(K_{i} X_{i}^{\prime}\right) \mathbb{E}\left(X_{i} X_{i}^{\prime}\right)^{-1} X_{i}\right)\left(K_{i}-\mathbb{E}\left(K_{i} X_{i}^{\prime}\right) \mathbb{E}\left(X_{i} X_{i}^{\prime}\right)^{-1} X_{i}\right)^{\prime}\right) .
\end{aligned}
$$
}


between education and in-degree. If conditional on other covariates, education and in-degree are positively (resp. negatively) correlated, then we expect the off-diagonal elements in the inverse of the matrix (24) to be negative (resp. positive). In our Add Health data, we find that education and in-degree are positively correlated, controlling for other covariates, and the off-diagonal elements in the inverse of the matrix (24) are indeed negative. However, we also find that these off-diagonal elements are relatively small compared with the diagonal elements in the inverse matrix. This suggests that the OLS biases in the returns to education and in-degree are mostly determined by their correlations with $\varepsilon_{i}$. In particular, a positive (resp. negative) correlation between in-degree and $\varepsilon_{i}$ will lead to an upward (resp. downward) bias in the returns to in-degree.

In-degree can be correlated with $\varepsilon_{i}$ for a number of reasons. For example, individual social capital could be poorly measured by in-degree. Alternatively, because in-degree depends on socializing and socializing depends on the unobserved preference for socializing $v_{i}$, if $v_{i}$ is correlated with $\varepsilon_{i}$, so is in-degree.

To speculate on the direction of the correlation between in-degree and $\varepsilon_{i}$ through $v_{i}$, we first show in a lemma that socializing is increasing in the unobserved preference for socializing.

Lemma 6. If the marginal utility from socializing $\frac{\partial V_{s}}{\partial S_{i}}\left(S_{i}, X_{i}, v_{i}\right)$ is increasing in $v_{i}$, i.e., students with higher $v_{i}$ enjoy more utility from each unit of socializing, then the optimal amount of socializing $S_{i}^{*}$ is increasing in $v_{i}$.

Proof. Suppose that the change of $v_{i}$ does not trigger any change in the equilibrium (e.g. through different equilibrium selection) so $\frac{\partial \mathbb{E}\left[S_{j}^{*} \mid X\right]}{\partial v_{i}}=0$. Taking the derivative of both sides of (15) with respect to $v_{i}$, we obtain

$$
\frac{\partial^{2} V_{s}}{\partial S_{i}^{2}}\left(S_{i}^{*}, X_{i}, v_{i}\right) \frac{\partial S_{i}^{*}}{\partial v_{i}}+\frac{\partial^{2} V_{s}}{\partial S_{i} \partial v_{i}}\left(S_{i}^{*}, X_{i}, v_{i}\right)=0
$$

By assumption $\frac{\partial^{2} V_{s}}{\partial S_{i}^{2}}\left(S_{i}^{*}, X_{i}, v_{i}\right)<0$ and $\frac{\partial^{2} V_{s}}{\partial S_{i} \partial v_{i}}\left(S_{i}^{*}, X_{i}, v_{i}\right)>0$, so we have $\frac{\partial S_{i}^{*}}{\partial v_{i}}>0$. The proof is complete.

Next we investigate the correlation between in-degree and $\varepsilon_{i}$ because in-degree is increasing in the time spent socializing. From the lemma, socializing is increasing in $v_{i}$. Therefore, we expect that in-degree is positively (resp. negatively) correlated with $\varepsilon_{i}$ if $v_{i}$ and $\varepsilon_{i}$ are positively (resp. negatively) correlated.

For example, unobserved communication skills in $v_{i}$ may contribute to higher social capital and better labor market performance, resulting in a positive correlation between indegree and $\varepsilon_{i}$. This will yield an upward bias in the social returns. On the other hand, if 
unobserved tastes for socializing in $v_{i}$ are in favor of leisure and anti-productive on the labor market, then we expect a negative correlation between in-degree and $\varepsilon_{i}$, yielding a downward bias in the social returns. Overall, the OLS bias in the social returns can be ambiguous, depending on whether the positive or negative correlation dominates.

\section{Proof of Proposition 5 (returns to socializing)}

Proof. If there are no social returns $\left(r_{s}=0\right)$, then the expected log earnings of $i$ becomes

$$
\begin{aligned}
\mathbb{E}\left[\ln Y \mid H_{i}, S_{i}, X, v_{i}, \eta_{i}\right] & =r_{e} a_{i}(X) H_{i}+\beta^{\prime} X_{i}+\mathbb{E}\left[\varepsilon_{i} \mid X, v_{i}, \eta_{i}\right] \\
& =r_{e} a_{i}(X)\left(1-S_{i}-L_{i}\right)+\beta^{\prime} X_{i}+\mathbb{E}\left[\varepsilon_{i} \mid X, v_{i}, \eta_{i}\right]
\end{aligned}
$$

Note that the coefficient of $S_{i}$ is negative

$$
\frac{\partial \mathbb{E}\left[\ln Y \mid H_{i}, S_{i}, X, v_{i}, \eta_{i}\right]}{\partial S_{i}}=-r_{e} a_{i}(X)<0
$$

In other words, for two students with the same amount of leisure, because there are no returns to socializing, if one socializes more, then her expected log earnings will be lower because she will attain a lower level of education due to less time spent studying. The proof is complete. 